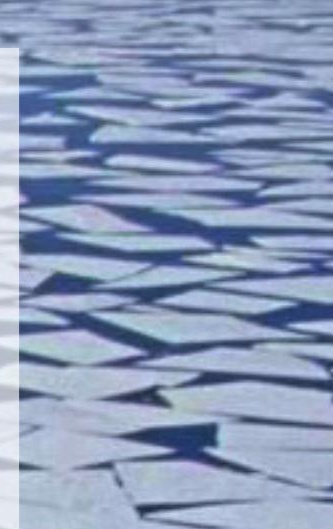

in $\rightarrow$ in
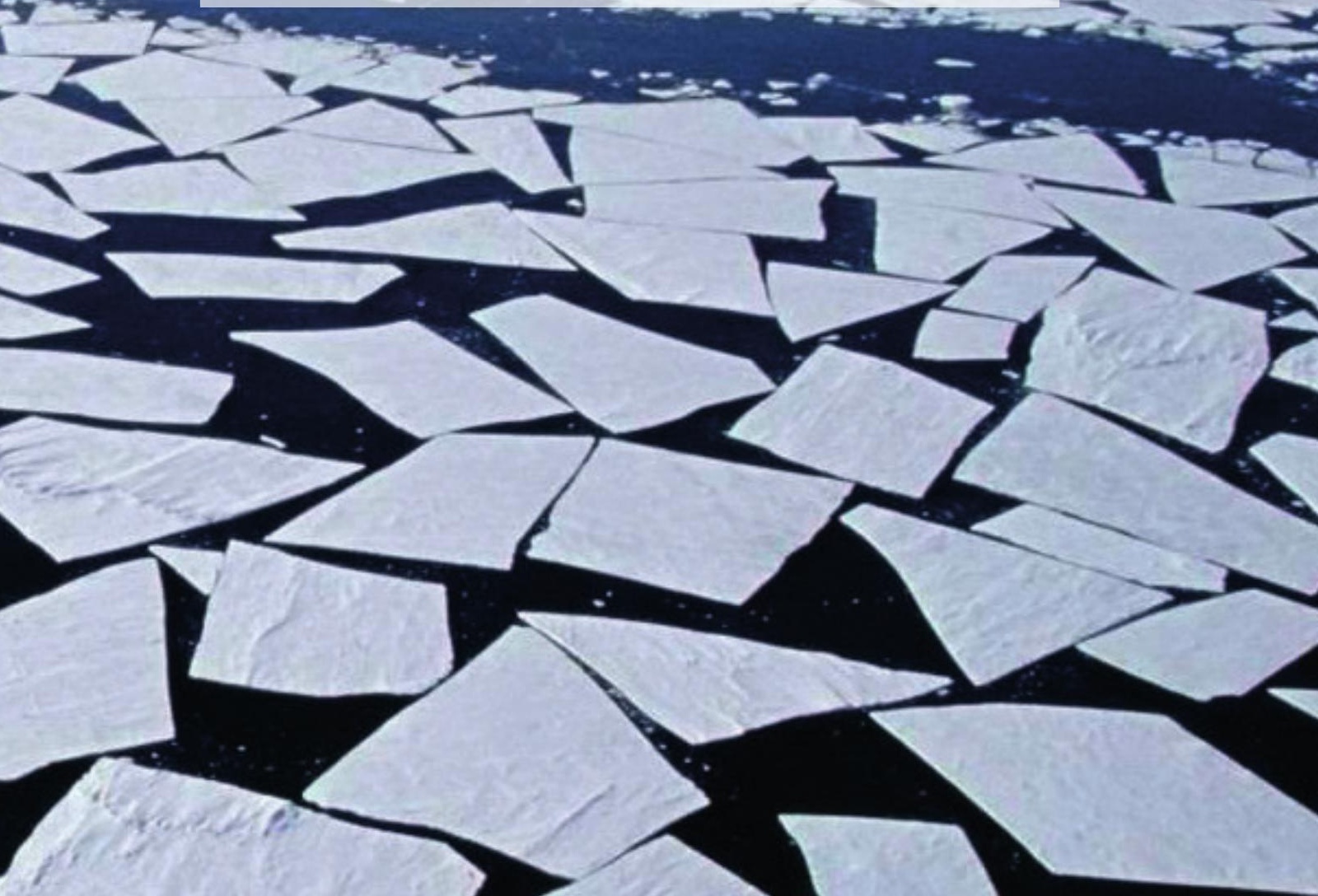



\section{Understanding the predictability of Arctic climate}

Folmer Krikken 


\section{Thesis committee}

\section{Promotor}

Prof. Dr W. Hazeleger

Special professor Climate Dynamics

Wageningen University \& Research

\section{Co-promotor}

Prof. Dr R. Bintanja

Honorary Professor Climate and Environmental Change

University of Groningen

\section{Other members}

Prof. Dr A.P. Siebesma, Delft Universtiy of Technology

Dr C.A. Katsman, Delft Universtiy of Technology

Prof. Dr R. Graversen, University of Tromsø, Norway

Prof. Dr F. Ludwig, Wageningen University \& Research

This research was conducted under the auspices of the Graduate School for Socio-economic and Natural Sciences of the Environment (SENSE). 


\section{Understanding the predictability of Arctic climate}

Folmer Krikken

Thesis

submitted in fulfilment of the requirements for the degree of doctor at Wageningen University

by the authority of the Rector Magnificus,

Prof. Dr A.P.J. Mol,

in the presence of the

Thesis Committee appointed by the Academic Board

to be defended in public

on Wednesday 5 September 2018

at 4 p.m. in the Aula. 
Folmer Krikken

Understanding the predictability of the Arctic climate,

112 pages.

PhD thesis, Wageningen University, Wageningen, the Netherlands (2018) With references, with summary in English

ISBN: 978-94-6343-485-0

DOI: https://doi.org/10.18174/456694 


\section{Contents}

Abstract 2

1. Introduction $\quad 4$

1.1 General introduction 4

1.2 The Arctic climate system $\quad 6$

$\begin{array}{lll}1.3 & \text { The changing Arctic climate } & 10\end{array}$

1.3.1 Observed sea ice changes 10

1.3.2 Arctic amplification 12

1.3.3 The Arctic climate towards the future: Climate model projections $\quad 14$

1.4 Impacts of Arctic climate change 14

1.4.1 Atmospheric and oceanic impacts 14

$\begin{array}{lll}1.4 .2 & \text { Ecological impacts } & 15\end{array}$

$\begin{array}{lll}1.4 .3 & \text { Economic impacts } & 16\end{array}$

$\begin{array}{lll}1.5 & \text { Predictability of Weather and Climate } & 17\end{array}$

$\begin{array}{lll}\text { 1.5.1 Weather predictions } & 17\end{array}$

$\begin{array}{lll}\text { 1.5.2 Seasonal to decadal predictions } & 18\end{array}$

$\begin{array}{ll}\text { 1.5.3 Climate prediction } & 19\end{array}$

1.6 Aims and outline $\quad 22$

2. Arctic Energy Budget in Relation to Sea Ice Variability on Monthly-to-Annual Time Scales $\quad 25$

$\begin{array}{lll}2.1 & \text { Introduction } & 27\end{array}$

2.2 Data and Methods $\quad 28$

2.3 Results $\quad 32$

2.3.1 Persistence $\quad 32$

2.3.2 Atmospheric energy balance and sea ice variability 34

2.3.3 Ocean energy balance and sea ice variability 38

$\begin{array}{lll}2.3 .4 & \text { Local surface radiation anomalies } & 38\end{array}$

$\begin{array}{lll}2.4 & \text { Discussion } & 39\end{array}$

2.5 Conclusions 46

3. Magnitude and pattern of Arctic warming governed by

3.1 Introduction 51

3.2 Results $\quad 52$

$\begin{array}{lll}3.3 & \text { Discussion } & 57\end{array}$

$\begin{array}{lll}3.4 & \text { Methods } & 57\end{array}$

4. Uncertainty in Arctic climate projections linked to $\begin{array}{ll}\text { downwelling longwave radiation } & 61\end{array}$

$\begin{array}{lll}4.1 & \text { Introduction } & 63\end{array}$

4.2 Results $\quad 64$

4.3 Methods $\quad 68$

$\begin{array}{lll}4.4 & \text { Supplementary information } & 70\end{array}$ 
5. Skill improvement of dynamical seasonal Arctic sea ice forecasts 75

$\begin{array}{lll}5.1 & \text { Introduction } & 77\end{array}$

$\begin{array}{lll}5.2 & \text { Data and Methods } & 78\end{array}$

$\begin{array}{lll}\text { 5.2.1 Datasets } & 78\end{array}$

5.2.2 Bias correction and ensemble calibration methods $\quad 78$

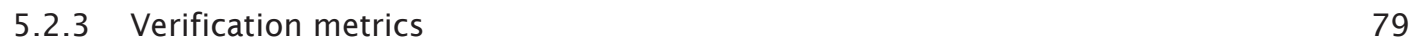

$\begin{array}{llr}5.3 & \text { Results } & 80\end{array}$

5.3.1 Forecast bias $\quad 80$

5.3.2 Impact of bias correction on forecast error $\quad 82$

5.3.3 Forecast skill $\quad 83$

$\begin{array}{lll}5.3 .4 & \text { Regional forecast skill } & 85\end{array}$

5.4 Conclusions and discussion $\quad 85$

6. General discussion and outlook $\quad 89$

6.1 Understanding seasonal predictability of the Arctic climate 91

6.2 Understanding long-term predictability of the Arctic climate 94

$\begin{array}{lll}6.3 \text { Outlook } & 96\end{array}$

$\begin{array}{ll}\text { Bibliography } & 97\end{array}$

$\begin{array}{lr}\text { Dankwoord } & 110\end{array}$

$\begin{array}{ll}\text { About the author } & 110\end{array}$

List of journal publications $\quad 111$

$\begin{array}{lr}\text { Graduate school certificate } & 112\end{array}$ 


\begin{abstract}
The barren and inhospitable Arctic region has over recent decades seen large changes in its natural environment. Observations have shown that the Arctic is warming twice as fast compared to the rest of the world, mostly noticed by the strong decrease of sea ice. These changes present large threats to the unique Arctic ecosystem and indigenous communities, but also provides opportunities such as improved navigation of the fabled northerly passages and exploration of natural resources. Hence, from a scientific, ecological and an economic viewpoint there is a strong need for accurate knowledge on future development of the Arctic climate, and specifically its sea ice cover. This thesis therefore focuses on the predictability of the Arctic climate on time scales ranging from seasonal to centennial, with an emphasis on the physical processes that give rise to, or inhibit, this predictability. This is achieved by studying the physical mechanisms related to Arctic climate variability and climate change, both in climate models and observations.
\end{abstract}

Over recent years there has been an increase in using fully coupled climate models for seasonal to decadal predictions. Hence, it is important to understand the physical processes that provide predictability beyond persistence of sea ice anomalies in these climate models. In chapter 2 we analyze the natural variability of Arctic sea ice from an energy budget perspective in multiple climate models and compare these results to observations. The Arctic energy balance components primarily indicate the important role of the ice-albedo feedback, through which sea ice anomalies in the melt season reemerge in the growth season. The role of the ocean lies mainly in storing heat content anomalies in spring and releasing them in autumn. Confirming a previous (observational) study, we demonstrate that there is delayed atmospheric response in of clouds in autumn to spring sea ice anomalies. Hence, there is no cloud-ice feedback in late spring and summer, but there is a cloud-ice feedback in autumn, which strengthens the ice-albedo feedback. Anomalies in insolation are, counter-intuitively, positively correlated with sea ice variability. This is primarily a result of reduced multiple reflection of insolation due to an albedo decrease. This effect counteracts the icealbedo effect up to $50 \%$. Reanalysis products confirm the main findings from the climate models.

Observed and projected climate warming is strongest in the Arctic regions, peaking in autumn/winter. Attempts to explain this feature have focused primarily on identifying the associated climate feedbacks, particularly the icealbedo and lapse-rate feedbacks. In chapter 3, we use a global climate model in idealized seasonal forcing simulations to show that Arctic warming (especially in winter) and sea ice decline are particularly sensitive to radiative forcing in spring, during which the energy is effectively 'absorbed' by the ocean (through sea ice melt and ocean warming, amplified by the ice-albedo feedback) and consequently released to the lower atmosphere in autumn and winter, mainly along the sea ice periphery. In contrast, winter radiative forcing causes a more uniform response 
centered over the Arctic Ocean. This finding suggests that intermodel differences in simulated Arctic (winter) warming can to a considerable degree be attributed to model uncertainties in Arctic radiative fluxes, which peak in summer.

The intermodel differences in projected Arctic warming are very large, owing to considerable differences between climate models. A clear understanding of this large uncertainty is currently lacking. In chapter 4 we use global climate models to show that springtime interannual variability in downwelling longwave radiation in the pre-industrial climate explains about two-thirds of the intermodel spread in projected Arctic warming under a high greenhouse gas emission scenario. This variability, which peaks on the land masses adjacent to the Arctic ocean, is related to the combined effects of the cloud radiative forcing and the albedo response to snowfall, which vary strongly among models in these regions. These processes govern interannual variability of downwelling longwave radiation in the pre-industrial climate, but also largely modulate the Arctic climate response. This finding elucidates the crucial interaction between clouds and surface radiation within the Arctic climate system. As such it provides important insights into possible reductions in the uncertainty in future Arctic climate projections that are required to constrain regional mitigation and adaptation strategies to Arctic climate change.

In chapter 5 we explore the error and improve the skill of the outcome from dynamical seasonal Arctic sea ice reforecasts using different bias correction and ensemble calibration methods. These reforecasts consist of a five-member ensemble from 1979 to 2012 using the general circulation model EC-Earth. The raw model forecasts show large biases in Arctic sea ice area, mainly due to a differently simulated seasonal cycle and long-term trend compared to observations. This translates very quickly (1-3 months) into large biases. We find that (heteroscedastic) extended logistic regressions are viable ensemble calibration methods, as the forecast skill is improved compared to standard bias correction methods. Analysis of regional skill of Arctic sea ice shows that the Northeast Passage and the Kara and Barents Sea are most predictable. These results demonstrate the importance of reducing model error and the potential for ensemble calibration in improving skill of seasonal forecasts of Arctic sea ice. 


\section{Chapter 1}

Introduction 


\section{Introduction}

\subsection{General introduction}

The Arctic region is the most northerly part of our planet. It is commonly referred to as the region north of the Arctic circle (figure 1.1), which represents the latitude at which during winter solstice the sun does not rise. The Arctic climate is characterized by cold and harsh conditions, long winters without sunshine and summers with continuous sunshine. The sea ice cover is one of the most important and unique features of the Arctic climate system. The Arctic region consists of a large ocean surrounded by land (figure 1.1), hence the climate is strongly affected by the ocean and its sea ice cover. During Arctic winter, sea ice covers the complete Arctic ocean and part of the surrounding seas (figure 1.2). During summer approximately $2 / 3$ of this sea ice melts away, resulting in a large seasonal cycle of the sea ice cover. Because the sea ice acts as a lid on the Arctic ocean, effectively separating the relatively warm ocean from the lower atmosphere, there is also a strong seasonal cycle in the lower atmospheric temperatures. Summer temperatures are generally confined to around freezing point during summer, as extra heat is used to melt sea ice and not warm the lower atmosphere. Winter temperatures can plummet to around $-40^{\circ} \mathrm{C}$, due to a lack of solar insolation (Serezze and Barry, 2009). This sharp temperature contrast between the lower atmosphere and ocean implies that changes in sea ice cover have a profound influence on the Arctic climate. The harsh and cold Arctic climate has led to the development of a unique ecosystem, with species specifically adapted to the Arctic climate. Further, the Arctic is home to a large population of indigenous communities. Their livelihoods are strongly connected to the unique Arctic climate, ecosystem and the sea ice cover through e.g. fishing, hunting and herding. 


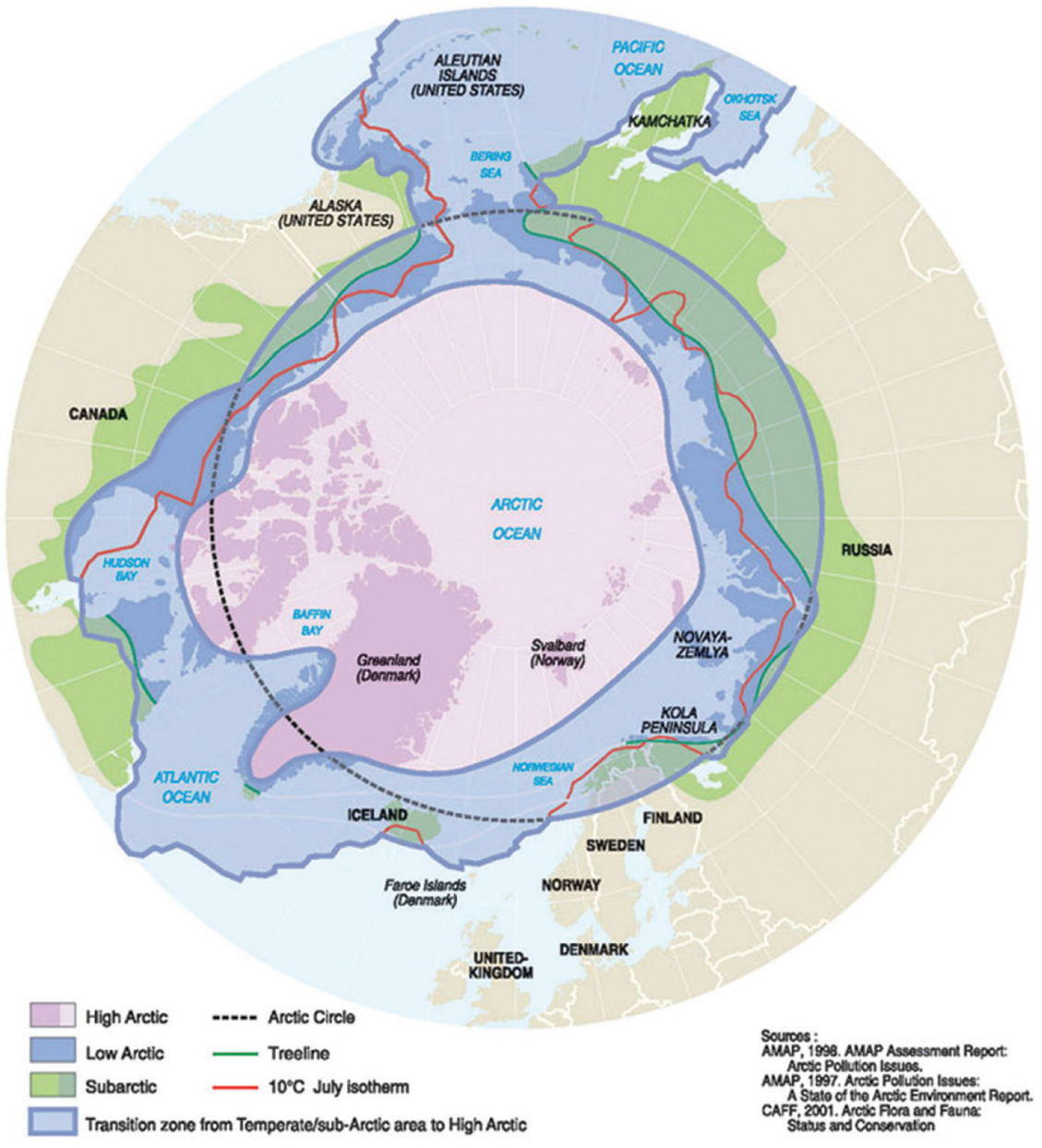

Figure 1.1: Map of the Arctic region according to multiple definitions.

Source: AMSA, 2009

Observations have shown that over recent decades the Arctic is warming twice as fast compared to the rest of the world (Cohen et al., 2014). This is mostly noticed by the strong decrease of sea ice, as the yearly sea ice minimum decreases at a rate of approximately $11.5 \%$ per decade (Comiso and Hall, 2014). These changes present large threats to the unique Arctic ecosystem and indigenous communities. However, the retreat of Arctic sea ice also provides opportunities. The reduced sea ice offers potential for improved navigation of the fabled northerly passages, fishing and exploration of natural resources. Hence, there is a strong need for accurate knowledge on the future state of the Arctic climate, and specifically its sea ice cover. The time scales over which this information is needed ranges from near-term (i.e. days to months) for e.g. information on ice-free passages or offshore operations, to centennial (climate projections) for use in adaptation and mitigation strategies for the Arctic region. 

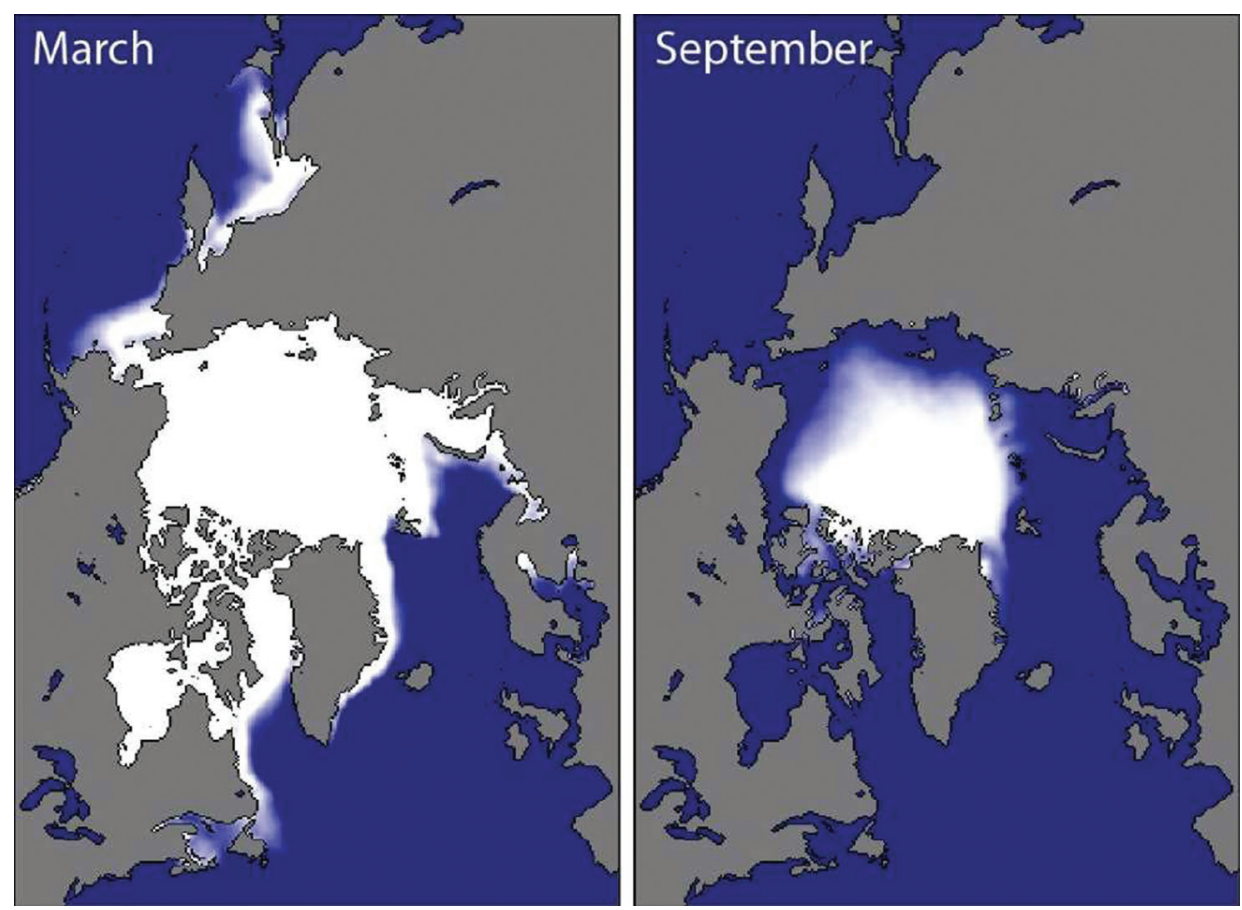

Figure 1.2: Map of the average sea ice cover (1980-2010) in March and September. Source: NSIDC

This thesis presents the results of a study on the predictability of the Arctic climate and on physical processes that can control this predictability, on time scales ranging from seasonal to centennial. First we will start with an introduction of the Arctic climate system and discuss the important changes that are observed and projected for the Arctic region. The 2 nd chapter will focus on physical processes that provide seasonal to yearly predictability of Arctic sea ice, through studying the surface energy balance in relation to sea ice variability. In chapter 3 we study the sensitivity of the Arctic climate system to the seasonality of a radiative forcing. This analysis is continued in chapter 4 , where we assess the importance of the seasonality of the radiative forcing in explaining the uncertainty in Arctic climate projections. In chapter 5 we assess the actual skill of yearly forecasts of Arctic sea ice, and the effect of (ensemble) bias-correction methods therein. All results are compiled and discussed in chapter 6 , including suggestions for future research.

\subsection{The Arctic climate system}

The Arctic climate is characterized by an integrated system of multiple components, namely the ocean, atmosphere, land and sea ice. These components are tightly connected through large energy fluxes from one component to another over the course of a year. These large energy fluxes are mostly driven by the large seasonality of solar radiation, which is absent during winter months but prevailing during summer due to 24 hours of sunshine per day. During summer, the abundant solar radiation 
causes widespread melt of snow and sea ice, and warming of the upper part of the Arctic ocean. During autumn, when solar radiation diminishes, the atmosphere starts to cool and becomes colder than the Earth's surface. This results in an energy flux from the Earth's surface to the atmosphere, yielding a cooling of the upper ocean and henceforth a large refreezing of the Arctic ocean and the peripheral seas (Serezze and Barry, 2009). Besides the local energy balance, there is also a large transport of energy towards the Arctic from lower latitudes. The energy that enters Earth's climate through solar radiation is unevenly distributed over the Earth, with more radiation absorbed at lower latitudes due to a higher solar elevation angle. Part of this surplus of energy is emitted by the Earth's surface in the form of longwave radiation towards the atmosphere and to space. The remaining surplus of energy in the tropics is redistributed by the atmosphere and ocean, through poleward transport of heat and moisture. Most of the energy that reaches the Arctic by the ocean is transported through the North Atlantic current (Fig. 1.3, label 6), which is the northerly branch of the Atlantic meridional overturning circulation (AMOC). This is an ocean current that transports warm water originating from the Gulf of Mexico towards western Europe and then continuous northward towards the Norwegian and Barents Sea. The inflow of water at the Pacific side of the Arctic is colder and less saline than the waters of the North Atlantic current (Fig 1.3, label 1).

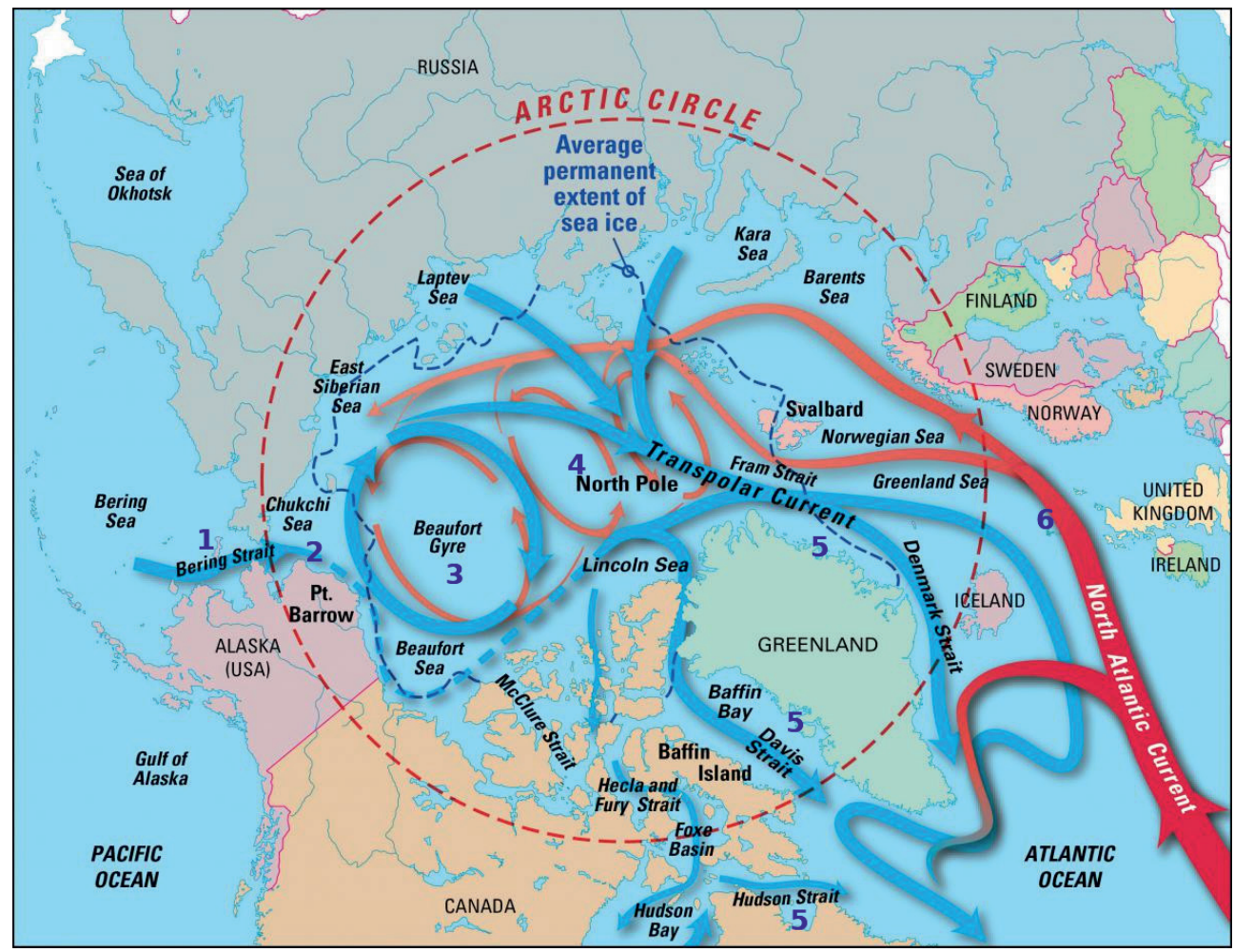

Figure 1.3: Illustration of the Arctic region and the ocean currents. Blue arrows represent relatively cold and fresh currents and red arrows relatively warm and saline currents. The dotted line represent the Arctic circle at 66 $33^{\prime}$ ' latitude. (Figure courtesy of Jack Cook, WHOI) 
The energy transport by the atmosphere is mainly through planetary waves (Graversen and Burtu, 2016), which are large-scale disturbances of the generally westerly circulation of the mid-latitudes. These disturbances bring in heat and moisture to the Arctic region, mainly in the winter months as the strength of these disturbances is larger when the meridional temperature gradient is large. Another important component of the Arctic climate system is the Greenland ice sheet. This vast body of ice almost completely covers Greenland, and is up to $3 \mathrm{~km}$ thick. Though it is also affected by climate change (Khan et al., 2014) and is a very important factor concerning sea level rise (Yan et al., 2014), it does not directly affect the predictability of the Arctic sea ice and is henceforth not further discussed.

The Arctic climate is thus characterized by the interplay of local radiative processes and inflow of energy from the ocean and atmosphere. The Arctic sea ice responds strongly to these different forcings. The inflow of warm and saline waters prevent the Arctic sea ice cover from spreading further south than $\sim 70^{\circ} \mathrm{N}$ at the Atlantic side of the Arctic, whilst at the Pacific side with the relative cold and less saline inflow current the sea ice can expand as far as $50^{\circ} \mathrm{N}$. Also, the large seasonality of the solar radiation causes the large seasonal cycle in sea ice cover (Fig 1.2). The sea ice however is not bound to one location. It is in constant motion as it gets pushed around by oceanic and atmospheric circulation and it can travel multiple kilometers per day (Kwok et al., 2013). Generally, there are two large wind-driven ocean circulations that affect sea ice. Over the Beaufort sea there is a climatological high pressure area (Beaufort high). This high pressure, and associated clockwise circulation, sets both the ice and ocean in motion through transfer of momentum resulting in the Beaufort Gyre (Fig. 1.3, label 3). The second large ocean current is the Transpolar Drift Stream (Fig 1.3, label 4), which pushes the ice from the central Arctic towards the Fram Strait and Greenland. The sea ice that gets pushed towards Greenland and the Canadian Archipelago gets compressed and deforms into ridges, and becomes the thickest ice found in the Arctic ( 4-10 meters). The ice that gets pushed towards the Fram Strait will exit the Arctic region and melt when it reaches the warmer waters of the Atlantic ocean.

The Arctic climate as described above illustrates the climatological mean. In other words, it is the average climate state over the last decades. At certain times however the actual state can strongly deviate from the recent climatological state. Changes in the Arctic climate and its sea ice cover are driven by two main components, long term climate change and short term natural climate variability. The former is mostly driven by changes in the external forcing. This is a forcing that acts on the climate system while being outside of the climate system itself. Examples are increased greenhouse gases, changes in solar radiation or large volcanic eruptions. Variability due to changes in external forcing has typical time scales of multiple decades and longer. Short term natural climate variability is caused by the chaotic nature of the climate system with typical time scales of days to multiple decades.

Variability on shorter time scales are e.g. a change in strength or direction of the Beaufort Gyre and Transpolar Drift Stream through changes in the local atmospheric pressure distribution. Variability on monthly to seasonal time scales are generally 


\section{Average Monthly Arctic Sea Ice Extent \\ September 1979 - 2017}

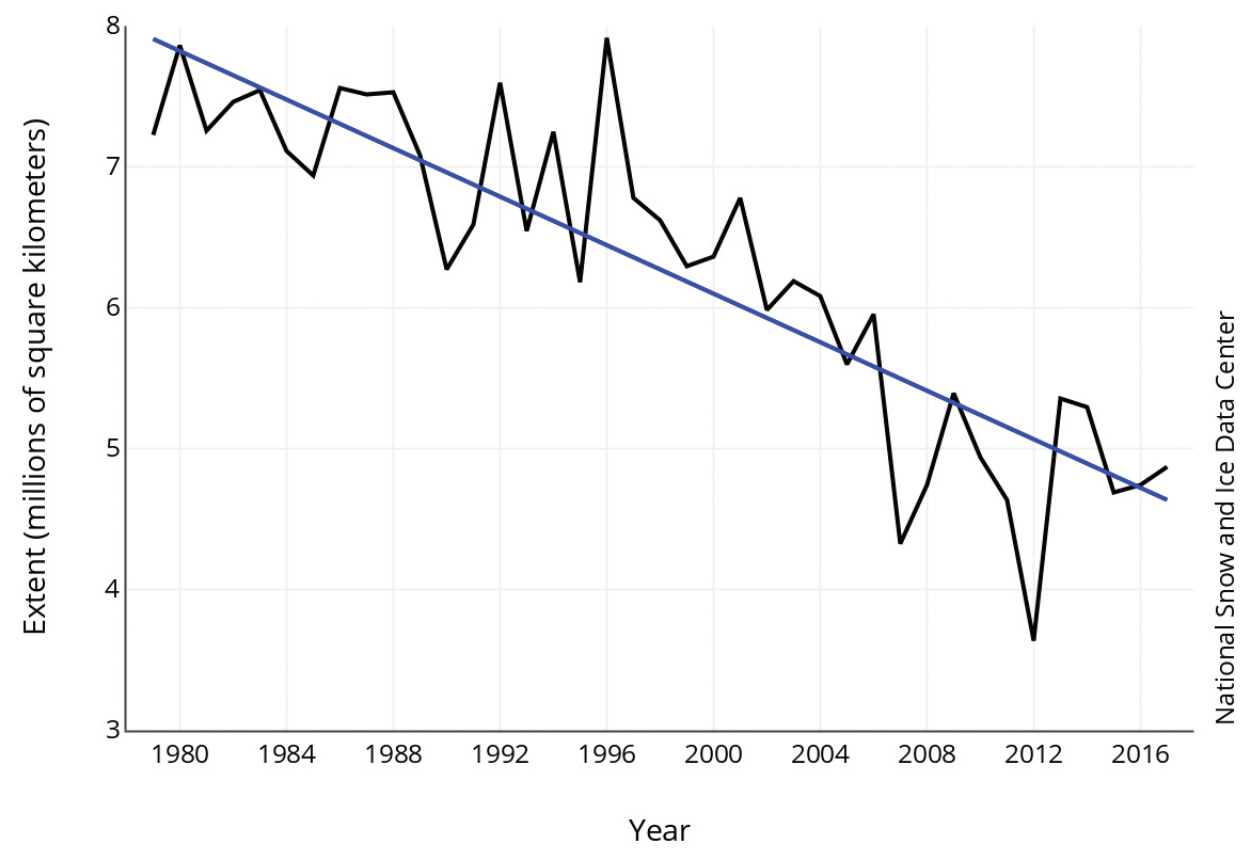

Figure 1.4: Average monthly Arctic sea ice extent in September from 1979 to 2017. Source: NSIDC

driven by larger scale atmospheric pressure distributions or changes in ocean circulation. The Arctic region is characterized by multiple processes that give rise to natural variability on longer time scales (Boer and Lambert, 2008). Important modes of variability in the Arctic region are, among others, the Arctic Oscillation (AO) and the Pacific Decadal Oscillation (PDO). The AO index describes the large scale atmospheric pressure distribution in the Arctic relative to the pressure at lower latitudes. A positive index (smaller difference in surface pressure between the Arctic and mid-latitudes), indicates a reduced westerly circulation and more warm (cold) air transported to (from) the Arctic. A negative index yields a stronger westerly circulation and a more isolated Arctic. The AO is therefore an important driver of variability of weather at the mid-latitudes and the summer Arctic sea ice variability (Stroeve et al., 2011). The PDO describes the main variability of sea surface temperature (SST) in the North Pacific Ocean. Though the PDO does not directly affect Arctic sea ice, it does modulate the response of the atmosphere to sea ice variability (Screen and Francis, 2016) and is therefore also an important mode of climate variability in the Arctic. Another important contributor to long term natural variability is the Atlantic meridional overturning circulation (AMOC). It describes the ocean heat transport from lower latitudes to the Arctic region. It varies over the course of years to decades, and thus alters the amount of heat transported towards the Arctic. This effects the location of the sea ice edge on the Atlantic side of the Arctic (Bitz et al., 2005) and the surface air temperature (Mahajan et al., 2011). 


\subsection{The changing Arctic climate}

\subsubsection{Observed sea ice changes}

The decrease of the sea ice in the Arctic is one of the most visible effects of recent climate change. Reliable continuous observations of the total sea ice coverage are available since 1979, with the advent of satellite observations. These observations show a clear trend towards less sea ice (Fig. 1.4), which is stronger during the sea ice minimum in September than during the sea ice maximum in March (Figure 1.1b). What is further evident in this figure is the large inter-annual variability on top of the long-term trend, especially in recent years. Another important variable to indicate the changes in sea ice is the thickness of the ice. Because the thickness of the ice has only been measured by satellites over the last 10 years, we show the age of sea ice here (Fig. 1.5), which is strongly related to the thickness (Tschudi et al., 2016), and of which a time series is available since 1985. This figure shows that there is a sharp drop in the age of the sea ice, and therefore in thickness. This indicates a transition from a particularly thick, multi-year ice cover to a thin, seasonal ice cover. This thin sea ice is much more susceptible to the harsh Arctic weather.
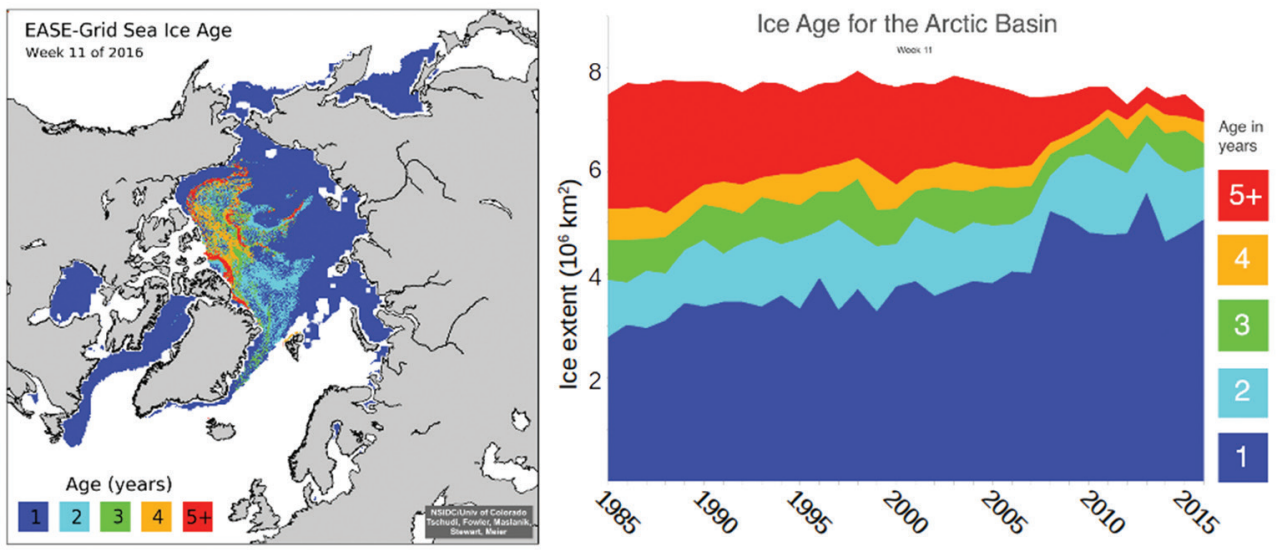

Figure 1.5: left: Sea ice age for March 2016 and right: the trend of different sea ice age categories from 1985 to 2016.

Source: NSIDC

The large inter-annual variability in sea ice coverage in recent years is thus also partly linked to the decrease of the thickness of the sea ice, and the relative increase of the fragile one-year ice (Stroeve et al., 2012). Due to these large fluctuations, it is difficult to say something about the state of the sea ice on the basis of a single year. Though the observational record shows a strong and significant trend (Cohen et al., 2014), it is relatively short from a climate perspective, as the observed changes can also be caused by natural changes in the climate system. Walsh et al. (2017) identified this problem and decided to collect and digitize as much information as possible about the sea ice state of the pre-satellite era. They have used, among other things, logs of whalers, newspaper articles, plane observations and maps made by the Danish 
Meteorological Institute. This results in a time series of sea ice from 1850 (Figure 1.6). Here, despite the higher uncertainty in the pre-1979 time series, we can see that there has never been such low coverage and strong decline of sea ice in the past 170 years (mainly for summer), and that the multi-decadal variability is much smaller than the inter-annual variability.

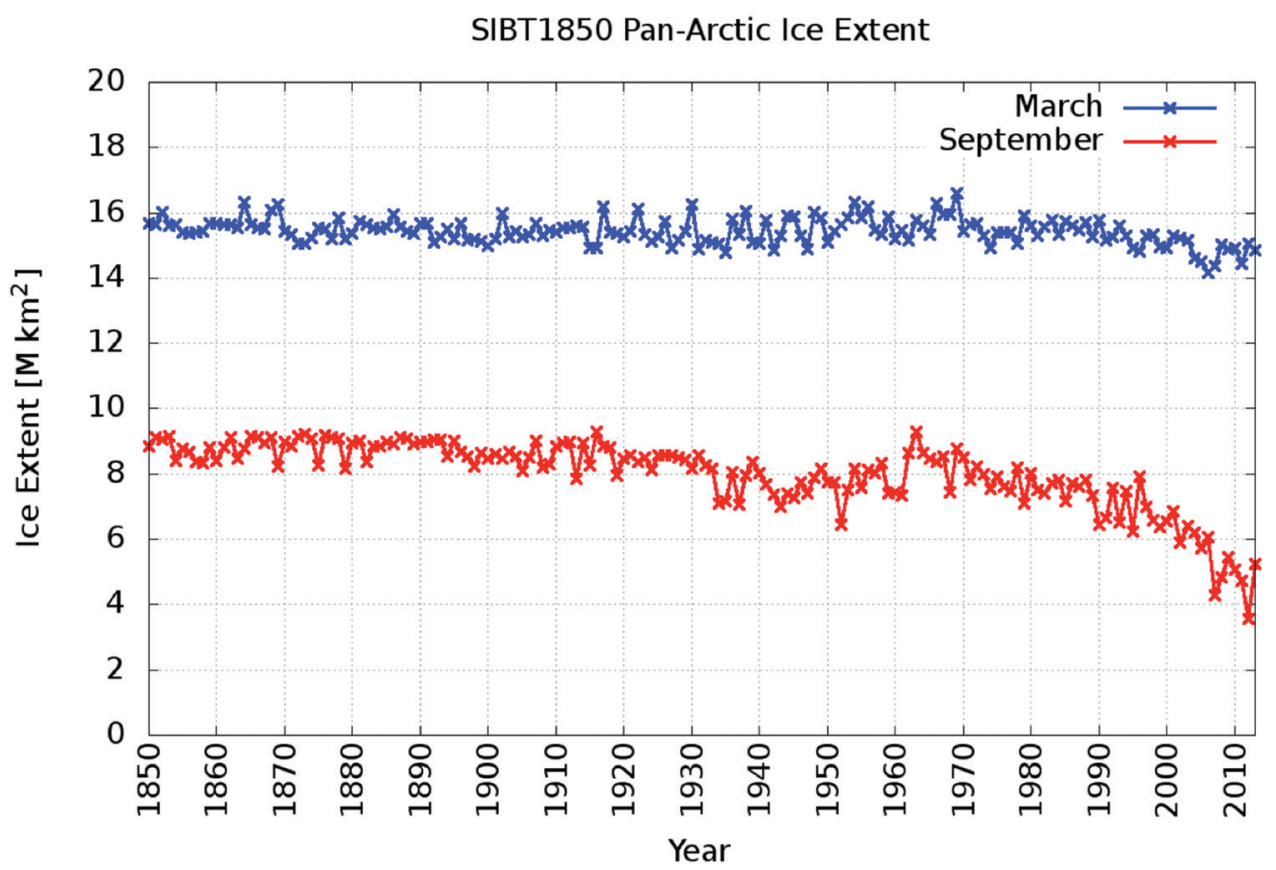

Figure 1.6: Sea ice extent for March and September from 1850 to currently. Excerpt from Walsh et al. (2017).

These results show that recent changes cannot be explained by natural variability alone. This raises the question on the relative importance of natural variability compared to changes in external forcing in the observed changes in the Arctic. Recent findings indeed point to an important role for natural variability. The PDO, which changed from strongly positive in the beginning of the satellite era to negative over the course of three decades, can explain part of retreat of sea ice (Screen and Francis, 2016). Furthermore, Ding et al. (2017) show that trends in summertime atmospheric circulation can explain up to $60 \%$ of the decline in September sea ice from 1979 onwards, where they relate the trend in summertime circulation to natural climate variability. Hence, the role of natural variability on the recent decline of Arctic sea ice seems as important as the increased external forcing. 


\subsubsection{Arctic amplification}

In addition to the sharp decline of sea ice, the temperature in the Arctic region also increases much faster than elsewhere in the world, and this increase is projected to strengthen (Stroeve et al., 2012). This process is called Arctic amplification. The temperature increases throughout the world due to the increase in greenhouse gases. These gases absorb longwave radiation with the result that less longwave radiation can escape to space. This leads to a radiative imbalance at the top of the atmosphere (TOA) between the incoming shortwave radiation and the outgoing longwave radiation. The surplus of energy causes an increase in air temperature, which will continue until the atmospheric temperature, and thus outgoing longwave radiation, matches the incoming solar radiation. This is the so-called Planck feedback. Though this feedback mechanism is active throughout the world, it is more efficient at higher temperatures (i.e. lower latitudes), because the relation between temperature and longwave radiation is highly non-linear. As a result, to overcome a TOA radiation imbalance the Arctic has to warm up more than the Tropical region. Another feedback mechanism is the well-known albedo (reflectivity of the earth's surface) feedback. Higher temperatures results in less sea ice or snow (lower albedo), which reflects less solar radiation, yielding a temperature increase, with subsequently more sea ice melt and even higher temperatures. Model studies indeed show that this makes a significant contribution to the Arctic warming (e.g. Pithan and Mauritsen, 2014). Another important mechanism is the supply of warm and humid air from the mid-latitudes through breaking planetary waves. This mild and humid air mass replaces the typical cold and clear Arctic air mass, resulting in higher temperatures, more clouds and less sea ice. Recent examples of this are December 2015, with temperatures above the freezing point (Figure 1.7), and in November 2016 until January 2017, where it was regularly 20 degrees warmer than normal in a large part of the Arctic (Graham et al., 2017). The frequency of these intrusions is increasing and can explain part of the Arctic warming (Woods and Caballaro, 2016; Graham et al., 2017).

A feature of both the albedo feedback and the intrusions of hot and humid air is that the warming takes place in the lower part of the troposphere. Where the additional heat at lower latitudes is mixed well over the troposphere by convection, the Arctic is characterized by a stable lower atmosphere that largely inhibits convection, and thus the vertical mixing of this extra heat over the troposphere. The heat is thus 'trapped' in the lower part of the troposphere, which causes the Arctic warming to be confined to the lower part of the troposphere. An additional effect of this is that the extra energy cannot escape easily to space as longwave radiation. The emitted longwave radiation from the lower atmosphere is partly absorbed by the colder air above and re-emitted again, but because the air is colder it emits less longwave radiation than it has absorbed. Hence, the TOA outgoing longwave radiation is less if the warming is mainly confined to the lower atmosphere. This effect is called the lapse rate feedback, and is, together with the surface albedo feedback, the main feedback mechanism behind the Arctic amplification (Pithan and Mauritsen, 2014). The recent sharp decline of sea ice and the rise in temperature are therefore mainly the result of increasing greenhouse gases, with different feedback mechanisms strengthening the Arctic amplification. 


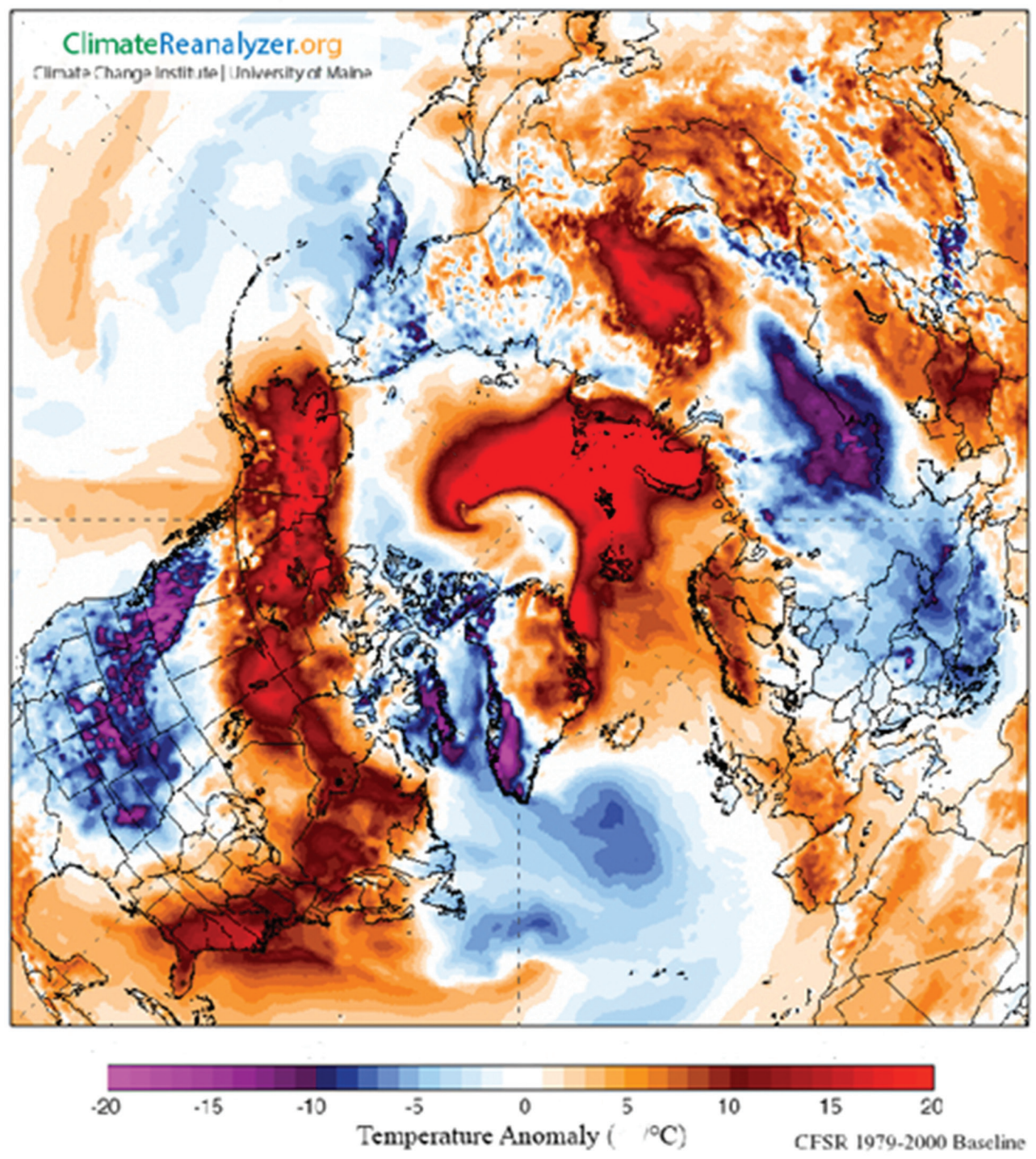

Figure 1.7: Temperature anomaly on 31 December 2015.

Source: www.climatereanalysis.org 


\subsubsection{The Arctic climate towards the future: Climate model projections}

One of the most pressing questions in current climate research is how the Arctic sea ice will evolve towards the future. A tool often used to study Earth's climate and its sensitivity to an increase of greenhouse gases are general circulation models (GCM's), also often referred to as 'climate models' in this thesis.

These climate models can be used to simulate previous, current and future climate states, provided that the external forcing is known. For future climate conditions this is difficult, as it is unclear how greenhouse gas emissions will evolve over the $21^{\text {st }}$ century. Therefore, multiple scenarios, labeled Representative Concentration Pathways (RCP's), were developed for $21^{\text {st }}$ century greenhouse gas concentrations ranging from strong climate mitigation (RCP2.6) to 'business as usual' (RCP8.5). The 2.6 and 8.5 refer to an increase of $\mathrm{Wm}^{-2}$ equivalent external forcing at 2100 relative to pre-industrial $(<1850)$ values (Moss et al., 2010). In order to provide information on the future development of Earths' climate, large Coupled Model Intercomparison Project were started (CMIP3 and CMIP5). Here, 'coupled' refers to a coupling in the model between the ocean, atmosphere, land surface and sea ice. A large suit of climate models performed a coordinated set of simulations, in which the models are run with the same external forcing. Such an experimental setup provides climate projections for the future, associated uncertainties of the projections measured by the multi-model spread, and an opportunity for studying the intermodel differences in order to understand and improve the climate models. Figure 1.8 shows the total Arctic sea ice for the climate projections of Arctic sea ice for multiple scenario's, based on the CMIP5 climate models. These results show that, independent of the scenario, the Arctic sea ice is projected to decrease rapidly over the first half of the 21 st century. The first predicted occurrence of an ice free summer ranges from around 2050 to 2100 for the RCP4.5 and RCP8.5 scenario's. However, many of these climate models seem to underestimate the current decline in sea ice (Figure 1.8, black line). Logically, the time for the first ice-free summer is then also underestimated. When corrected for this (Massonet et al., 2012), this time is somewhere between 2040 and 2060.

\subsection{Impacts of Arctic climate change}

The changing Arctic climate has many local and non-local effects. In this section we will give a brief overview of some of the effects for the climate system, ecology and economy.

\subsubsection{Atmospheric and oceanic impacts}

As previously mentioned, the Arctic warming is most profound in the lower part of the atmosphere. When air warms up it expands, causing the column of air to become thicker thus increasing the pressure aloft. This can lower the meridional pressure 
gradient between the mid-latitudes and the Arctic. The strength of this pressure gradient largely determines the weather in the Arctic and the mid-latitudes. A higher pressure gradient can result in a stronger westerly (zonal) circulation that isolates the Arctic region, whilst a lower pressure gradient yields a weaker zonal circulation and an increase of the north-south (meridional) component of the wind. The latter gives more transport of heat and moisture towards the Arctic through breaking planetary waves, whilst also yielding more persistent and extreme weather in the midlatitudes. There is indeed evidence pointing to increased zonal wind speeds in recent times (e.g. Francis and Vavrus, 2012). However, other research shows that this relation is very sensitive to where and how the activity of breaking planetary waves is computed (e.g. Screen and Simmons, 2013; Barnes, 2013), and that the signal to noise ratio for this relation is still too small in order to draw clear conclusions (Hopsch et al., 2012). Hence, the impact of reduced arctic sea ice on mid-latitude weather is still a very active research area. Climate projections for the Arctic show increased precipitation and river-runoff in the Arctic region (Bintanja and Selten, 2014). This results in more fresh water in the upper Arctic ocean and peripheral seas. This cold and less saline water can prevent the deep-water formation process of the AMOC, which can reduce the strength AMOC (e.g. Jackson and Wood, 2017). This can reduce northward heat transfer, which might counter the warming to some extent, but can cause more warming in other parts of the world (ACIA, 2004). Also, the carbon uptake of the ocean can decrease due to a decreasing AMOC, resulting in higher carbon dioxide levels in the atmosphere (Fontela et al. 2016).

\subsubsection{Ecological impacts}

The main region of the Arctic ice pack with biological activity is the marginal ice zone. It represents the transition between open water and sea ice, and is defined as the region which is close enough to the open ocean to be affected by its presence. The region is characterized by enhanced mixing of the upper ocean due to wave activity and sea ice melting. The Arctic warming and associated retreat of sea ice can lead to a large loss of habitat for biological activity such as sea ice algae and sub-ice phytoplankton (Post el al., 2013). Both are important sources of the total primary production in the Arctic and thus the basis of the food chain in the Arctic (Gosselin et al., 1997). This has consequences for higher consumers, such as cod (Ji et al., 2013), seabirds and marine mammals (Moody et al., 2012). Many species also depend on the sea ice for foraging, resting and reproduction. For example, the decline of sea ice directly affects the body condition and abundance of polar bears (Stirling and Derocher, 2012), the habitat and reproduction of ringed seals (Hezel et al., 2012) and the habitat of the Pacific walrus (Fishbach et al., 2009). The Arctic is also already becoming more accessible for species that normally live further south, whilst natural boundaries such as ice or ocean, or a lack of sea ice, prevent Arctic species from moving further north. This results in increased conflicts between e.g. the Arctic fox with the red fox, or hybridization between e.g. the polar bear with the grizzly bear (Kelly et al., 2010). The warmer Arctic also affects vegetation, with an earlier start of the plant growing season, which mismatches with the caribou arrival that normally feed on these plants (Kerby and Post, 2013). 
These example are only a fraction of the widespread impact of the changing Arctic on its unique Ecology (Post et al., 2013). Projected changes in the climate will undoubtedly further impact the ecology, though it is difficult to predict how the ecology will change with it (Gilg et al., 2011, Lameris et al., 2017). The rapid climate change observed in the Arctic is already inducing large structural changes in ecosystems, e.g. with northward migration of fish (cod) (Fossheim et al., 2015).

\subsubsection{Economic impacts}

The retreating sea ice also offers potential for economic development. The Arctic region offers a wealth of natural resources, such as oil and gas fields and numerous minerals, but also biological resources such as salmon, cod and pollock. These are becoming better accessible with the retreat of sea ice, which sparks economic activities in the region, and increases the amount of destination traffic. It is estimated that up to $30 \%$ of the world's undiscovered natural gas and $13 \%$ of its undiscovered oil are located in the Arctic (Gautier et al., 2009). The fabled northerly passages are also becoming more frequently ice-free, which results in more trans-polar shipping, mainly through the Northern sea route (NSR) and to a lesser extent the North Westerly Passage (NWP). The northerly passages have the potential to significantly reduce the length and travel time between western Europe and Asia, which can substantially lower the costs (Liu and Kronbak, 2010). The number of transits through the Arctic region steadily increases (Eguiluz et al., 2016), though the numbers are still vastly lower compared to the Suez canal and the Panama canal. Projections of Arctic sea ice of the 21 st century show a steady increase of the shipping-season length (Melia et al., 2016).

Though there are a lot of economic opportunities, there are also economic threats associated with Arctic warming. The thawing of the Arctic permafrost in the Arctic region will likely release vast amounts of methane, either steadily over 50 years or suddenly (Shakhova et al., 2010). This enhanced methane release can significantly amplify global warming which has an estimated cost of 60 trillion dollars (Whiteman et al., 2013). Hence, the projected costs of Arctic warming far out way the benefits. 


\subsection{Predictability of Weather and Climate}

An important part of this thesis is assessing the predictability of the Arctic climate system on multiple time and length scales. Therefore in this section we will introduce weather to climate predictions and the models used for these predictions in more detail.

\subsubsection{Weather predictions}

A main goal of meteorology is to predict how the weather will develop towards the future. Though weather predictions have already been around since the Babylonians, the basis of the modern weather predictions was laid by Abbe (Abbe, 1901) and Bjerknes (Bjerknes, 1904) in the beginning of the 20th century. They both recognized that the laws of physics could be used to describe atmospheric processes (i.e. weather). Hence, if the initial state of the atmosphere is known, one can use the laws of physics to predict how the weather will develop. With the advent of the computer mid 20th century it became possible to solve these equations numerically, and produce the first numerical weather predictions (NWP). The problem at that time however was, without sufficient computer resources, that producing the forecast took longer than the time for which the forecast was valid. With the more powerful (super)computers from the 1970's onwards, skillful weather predictions were created (Lynch, 2008), though still having a limited level of detail in the beginning. Over the recent decades the level of detail of the forecasts has increased strongly due to increasing computer power, better weather models and a better estimate of the initial state, leading to steady increase of forecast quality (Bauer et al., 2015).

The quality of the weather predictions thus depends on how well the initial state matches the real initial state, and the quality of the weather model. The former depends on the quantity and the quality of the observations, and on how all that data is assimilated in the weather model. The latter depends on many aspects of the weather model, such as the horizontal and vertical resolution of the model and the quality of the parameterizations. Note however, that even with a perfect initial state and a perfect weather model the predictability of weather is still limited. This is due to the chaotic nature of the climate system. A small error in e.g. the initial state or due to numerical and physical approximations can lead to large errors at later times because of the non-linearity of the forecast equations. The predictability of our weather is henceforth inherently limited. Edward Lorenz (Lorenz, 1963) found that the rate at which these errors grow is state dependent, i.e. sometimes these errors grow rapidly (unpredictable weather) and sometimes they grow slowly (predictable weather). This error growth can be quantified by starting multiple forecasts from slightly perturbed initial conditions that reflect the uncertainty of the observed initial state, i.e. ensemble forecasting. In this way, we not only acquire an estimate of future weather, but also the uncertainties or probabilities associated with specific forecasts (figure 1.8). 
The chaotic atmosphere is thus only limited predictable, hence the follow-up question is: how far ahead can we predict the weather? Currently, the large scale atmospheric flow, more specifically the $500 \mathrm{hPa}$ geopotential height, is on average skillfully predictable up to 10 days ahead (Bauer et al., 2015). The word 'skillfully' here represents that it matches the observations by at least $60 \%$, measured as an anomaly correlation.

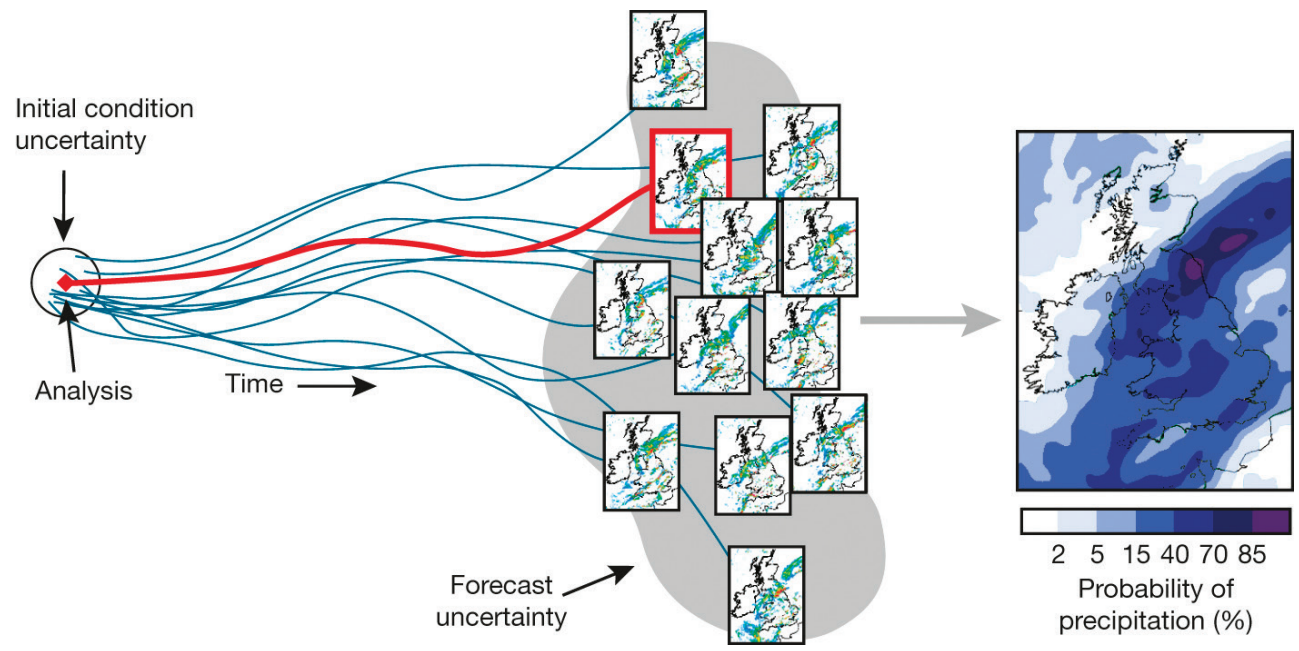

Figure 1.8: Schematic diagram of an ensemble forecast used to estimate the probability of precipitation over the UK. Excerpt from Bauer et al. (2015).

\subsubsection{Seasonal to decadal predictions}

So how is it possible that we can make seasonal predictions, or even up to decadal time scales, whilst the atmospheric flow is only predictable for a short time? The answer lies in the fact that there are multiple sources that provide predictability. The large-scale atmospheric flow is the main source of predictability at shorter timescales. Predictability at longer times scales is mainly based on slow modes of climate variability, i.e. changes in weather that can last for weeks or months. One of the most well-known examples herein is the El Nino Southern Oscillation (ENSO) (Cane and Zebiak, 1985), which is a fluctuation in sea surface temperature and air pressure in the equatorial Pacific Ocean which affects weather at large parts of our planet (Wallace et al., 1998). An important aspect in many of these mechanisms is the ocean, as the variability in the ocean generally occurs on much longer time scales.

Weather models consist mostly of an atmospheric model and as such cannot simulate the mechanisms that provide predictability at longer time scales. In order to adequately simulate these mechanisms a model is needed that describes the processes in, and the interactions between, the ocean, land, atmosphere and sea ice. These models are called general (or global) circulation models (GCM's). Because of the increased complexity of these models due to the added ocean and sea ice components and the generally longer simulations performed with these models, they tend to have a coarser spatial resolution (less detail) compared to the weather models. 
If these GCM's are initialized with the observed state and can accurately simulate the mechanisms that provide predictability, there is a strong potential for seasonal to decadal predictions (Smith et al., 2007). The potential is however strongly related to the specific processes in the regional climates. In the Arctic region there are multiple processes that give rise to long term climate variability (see section 1.2), thus providing a basis for seasonal-to-decadal predictions (Boer et al., 2004; Seitola and Jarvinen, 2014). Important sources of seasonal predictability are e.g. persistence of sea ice (volume) anomalies and sea surface temperature (SST) anomalies (BlanchardWrigglesworth et al. 2015). Also, the AO provides some predictability (Stockdale et al., 2015) on seasonal time scales. Predictability on longer time scales can be achieved by e.g. variability in the PDO (Screen and Francis, 2016) or the AMOC. Initialized climate model forecasts from Yeager et al. (2015) show that the ice cover is likely to melt less rapidly over the next 10 years due to a slight decrease in heat supply through the AMOC, which could partly offset the negative trend.

The skill of these forecasts is however limited, as the forecasts are hampered by model error and observational uncertainty, specifically for the Arctic region. Forecast biases can grow more strongly in these models because of its fully coupled system and relatively long simulations (Hawkins and Sutton, 2007). Hence, after initialisation, GCM's tend to drift back towards their preferred biased state (Meehl et al., 2009). Therefore all forecasts need to undergo bias correction. The quality of the forecasts thus strongly depends on the quality of the bias-correction (Van Olderborgh et al., 2012, Fuckar et al., 2015). As a consequence, the full potential of Arctic sea ice forecasts is still far from reached (Guemas et al., 2014). Because of the large potential, but also its drawbacks, this is still a very active field of research (Meehl et al., 2009; 2012). This is studied in more detail in chapter 5.

\subsubsection{Climate prediction}

Though GCM's are currently also used for seasonal-to-decadal predictions, it is more commonly used to study processes in our climate and its response to increased greenhouse gases as described in section 1.3.3. In contrast to weather and seasonal prediction, where their skill is inherently limited due to the chaotic nature of our climate system, this is only partly true for climate modeling. Generally, in climate simulations we are not interested in the exact timing of a certain weather event, but more in the climatological distribution of certain meteorological variables, and how this changes under different external forcings. 


\section{Decline in Arctic Sea Ice Extent}

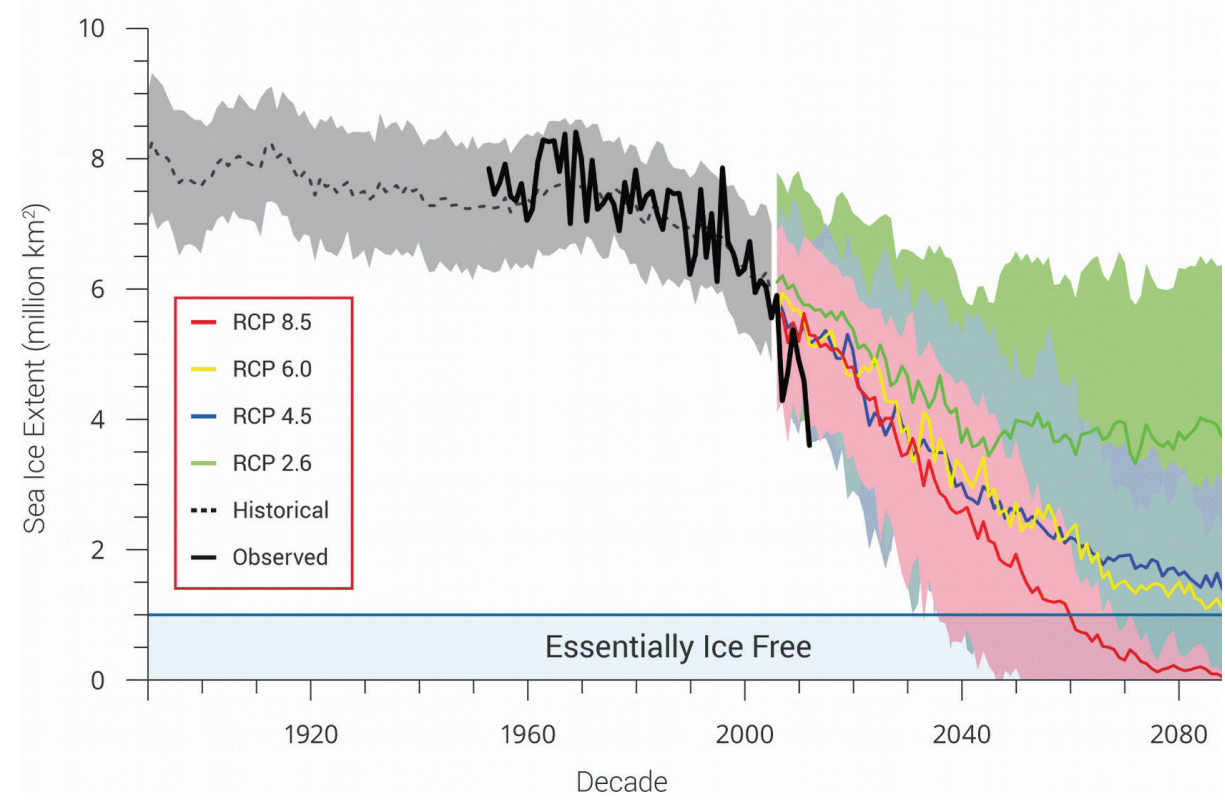

Figure 1.9: Projected sea ice evolution in the 20st and 21 st century for different scenarios. The dark lines represent the CMIP5 multi-model mean, and the bandwidth around the line represent one standard deviation multi-model uncertainty. Excerpt from Stroeve et al. (2012).

Climate simulations are not initialized from an observed climate state, hence for any moment in time the observed and simulated climates can be in different phases of large scale climate variability. When comparing observations with climate model results this must be taken into account. Climate models are generally run in an ensemble mode, where multiple members are started from slightly different initial states. The ensemble mean of all these members then represents the average model climate and the ensemble spread represents the size of the internal climate variability. Because the observed climate state is only one possible outcome of many it can, for years or even longer, reverse or strengthen observed trends associated with changes in external forcing. A possible example of this can be seen in figure 1.9, where the observations of September Arctic sea ice show a much stronger trend than simulated by the climate models. This could either be caused by an underestimation of the trend by the climate models, or it could be that the observed recent trend is partly caused by natural variability. Initially this bias was attributed to a too low external forcing in the climate models (Stroeve et al., 2007), or because the models fail to reproduce complex dynamical feedbacks (Rampal et al., 2011). However, as already mentioned in section 1.3.1, recent findings (e.g. Ding et al., 2017; Screen and Francis, 2016) point to an important role of natural variability. This obviously has important ramifications for the trust in the $21^{\text {st }}$ century climate projections. Natural climate variability is thus also an important source of uncertainty in climate projections. 
Another important source of uncertainty is that not all climate models are created equal. This translates into large differences in how well models can reconstruct the observed climate, and even larger difference between the models' response to a change in external forcing (i.e. climate sensitivity). This uncertainty is be quantified by the multi-model spread, as e.g. depicted in figure 1.9 by the bandwidth around the multi-model mean sea ice. This source of uncertainty for Arctic climate projections will be discussed in more detail in chapter 4 . Further, as already discussed in section 1.3.3, the future greenhouse gas forcing is uncertain as it depends on complex carbon cycle feedbacks (Friedlingstein et al., 2006) and on how mankind can limit further emission of greenhouse gases. The latter is included in current climate projections through the different scenario's, as illustrated in figure 1.9 for the Arctic sea ice development over the $21^{\text {st }}$ century under different RCP's. The former however is not yet universally included as most models lack an interactive carbon cycle, which can lead to an underestimation of the uncertainty in climate projections (Bodman et al., 2016).

Henceforth, the predictability of our climate is limited due to a lack of knowledge of our climate system, computational restraints preventing more detail in the simulations, uncertaintties in the observed state and uncertainties in changes in external forcings such as future greenhouse gas concentrations and volcano eruptions. 


\subsection{Aims and outline}

The primary aim of this thesis is to assess the predictability of the Arctic climate, with an emphasis on its sea ice cover, on timescales ranging from monthly to centennial. Predictability of the Arctic sea ice on scales from monthly to annual is only possible if there are mechanisms that provide predictability on those time scales, and if these are present in the models used for these predictions. This poses the questions:

- What are the physical mechanisms in current climate models that can provide predictability on seasonal to yearly time scales?

To be able to answer this question we performed a process-based evaluation of the Arctic sea ice characteristics in chapter 2 , by looking at the monthly-to-annual Arctic variability from an energy balance perspective. Here we used data from multiple models from the CMIP5 dataset, and studied lead-lag relations between the different components of the energy balance and the Arctic sea ice properties, both locally and averaged over the Arctic region. We also identified the physical processes that provide the inherent predictability found in Arctic region.

The Arctic climate is a complex dynamical system with multiple feedback mechanisms active over different parts of the year (e.g. Blanchard-Wrigglesworth et al., 2011; Pithan et al., 2014). Therefore, the impact of a radiative forcing can also differ throughout the season. Furthermore, the projected climate response has a distinct seasonal cycle with the strongest warming in winter months (Bintanja and van der Linden, 2013). This poses the question:

- How sensitive is the Arctic climate to the seasonality of a radiative forcing?

We test this in chapter 3 through applying an artificial longwave radiative forcing for each season separately in the EC-Earth climate model (Hazeleger et al., 2010; 2012), and then study the response. This novel approach leads to new insights in the relevant processes at play and the importance of spring radiative forcing.

As demonstrated in figure 7 , the intermodel spread in climate projections of Arctic sea ice is very large. The projected first occurrence of an ice-free Arctic spans almost the complete 21 st century (Stroeve et al., 2012). A clear understanding of the sources behind the large uncertainty is currently lacking. Motivated by the results from chapter 3, which demonstrates the important role of downwelling longwave radiation (DLR) in spring, raised the question:

- What is the role of downwelling longwave radiation in the intermodel spread in future climate projections of Arctic climate change?

We answer this question in chapter 4, through an intermodel comparison study using the CMIP5 climate model dataset. Here we study whether the intermodel relation between DLR characteristics in the pre-industrial climate and the Arctic climate response to increased greenhouse gases and study the mechanisms that explain this intermodel relation. 
In the fifth chapter we studied processes which provide potential predictability of Arctic sea ice. This raises the question as how this potential predictability translates to real predictability of the Arctic sea ice, hence the question:

- How well can a climate model re-forecast the Arctic sea ice on seasonal to yearly timescales?

We test this in chapter 5 on a set of yearly predictions of Arctic sea ice. The forecast consist of a five-member ensemble, re-forecasts from 1981 to 2012 for 3 different start months, using the fully coupled EC-Earth GCM which are initialized from estimates of observed data. We analyze pan-Arctic and regional skill of these forecasts, and use different bias-correction and ensemble calibration techniques to test how they improve the forecasts. 



\section{Chapter 2}

Arctic Energy Budget in Relation to Sea Ice Variability on Monthly-to-Annual Time Scales 


\begin{abstract}
The large decrease in Arctic sea ice in recent years has triggered a strong interest in Arctic sea ice pre-dictions on seasonal-to-decadal time scales. Hence, it is important to understand physical processes that provide enhanced predictability beyond persistence of sea ice anomalies. This study analyzes the natural variability of Arctic sea ice from an energy budget perspective, using 15 climate models from phase 5 of CMIP (CMIP5), and compares these results to reanalysis data. The authors quantify the persistence of sea ice anomalies and the cross correlation with the surface and top-of-atmosphere energy budget components. The Arctic energy balance components primarily indicate the important role of the seasonal ice-albedo feedback, through which sea ice anomalies in the melt season reemerge in the growth season. This is a robust anomaly reemergence mechanism among all 15 climate models. The role of the ocean lies mainly in storing heat content anomalies in spring and releasing them in autumn. Ocean heat flux variations play only a minor role. Confirming a previous (observational) study, the authors demonstrate that there is no direct atmospheric response of clouds to spring sea ice anomalies, but a delayed response is evident in autumn. Hence, there is no cloud-ice feedback in late spring and summer, but there is a cloud-ice feedback in autumn, which strengthens the ice-albedo feedback. Anomalies in insolation are positively correlated with sea ice variability. This is primarily a result of reduced multiple reflection of insolation due to an albedo decrease. This effect counteracts the ice-albedo effect up to 50\%. ERA-Interim and Ocean Reanalysis System 4 (ORAS4) confirm the main findings from the climate models.
\end{abstract}




\subsection{Introduction}

The Arctic sea ice has shown a rapid decrease over the last few decades. An ice-free Arctic summer is already likely within the first half of this century (Overland and Wang, 2013). With the sea ice in the Arctic region retreating, the economic activities in the region are expanding and diversifying. More shipping lanes are becoming ice free, and natural resources will become better accessible (Stephenson et al., 2013). These increasing economic activities offer opportunities, but also threats, to the region. To be able to reduce the stakes at play and improve the operational planning for offshore activities in the Arctic region, improvements on forecasts of Arctic sea ice on seasonal-tomultiyear scales are needed.

Arctic sea ice forecasts for seasonal-to-annual timescales are often based on statistical methods (e.g. Lindsay et al., 2008; Kapsch et al., 2013). With the fast-changing Arctic climate, however, the historical records on which the statistical relations are based are not necessarily valid for the current climate state. Another method currently employed is the use of initialized simulations with fully coupled (atmosphere and ocean) climate models (e.g. Sigmond et al., 2013; Chevallieret al., 2013; Wang et al., 2013). However, correct initializations are still hampered by a lack of robust sea icethickness observations and by model error (Holtslag et al., 2013). These simulations show increased forecast skill compared to anomaly persistence models (Sigmond et al., 2013). It is noteworthy, however, that even though the dynamical model forecast skill is higher than the relative simple anomaly persistence model, an important source of the dynamical forecast skill on seasonal-to-annual time scales originates from persistence of anomalies (Sigmond et al., 2013). It is therefore important to understand the physical mechanisms behind these processes.

Multiple studies (e.g., Bitz et al., 2005; Holland et al., 2011 ; Blanchard-Wrigglesworth et al., 2011, hereafter BW11; Chevallier and Salas-Mélia 2012) have investigated the inherent predictability of Arctic sea ice. These studies show a typical decorrelation time scale of 2-5 months, with higher persistence during summer and winter and lower persistence in between. Furthermore, a reemergence of sea ice anomalies is often observed in the ice-growth season that originates from the ice-melt season. The original anomaly in spring yields a (persistent) sea surface temperature (SST) anomaly because of reduced or enhanced cumulative heating, which again results in a sea ice anomaly in the growth season (BW11; Day et al., 2014, hereafter DA14). Another mechanism that offers predictability is the maintenance of the sea ice edge in winter because of the convergence of heat transported by ocean currents (Bitz et al., 2005). The analysis of Bitz et al. (2005) suggests that absorption of shortwave radiation mainly determines the rate of ice melting in the marginal ice zone but that the ice edge is primarily determined by the strength and region of ocean heat flux convergence.

All these processes can lead to enhanced predictability on seasonal-to-annual time scales and can bridge the gap between short-term predictability originating from correct initialization and longer term predictability originating from external forcing (BW1 1; van Oldenborgh et al., 2012). In this study, we aim for a better understanding of the mechanisms that offer predictability on seasonal-to-annual time scales. 
Therefore,we perform a process-based evaluation of the Arctic sea ice characteristics by looking at the monthly-to-annual Arctic variability from an energy balance perspective. Herein we study lead-lag relations between the different components of the energy balance and the Arctic sea ice properties, both locally and averaged over the Arctic region, and identify the physical processes that provide the inherent predictability found in Arctic sea ice. In this way, we also test the robustness of the findings of BW11 and DA14 by extending their analysis with a CMIP5 multi-model analysis.

Table 1.1: List of selected CMIP5 climate models. The models with an asterisk are not included in the calculations of the cloud radiative forcing because clear-sky radiation components were not available.

\begin{tabular}{llll}
\hline \multicolumn{3}{c}{ CMIP5 models } \\
\hline 1 & ACCESS1.0 & 9 & MIROC-ESM \\
2 & ACCESS1.3 & 10 & MIROC-ESM-CHEM \\
3 & CMCC-CMS* & 11 & MPI-ESM-LR \\
4 & CNRM-CM5 & 12 & MRI-CGCM3 \\
5 & CSIRO Mk3.6.0* & 13 & NorESM1-M \\
6 & GFDL-ESM2G & 14 & NorESM1-ME \\
7 & GFDL-E2-R & 15 & BCC_CSM1.1 \\
8 & GISS-E2-H/R-CC & &
\end{tabular}

\subsection{Data and Methods}

Our analysis is based on a multi-model ensemble of atmosphere-ocean general circulation models (AOGCMs) and Earth system models (ESMs; see Table 1), which are all part of phase 5 of the Coupled Model Inter-comparison Project (CMIP5) dataset (Taylor et al., 2012). The selection criteria were data availability, in particular ocean data for constructing the energy balance. From this dataset we selected the control simulations, which have fixed atmospheric constituents equal to the values from the pre-industrial era (1850). The control simulations allow us to focus on the role of natural variability in Arctic sea ice, as it lacks a long-term trend in the data because of changing external forcing. It must be noted here that the Arctic sea ice in the preindustrial simulations might not be representative for the current sea ice conditions. The thinning of the Arctic sea ice over the last decades (Serreze et al., 2007) has led to an increase of relatively thin first-year ice, which is much more susceptible to (chaotic) weather forcings, resulting in reduced persistence and thus predictability (Holland et al., 2011). Therefore, we will also perform part of the analysis with representative concentration pathway 4.5 (RCP4.5) climate simulations, in which the radiative forcing increases with $4.5 \mathrm{~W} \mathrm{~m}^{-2}$ in 2100 (relative to pre-industrial forcing), to see if some of the findings presented here are also valid in the lower sea ice area (SIA) regimes. From the CMIP5 monthly dataset we select only the Arctic region, here defined as north of $65^{\circ} \mathrm{N}$, and 200 years of simulation time for each model. 
This latitude does not cover the complete Arctic region, but it allows us to more accurately close the energy balance over a region. Figure 1.1 illustrates the different components of the energy balance that are computed. We focus on both atmospheric and oceanic components. The atmospheric energy balance can be formulated by:

$$
d M S E / d t=F_{\text {TOA }}+F_{65 N-A}+F_{\text {SURFACE }}
$$

where FTOA represents the net radiation at the top of the atmosphere (TOA), F65N-A is the moist static en- ergy (MSE) flux across $650 \mathrm{~N}$ from the surface to the TOA, $\mathrm{F}_{\text {SURFACE }}$ is the sum of net radiation and turbulent fluxes at the surface, and dMSE/dt is the change in moist static energy content over time. The latter is calculated by:

$$
M S E=1 / g \int_{0}^{p_{s f c}} \int_{65}^{90} \int_{0}^{360}\left(c_{p} T+L q+\phi_{5}\right) d x d y d p
$$

where $\mathrm{g}$ is the gravitational acceleration, psfc is the surface pressure, cp is the specific heat for air at constant pressure, $T$ is the temperature in kelvin, $L$ is the latent heat of evaporation, $\mathrm{q}$ is the specific humidity, and Fs is the surface geopotential. By subtracting the values of two subsequent months and dividing by the time step (1 month) we determine the change of MSE over time. The energy flux at $65^{\circ} \mathrm{N}$ is assumed to be the residual of the other terms in Eq. (1). The oceanic energy balance can be approximated in a similar way:

$$
d Q / d t=F_{65 N-0}+F_{\text {SURFACE }}
$$

where $\mathrm{F}_{65 \mathrm{~N}-\mathrm{O}}$ is the meridional ocean heat flux at $65^{\circ} \mathrm{N}$, FSURFACE is the heat flux into the ocean from the surface, and dQ/dt is the change in ocean heat content $(\mathrm{OHC})$ over time, which is calculated by

$$
Q=\int_{z_{\text {scc }}}^{z_{\text {sobed }}} \int_{65}^{90} \int_{0}^{360} p c_{p} T d x d y d z
$$

where $r$ is the density, $c_{p}$ the specific heat of water, $T$ the temperature of the ocean in kelvin, and $z$ seabed and $z_{\text {sfc }}$ are respectively the height of the seabed and of the ocean surface. Again, $\mathrm{F}_{65 \mathrm{~N}-\mathrm{O}}$ is the residual of the other terms in Eq. (2.3). 


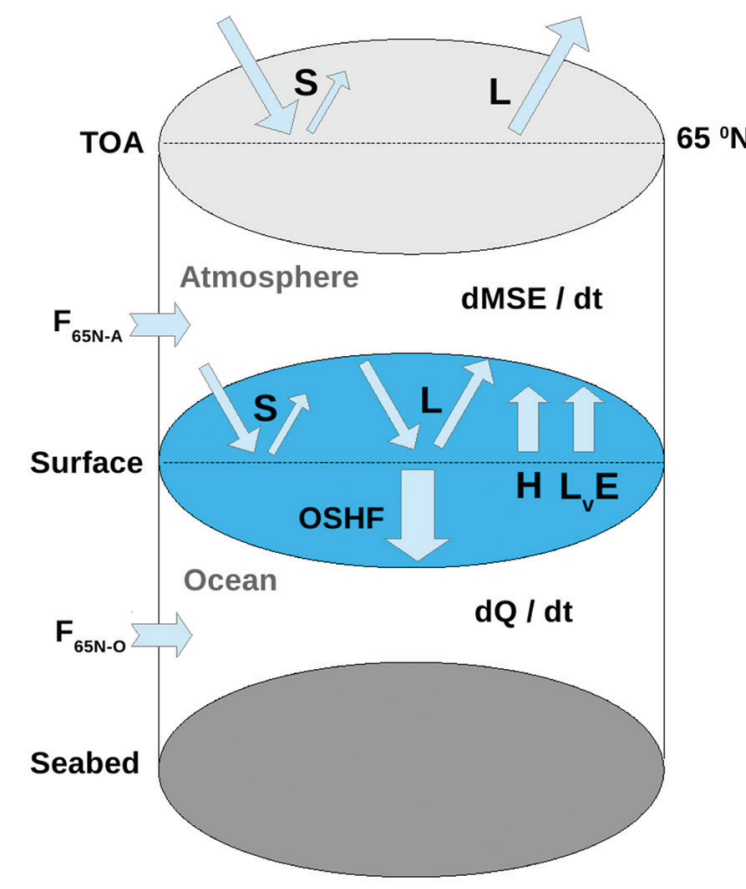

Figure 2.1: Conceptual view of Arctic energy balance components. The $H$ indicates the sensible heat flux and the term LvE is the latent heat flux. We refer to section 2.2 for the definition of the remaining terms/variables.

We analyze the relation of the different components of the atmospheric and ocean energy balance with the (lagged) Arctic sea ice, both locally and averaged over the Arctic region. The anomalies for the statistical calculations are computed by 1) removing a linear trend to correct for any model drift, 2) removing the average seasonal cycle, and 3) subtracting an 11 -yr running mean. This last step allows for a better evaluation of the seasonal-to-annual predictability, as otherwise the signal is dominated by low- frequency climate variability, as demonstrated by DA14. Note that the latter is not the focus of this analysis. The linear trend and $11-y r$ running mean were computed and subtracted for the 12 months individually, to avoid introducing an artificial seasonal signal when the anomalies are not evenly distributed over the season. Model results will be compared to observational and reanalysis products. For Arctic sea ice observations we use the Bootstrap sea ice concentrations from NSIDC (Comiso, 2000). The reanalysis products are ERA-Interim (Dee et al., 2011) and Ocean Reanalysis System 4 (ORAS4; Balmaseda et al., 2013). These reanalysis products should be used carefully in data-sparse regions such as the Arctic. Lindsay et al. (2014) evaluated seven different reanalysis products that cover the Arctic, and ERA-Interim was one of the three reanalysis products that stood out as being more consistent with observations. Zygmuntowska et al. (2012) did however find a strong dry bias in summer. From ORAS4 we do not use the first two decades, as these have large uncertainties (Balmaseda et al., 2013). For the comparison we use all five ensemble members of ORAS4 but present only the ensemble mean. For ERA-Interim, 
ORAS4, and NSIDC Arctic sea ice observations we use the years 1979-2013. The (lagged) relations are quantified by calculating the correlation coefficient between different physical quantities. The multi-model mean is computed by combining the individual correlation scores through Fisher's $z$ transformation. The associated $p$ values are combined using Fisher's combined probability test. For the model results and the observations, significance levels of $99 \%$ and $95 \%$, respectively, were chosen. Note that, because of the large amount of data (i.e., a large sample size), correlation scores of lower than 0.1 are already significant. The average decorrelation time scale per month, here defined as the e-folding time scale of SIA, was calculated by fitting an exponential decaying function to the first months where the correlation coefficient is higher than 1/e. The climate models, NSIDC observations, and reanalyses from ERA-Interim and ORAS4 all undergo the same filtering procedure. The total Arctic sea ice can be quantified by the total extent, area, and volume. Extent is defined as the sum of gridcell areas with more than 15\% sea ice coverage, and area as the sum of the sea ice-covered part of the grid cells. In this research we will focus on the sea ice area instead of the sea ice extent, as the area is a more relevant variable from an energetic and end-user viewpoint. Additionally, BW11 and DA14 found comparable results in lead-lag relations between sea ice area and ex- tent. Sea ice volume is also an important variable, as shown by Chevallier and Salas-Mélia (2012), but mainly as a predictor for sea ice area anomalies. A first analysis revealed that the Arctic integrated $\mathrm{F}_{65 \mathrm{~N}-\mathrm{A}}$, dMSE/dt, and the turbulent surface fluxes showed no clear relation with sea ice variability. Therefore, we have excluded these results from section 3 . 


\subsection{Results}

In this section we present the lagged correlation of sea ice and the cross correlation between energy balance components and lagged sea ice.

\subsubsection{Persistence}

First we will follow the analysis of BW1 1 and determine the lagged correlation of sea ice to investigate the decorrelation time scale and possible reemergence of anomalies in sea ice. Figure 2.2a shows the multi-model mean lagged correlation of sea ice. From this figure we can identify some distinct patterns, which we will go through one by one. First, a typical decorrelation time scale of 2-5 months is evident (indicated in figure $2.2 \mathrm{a}$ by a 1 ), with the higher values in late winter and late summer and lower values in spring and autumn. Second, a re- emergence limb is visible (indicated by a 2) during autumn, which is related to SST anomalies originating from SIA anomalies in the melt season and its prolonged/ shortened shortwave cumulative heating (i.e. a sea ice- albedo effect). Hence, we can identify pairs of months in the reemergence of anomalies coupled through the location of the sea ice edge (May and December, June and November, etc.) (BW1 1). Furthermore, a relative weak winter-to-winter (JanuaryMarch) reemergence is visible (indicated by a 3). Bitz el al. (2005) relate this winterto-winter reemergence to regions of ocean heat flux convergence anomalies, which determine the winter sea ice edge. Because of the relatively long time scales of these processes, this offers a winter-to-winter predictability. From this figure, however, it is difficult to isolate the winter-to-winter reemergence from the sea ice-albedo effect. Last, a weak growth-to-melt reemergence is found (indicated by a 4), although this is mainly visible as enhanced persistence. BW1 1 relate this reemergence to sea icethickness anomalies, which originate from a later (or earlier) freeze up resulting in less time for the ice to grow thicker. The thinner ice will become ice free earlier, which results in a reemergence of the original SIA anomaly. Note that the enhanced persistence in winter and summer is mostly due to these reemergence mechanisms.

To illustrate that there is added information beyond simple persistence of anomalies, figure $2.2 \mathrm{~b}$ shows a simple persistence model (exponential decay) based on the decorrelation time scales found in figure 2.2a. Especially at longer time scales there is added information, mainly because of the reemergence mechanisms.

The lagged correlation patterns found in figure 2.2a are comparable to those found by BW1 1 and DA14. Note, however, that the low-frequency climate variability is removed by subtracting an 11-yr running mean, which makes a direct comparison between their figures and figure 2.2a difficult. BW1 1 and DA14 also found a stronger winterto-winter and summer-to-summer reemergence of SIA anomalies, which is largely absent in figure 2.2a. The first is, as already described, said to be related to ocean heat flux convergence and the latter to sea ice-thickness anomalies, which determine to some extent the summer sea ice minimum anomalies (BW11). Because these processes are related to climate processes on longer time scales, these reemergence processes are partly removed by subtracting the 11 -yr running mean. Indeed, if we do 
not remove an 11 -yr running mean, these reemergence mechanisms are also present in the lagged correlation plots (not shown). Even though in this analysis we use 15 different climate models, the correlation patterns are comparable to the results from BW1 1 and DA14. This illustrates that the patterns found are quite robust across the different climate models. This is further illustrated in figure $2.2 \mathrm{c}$, which shows the standard deviation of the correlation scores between the different models. The areas (months) where the persistence and reemergence patterns are visible show a relative low standard deviation, indicating little spread between the models. An exception herein is the winter enhanced persistence.
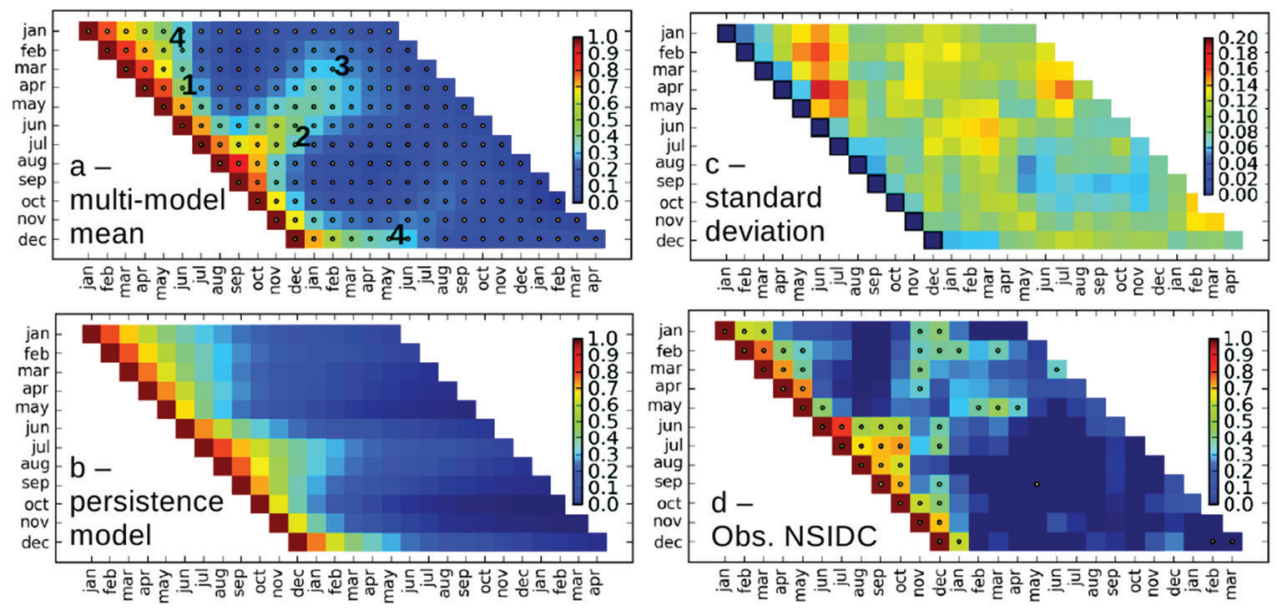

Figure 2.2 (a) Lagged correlation of total SIA for multi-model mean, (b) simple exponential decay persistence model, (c) the standard deviation between the lagged correlation of different climate models, and $(d)$ the lagged correlation of total SIA from observations (NSIDC). The black dots indicate significant values on the $99 \%$ level for multi-model mean in (a) and $95 \%$ level for ERAInterim in (d). See text for the definition of the numbers in (a)

When we compare the lagged correlation found in the multi-model mean to the observations (figure 2.2d) of total Arctic sea ice we notice distinct differences. There is a more distinct winter-to-winter reemergence, but the melt-to-freeze reemergence is partly lacking. Also, the melt-to-growth reemergence is absent. It must be noted that the observations cover only the satellite era (1979-2013) and show a strong trend toward less and thinner sea ice. A fair comparison between observations and CMIP5 preindustrial simulations is therefore difficult. However, the proposed mechanism behind the persistence and reemergence of sea ice anomalies should still be active in the current Arctic climate. Note that the decorrelation time scales are much smaller (2-3 months) except in the summer months. Also, the enhanced persistence in winter is largely absent. This is, as figure $2.2 \mathrm{c}$ shows, also not agreed on in all models. This may indicate that some models overestimate predictability in winter months. The results agree with what BW11 found in their comparison with observations. 


\subsubsection{Atmospheric energy balance and sea ice variability}

Next, we study the relation between components of the Arctic energy budget and the total SIA. Figure 2.3 shows the cross correlation between the surface net radiation (SNR) and top-ofatmosphere net radiation (TOANR) and the total SIA, with lags ranging from -4 (sea ice leads) to +12 months (sea ice lags). The first row shows the correlation between January SNR and lagged SIA, the second row for February, and so forth. The zero lags are marked by black squares. This figure therefore allows us to study SIA anomalies before and after net radiation anomalies for every individual month. To simplify further explanations, we describe relationships with respect to negative sea ice anomalies only. If we look at figure 2.3a and 2.3b, SNR and TOANR of May-August (on the vertical axis) show a relative strong negative correlation with SIA, where in the months October-March (vertical axis) there is mainly a positive correlation. The negative correlation indicates that a positive anomaly in SNR (i.e., more net radiation to- ward the surface) relates to less sea ice. The positive correlation in the autumn months can be explained by the fact that the extra heat absorbed by the ocean in spring and summer, because of less sea ice, has to be released to the atmosphere before sea ice can grow again. Hence, less sea ice in spring and summer relates to a more positive net radiation in spring and summer but a more negative net radiation in autumn. A distinct feature in figure $2.3 \mathrm{a}$ and $2.3 \mathrm{~b}$ is that the negative correlations are mainly found at positive lags; that is, positive net radiation anomalies lead to less sea ice. The highest positive correlations, however, are mainly found at negative lag; that is, less sea ice leads to negative net radiation anomalies. The TOANR in November and December must be noted as an exception, with relatively large positive correlation at lag zero and lag one. The negative correlation in summer can be seen as a positive feedback on sea ice anomalies, which can enhance the persistence of sea ice anomalies. Further, in the negative correlation found in summer, we can clearly identify the pairs of months in the sea ice edge locations (May and December, June and November, etc.), as described in the previous section. When comparing both figures (figures $2.3 \mathrm{a}, \mathrm{b}$ ) with ERA-Interim (figures $2.3 \mathrm{c}$,d), we find
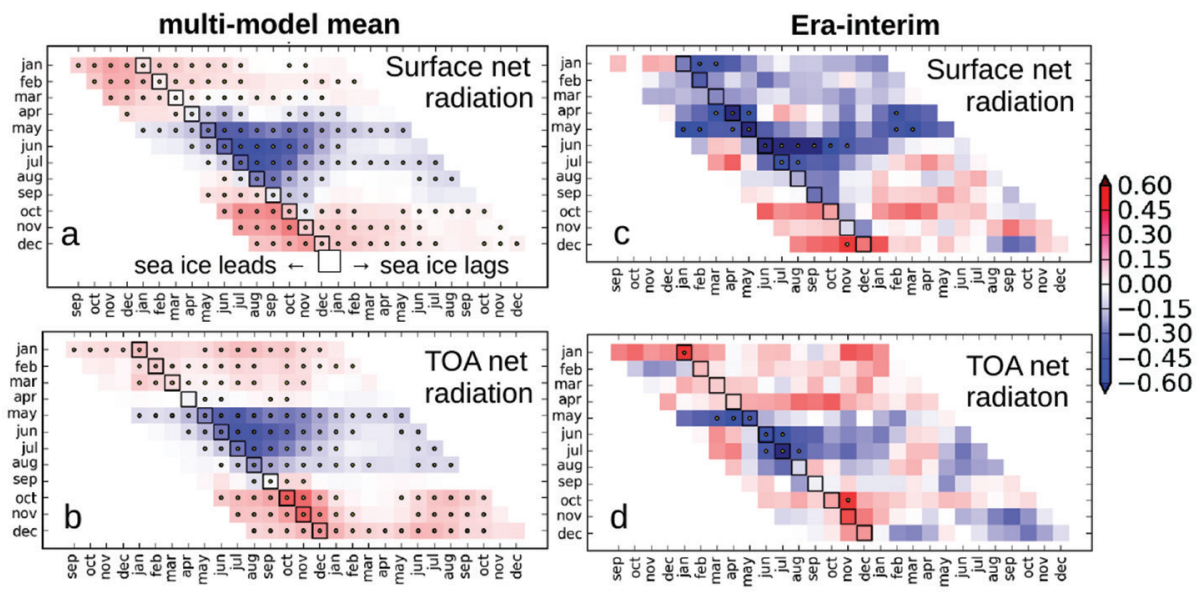

Figure 2.3: Cross-correlation plots of total SIA (horizontal) and (a) SNR (vertical) and (b) TOA net radiation. (c),(d) As in (a),(b), but for ERA-Interim. Zero lags are indicated by black squares. Also, where sea ice anomalies lead and lag relative to the radiation anomaly are illustrated in (a). The black dots indicate significant values on the 99\% level for multi-model mean and 95\% level for ERA-Interim. 
many similarities. Again, however, the ERA-Interim data are much noisier because of their shorter time span (1979-2013), making it more difficult to distinguish noise from signal. The main features found in figure $2.3 \mathrm{a}$ and $2.3 \mathrm{~b}$ are also visible in ERAInterim (figures $2.3 \mathrm{c}$,d). A distinct difference, however, is the relative strong negative correlation for April and May SNR. To identify the role of the individual components of SNR and TOANR, and to be able to explain some features found in figure 2.3, we have calculated the lead-lag relations between the individual radiation components and the total SIA. Figure 2.4 shows the individual radiation components of the SNR. The radiation components are defined positive downwards. A positive radiation anomaly is thus either more radiation downwards, or less radiation upwards. The radiation components are labeled as $S$ or $L$ for respectively shortwave and longwave, and $\uparrow$ or $\downarrow$ to indicate the upwelling or downwelling component. A first look at the multi-model mean and ERA-Interim reveals that all radiation components match reasonably well, both in sign of correlation as in amplitude, which gives reasonable confidence in the multi-model mean. A striking feature in figure $2.4 \mathrm{a}-\mathrm{d}$ is the relative high correlation found in early spring for all 4 plots, which is not seen in the net radiation plots in figure 2.3a-b. The strongest correlations are found in $\mathrm{S} \uparrow$ and $\mathrm{L} \uparrow$. The negative correlation of $\mathrm{S} \uparrow$ can be easily explained, as this is directly related to the amount of solar radiation absorbed by the Arctic region, thus heavily dependent on surface albedo. More radiation absorbed in the ocean, i.e. a positive anomaly of $\mathrm{S} \uparrow$, relates to less sea ice. Interestingly, when comparing figure 2.2a with $3.4 \mathrm{a}$, we find that the $\mathrm{S} \uparrow$ anomaly of April and May is even a better predictor for September total SIA than sea ice itself (the correlation coefficient is 0.15 higher). We will discuss this in more detail in the next section. Note however that this is not evident in ERA-Interim.

$\mathrm{L} \uparrow$ (figure 2.4c) shows strong resemblance to $\mathrm{S} \uparrow$ in correlation strength, albeit positive values. This may seem counter-intuitive, as less energy away from the surface would result in a warmer surface, thus less sea ice, which would yield a negative correlation. However, $L \uparrow$ anomalies originate from surface temperature anomalies, linked through the Stefan-Boltzmann relation. $L \uparrow$ therefore acts to restore surface temperature anomalies to their equilibrium state and is therefore of opposite sign to the radiation components that force a surface temperature anomaly.

The role of $L \downarrow$ (figure $2.4 \mathrm{~d}$ ) is different, as this is mainly related to the amount and height of clouds and humidity, which emit longwave radiation back to the surface. The negative correlation found in figure 4 can be explained by more $L \downarrow$, thus a positive anomaly, resulting in a negative SIA anomaly. The fact that $L \downarrow$ shows relative high correlation, especially in autumn, suggests that clouds and humidity play an important role in SIA variability. This relation will be explained in more detail in the discussion. The role of $\mathrm{S} \downarrow$ is more difficult to understand. Figure $2.4 \mathrm{~b}$ shows positive correlations between shortwave down and sea ice anomalies. This indicates that with less shortwave radiation reaching the surface there is also less sea ice, which may seem counter-intuitive. These results therefore again point to a possible influence of clouds. It is striking however, that the variables most influenced by clouds ( $\downarrow \downarrow$ and $\mathrm{S} \downarrow$ ) show no clear relation with SIA in July. Shortwave radiation is largely absent in Arctic winter, hence longwave is dominant over shortwave in winter months, which explains the positive correlations found in the winter months in figure 2.3. The fact that $L \uparrow$ 

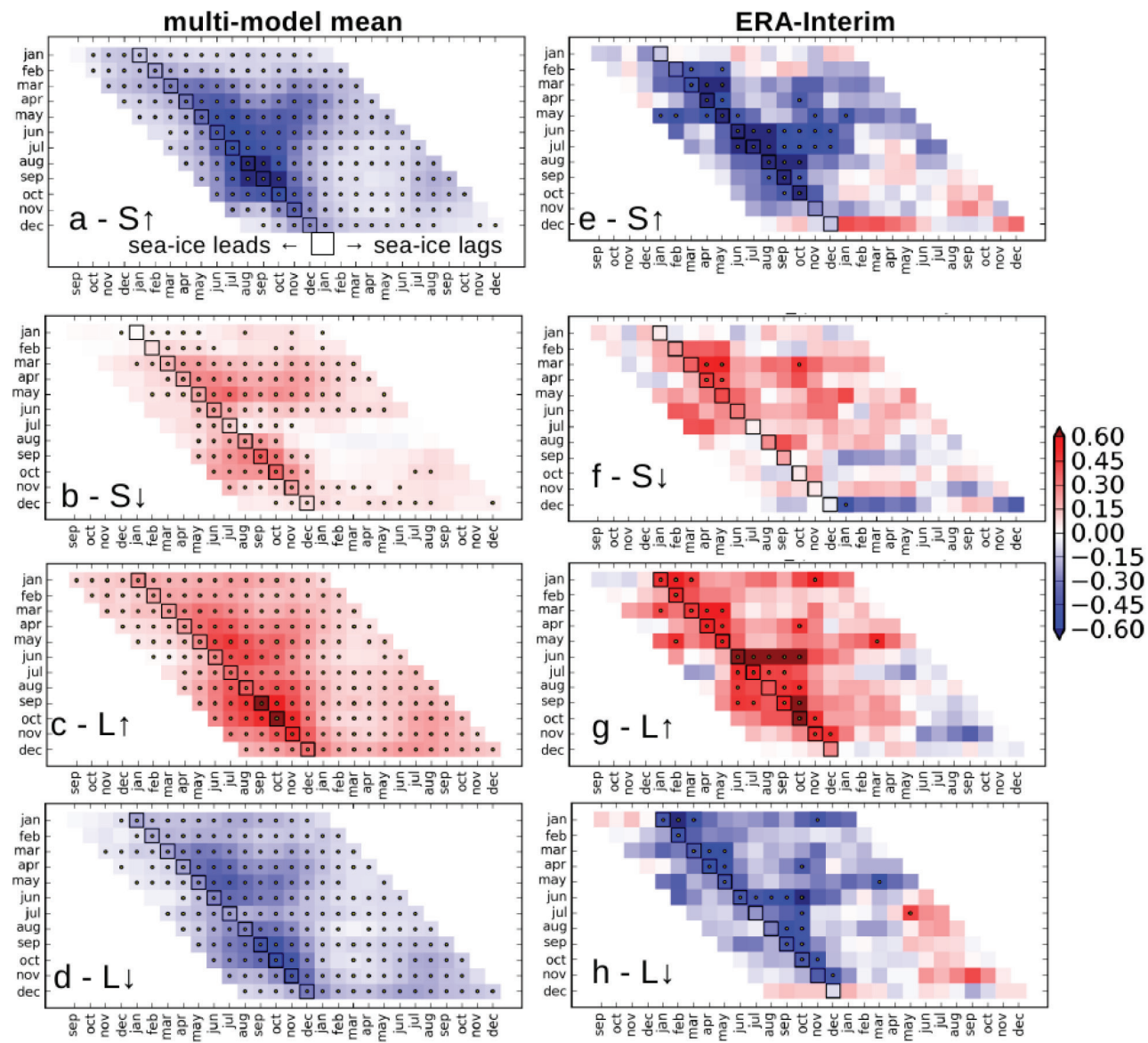

Figure 2.4: As in Fig. 2.3, but for surface radiation components (a) $S \uparrow$, (b) $S \downarrow$, (c) $L \uparrow$, and (d) $L \downarrow$. (e)-(h) As in (a)-(d), but for ERA-Interim.

anomalies mainly follow after SIA anomalies also explains the positive correlation in figure 2.3a-b at negative lags. Another distinct pattern found in all plots in figure 2.4 is the difference between radiation anomalies in December to May, and June to October. In general, the former are not preceded by SIA anomalies, and the latter are. In March to May, the radiation anomalies precede sea ice anomalies, thus act as a forcing. From June onwards, the sea ice anomalies originating in June seem to persist and possibly strengthen the sea ice and radiation anomaly in the subsequent months through the sea ice albedo effect. The TOANR components (figure 2.5) show similar patterns, albeit less strong and no clear relation between early spring radiation and total SIA. Also, the $\mathrm{S} \uparrow$ has no relation with total SIA anomalies from October onwards, which is in contrast to the surface $\mathrm{S} \uparrow$. This also explains the relative strong positive correlation found in figure $2.3 \mathrm{~b}$ in the autumn months, as when the influence of $\mathrm{S} \uparrow$ is absent, TOANR is only dependent on $\mathrm{L} \uparrow$. We can identify the same differences between the multi-model mean and ERA-Interim as with figure 2.4. Because correlation only indicates how much two variables can covary, but nothing about the amplitude of both signals, we also performed the above analysis by calculating the regression 
coefficients (not shown). This helps us to identify the relative importance of the different energy balance components. The results indicate that the amplitudes of the radiation anomalies correlated with sea ice anomalies are in the same order of magnitude (not shown), with $\mathrm{S} \uparrow$ and $\mathrm{L} \uparrow$ slightly higher.
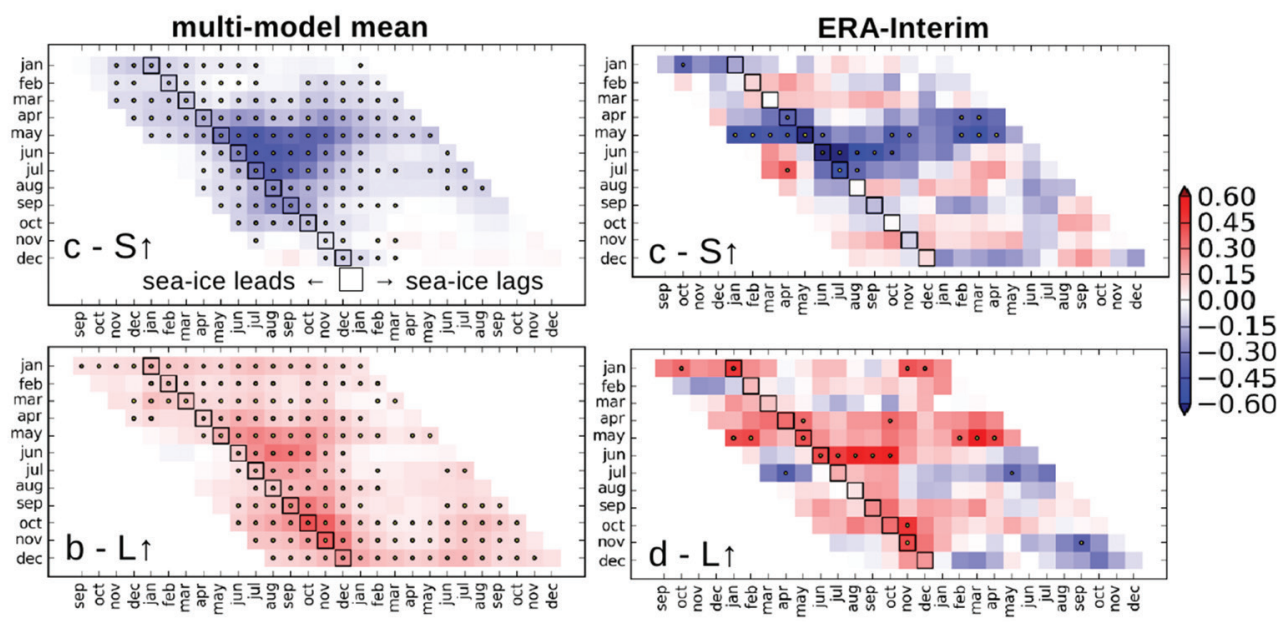

Figure 2.5. As in Fig. 2.3, but for TOA radiation components: (a) $S \uparrow$ and (b) $L \uparrow$. (c),(d) As in (a),(b), but for ERA-Interim.
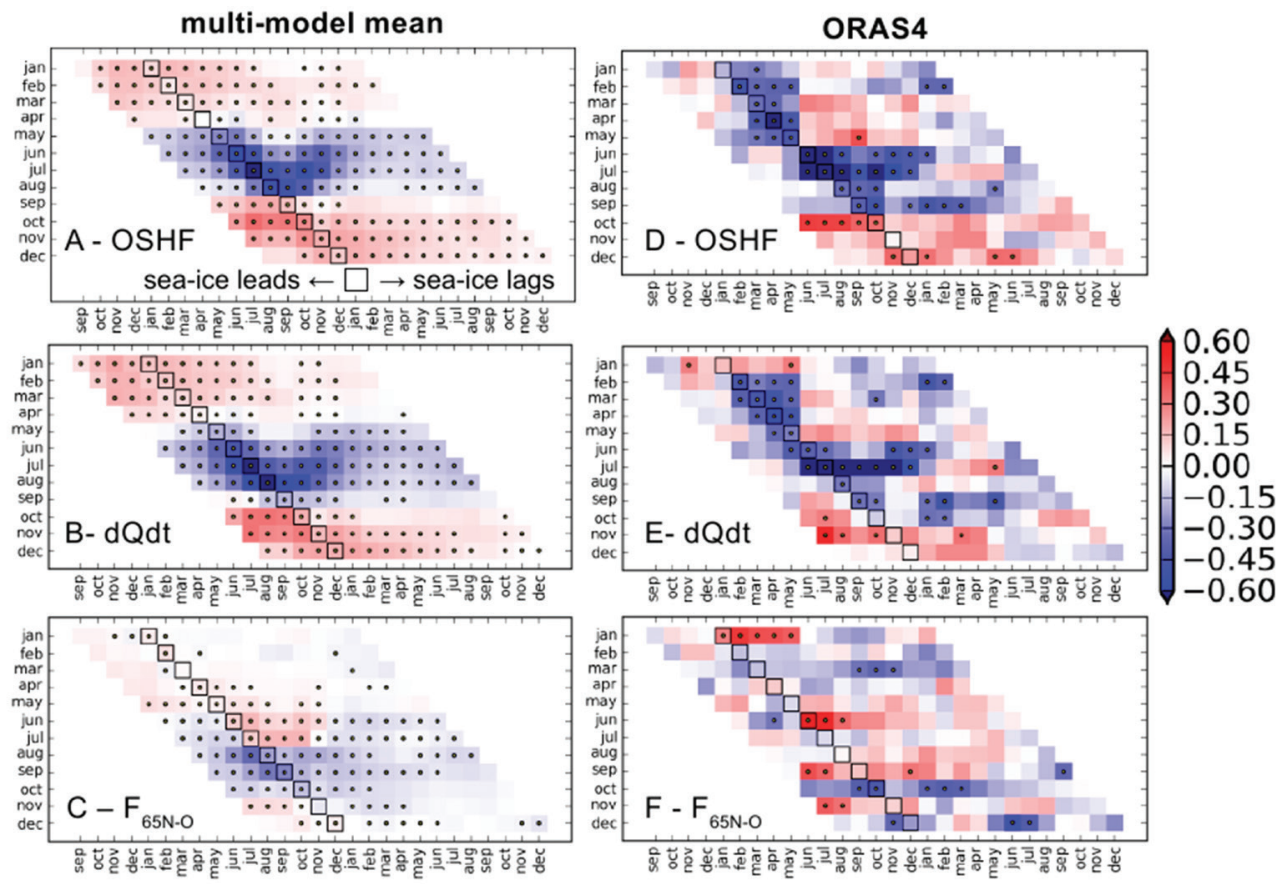

Figure 2.6. As in Fig. 2.3, but for (a) OSHF, (b) dQdt, and (c) the 650N meridional ocean heat flux. (d) $-(f)$ As in (a)-(c), but for ORAS4. 


\subsubsection{Ocean energy balance and sea ice variability}

Next, we study the components of the ocean energy balance in relation to sea ice variability. Figure 2.6 shows the components of the ocean energy balance in relation to SIA anomalies. The ocean surface heat flux (OSHF), defined as positive down, is the heat flux at the top of the water column. Hence, it is at open ocean strongly related to the surface net radiation, and also yields comparable results except for the months April and May. The negative correlation in summer months is explained by more radiation into the ocean, relating to negative total SIA anomalies. As also described in section 2.2, the extra heat in the ocean has to be released back to the atmosphere before ice can grow again. Thus, less sea ice relates to a more positive OSHF in late spring and summer, but to a more negative OSHF in autumn, hence the positive correlation in autumn months at negative lags. The change in ocean heat content (dQdt) gives almost the same results as the OSHF, which indicates that with a 11 year running mean removed, most of the variability in dQdt is related to variability in OSHF. The correlation between the OSHF and dQdt anomalies vary from 0.6 to 0.8 between the models (not shown), which further strengthens this idea. There is some impact of ocean heat transport in summer in the models (both in forcing as in response), but from ORAS4 no clear relation is found. These findings support the idea that, with low-frequency climate variability removed, the main function of the ocean in relation to SIA variability is to store SST anomalies forced by OSHF anomalies. ORAS4 yields generally the same results, except for the summer months in OSHF where the negative correlation is not as strong as in the multi-model mean.

\subsubsection{Local surface radiation anomalies}

To identify which regions in the Arctic sea ice cover are related to the spring and summer correlation found in figure 2.4a, we have plotted the local $\mathrm{S} \uparrow$ anomaly of April (figure 2.7a) and July (figure 2.7b), correlated with the total SIA anomaly of the subsequent 8 months. The regions that show higher correlation for the April S $\uparrow$ are the Bering Sea and the Barents Sea, where the latter also shows relative strong correlation up to lag 3 and a weak reemergence in lag 7 . For the July S $\uparrow$ anomaly the main region consists of the Beaufort, Chuckchi, East-Siberian, Laptev and Kara Sea. For both figure $2.7 \mathrm{a}$ as $2.7 \mathrm{~b}$, the regions with relative high correlation are situated close to the sea ice edges, except for typical sea ice export regions (e.g. the Fram export region). The other radiation components show similar spatial patterns (not shown), indicating that the anomalies for $S \uparrow, S \downarrow, L \uparrow$ and $L \downarrow$ are all spatially related. It must be noted here that the multi-model mean correlation is quite small, mostly between 0.2 and 0.3 . The correlation for the individual models is often higher ( $0.4-0.5$ ). The lower multi-model mean is caused by differences in location of the sea ice edge, which therefore also changes the regions where the higher correlations are found. The multi-model mean therefore results in a lower correlation and spread over a larger area. Figure 2.7 can also help us to understand why spring $\mathrm{S} \uparrow$ is a better predictor for September sea ice area than spring sea ice itself (as seen in figure 2.3 and 2.4). This can be explained by the fact that a SIA anomaly in spring only provides information in the region of the sea ice edge, whilst the sea ice edge in September 
is far more to the north. The spring Arctic integrated upwelling solar radiation does contain information about conditions further north through surface albedo anomalies. The albedo of sea ice slowly decreases in spring because of melting of snow and ice and the formation of melt-ponds. A change in surface albedo in spring therefore provides information on the rate of melting at the region of the sea ice edge in September, as also suggested by Schröder et al. (2014) who show that spring meltpond fraction could be a good predictor for September sea ice.

\subsection{Discussion}

The results above support the important role of the sea ice albedo effect, which is manifested in SST anomalies originating from prolonged, or shortened, cumulative heating by shortwave radiation as a result of SIA anomalies. This is especially evident in OSHF, OHC and $\mathrm{S} \uparrow$ anomalies. The atmospheric radiation components, however, also point to an important role for clouds in explaining SIA anomalies, notably the correlation between $\mathrm{L} \downarrow$ and SIA, and the positive correlation between $S \downarrow$ and SIA. The role of clouds on Arctic sea ice variability has been investigated before, both in observational studies (e.g. Francis et al., 2005; Kay and Gettelman, 2009) and in modeling studies (e.g. Gorodetskaya and Tremblay, 2008). These studies emphasize the complicated relationship between clouds and Arctic sea ice, because the cloud radiative forcing (CRF) is strongly dependent on the insolation, surface albedo and the type of clouds, which in turn vary strongly during the season. Here we elaborate further on the role of clouds in the context of this study.

In order to understand and quantify the relation between the radiation components, clouds and sea ice variability we determine how radiation and cloud anomalies evolve, prior to, and after, the occurrence of sea ice anomalies. We do this by first selecting the locations and times of sea ice anomalies, for all models. Herein we distinguish between positive and negative sea ice anomalies. We will only consider negative sea ice anomalies to simplify the explanation. For these negative sea ice anomalies we calculate the radiation and cloud anomalies in the range of 12 months prior and 12 months after, and at the location of, the occurrence of sea ice anomalies. The radiation and cloud anomalies are computed relative to sea ice conditions. In this way the anomaly represents the difference between sea ice and open water conditions. The radiation and cloud anomalies are then averaged over the different grid points, years and models to get the average anomaly, prior to and after a sea ice anomaly, for the different months. The results are presented in figure 2.8. We also performed the above analysis for positive sea ice anomalies. These values are generally similar, but of opposite sign. Note that, in contrast to figure 2.3-2.6, here the radiation anomalies are lagged and not the sea ice anomalies. 


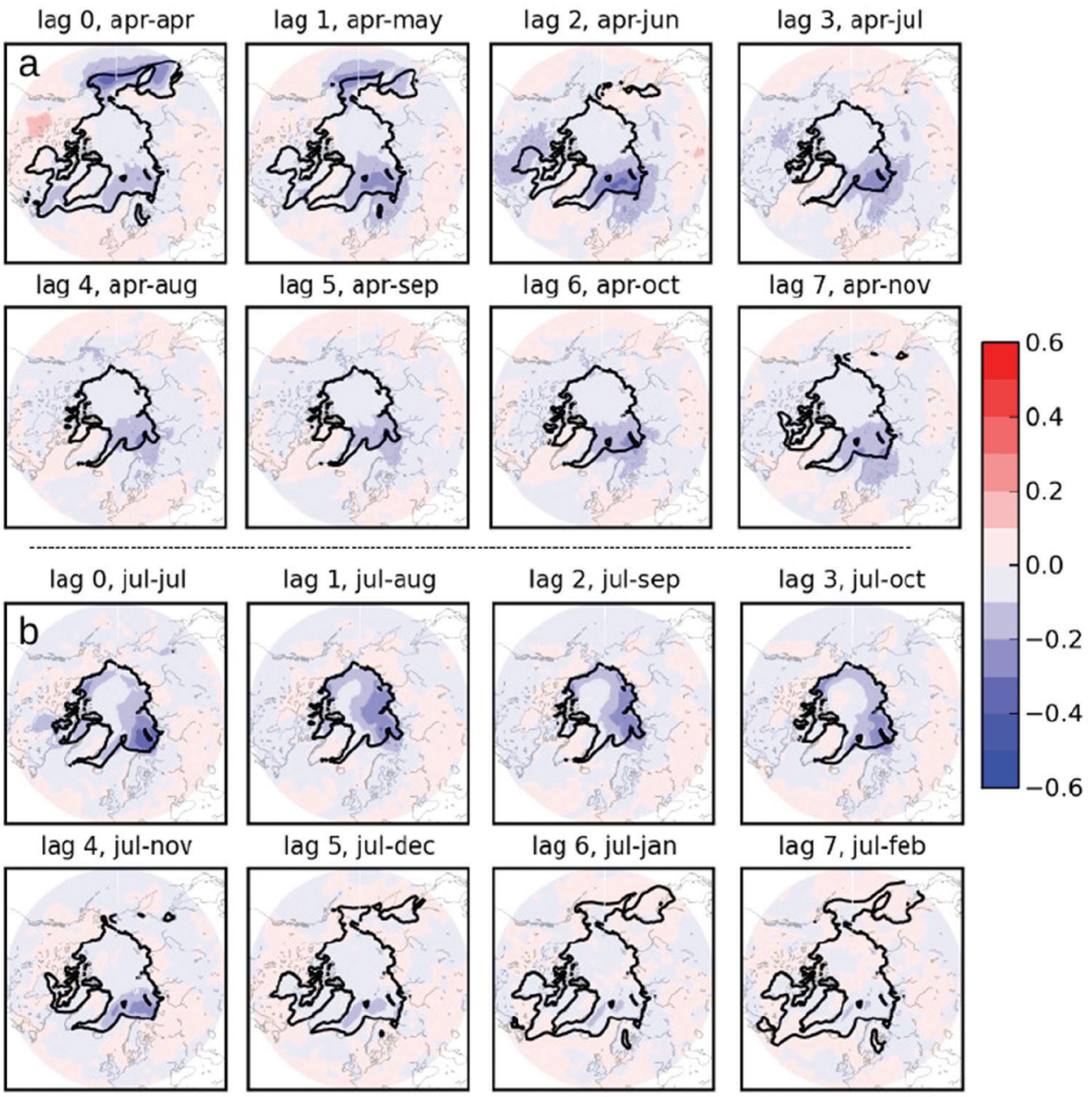

Figure 2.7: Correlation between the local surface $S \uparrow$ of (a) April and (b) July and total SIA for Iags 0 -7. The black contours indicate the model mean sea ice edge.

From figure 2.8a we can see that a negative sea ice anomaly in spring relates, on average, to a SNR anomaly of $\sim 25 \mathrm{~W} \mathrm{~m}^{-2}$ at zero lag (indicated by a 1 in figure $2.8 \mathrm{a}$ ). In late autumn and winter, the SNR anomaly at zero lag is very small compared to spring and summer (indicated by a 2). However, we do find a positive SNR anomaly of $\sim 12-18 \mathrm{~W} \mathrm{~m}^{-2}$ prior to the sea ice anomalies in late autumn / winter (indicated by a 2.3). This nicely illustrates the reemergence of an anomaly in autumn from an original anomaly in spring, as illustrated before in figure 2.2a. This figure shows the pairs of months (May-Dec, Jun-Nov etc.) that share the location of the sea ice edge. These pairs of months can also be seen in the shortwave (figure $2.8 \mathrm{~g}-\mathrm{h}$ ) and longwave (figure $2.8 \mathrm{~b}-\mathrm{c}$ ) radiation components. The individual radiation components also reveal that the increase in SNR of $\sim 25 \mathrm{~W} \mathrm{~m}^{-2}$ in late spring / summer is mainly related to a positive anomaly of $\mathrm{S} \uparrow$, i.e. less upwelling solar radiation, which is directly related to the decreasing surface albedo. Interestingly however, the $\mathrm{S} \downarrow$ decreases by 
$20 \mathrm{Wm}^{-2}$, which partly compensates for the reduced $\mathrm{S} \uparrow$. Less $\mathrm{S} \downarrow$ could be caused by a higher cloud fraction related to enhanced evaporation from open water, but as figure 2.8e shows, June to August show no cloud response to a sea ice anomaly (indicated by a 4 in figure. $2.8 \mathrm{e}$ ). The decrease in $\mathrm{S} \downarrow$ is then most likely related to the multiple reflection component of $\mathrm{S} \downarrow$, which reduces as the surface albedo becomes smaller. We can estimate the reduction of $S \downarrow$ due to a surface albedo change. For a non-absorbing cloud, $S \downarrow$ is given by $S \downarrow=F_{0}(1-r) /(1-\alpha r)$ (e.g. Shine 1984; DeWeaver et al. 2008), where $F_{0}$ is the solar downwelling radiation above the cloud, $r$ the cloud reflectivity and $\alpha$ the surface albedo. Following DeWeaver et al. (2008) we assume an Arctic cloud reflectance of 0.7. Values associated with the decrease in $\mathrm{S} \downarrow$ are a decrease in albedo from $\sim 0.5$ to $\sim 0.25$, a $\mathrm{F}_{0}$ of $\sim 320 \mathrm{~W} \mathrm{~m}-2$ and a cloud fraction of $\sim 0.7$ (not shown), which yields a decrease of $\sim 22 \mathrm{~W} \mathrm{m-2}$. This indicates that the decrease of $\mathrm{S} \downarrow$ can indeed be caused by the decrease of the multiple reflection component of $S \downarrow$.

Figure $2.8 \mathrm{f}$ shows the anomaly of OSHF due to less sea ice. It increases $\sim 60 \mathrm{~W} \mathrm{~m}^{-2}$, which is more than twice the response of SNR. This can be explained by the fact that the extra solar radiation is directly absorbed by the ocean, whilst if there were ice, a large portion of this energy is absorbed by the sea ice and only a small portion of that reaches the water column.

Even though there is no direct cloud response from June till August to sea ice anomalies, we do find a delayed response (indicated by a 5 in figure 2.8e). Such a delayed response can also be found in the turbulent fluxes (figure $2.8 \mathrm{~d}$,i) and the longwave radiation components (figure $2.8 \mathrm{~b}, \mathrm{~g}$ ). These results correspond to findings from Kay and Gettelman (2009), who found a seasonal dependence on cloud response to sea ice decline in an observation study in the 2006-2008 period. They found no clear cloud response in summer on sea ice anomalies, while in early fall more clouds did form. They related the lack of response in summer to a weaker ocean-atmosphere coupling because of stronger atmospheric stability and weaker air-sea temperature gradients. In early fall however, the lower static-stability and stronger air-sea temperature gradients result in stronger turbulent fluxes, which are in turn further strengthened by the SST anomaly. The larger turbulent fluxes increase the moisture in the air, hence yield a higher cloud fraction, which in turn enhances $L \downarrow$. Our analysis supports this finding, and shows that this is an integral part of the seasonal sea ice albedo feedback in the climate models used for this analysis. 


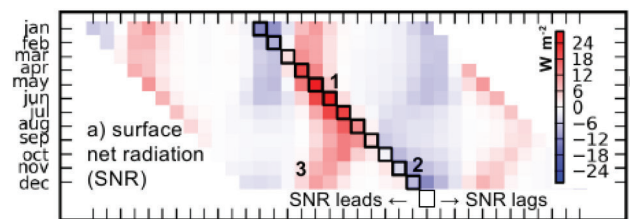

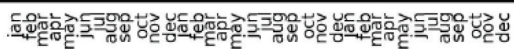

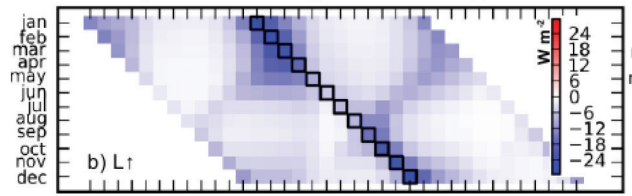

둔에

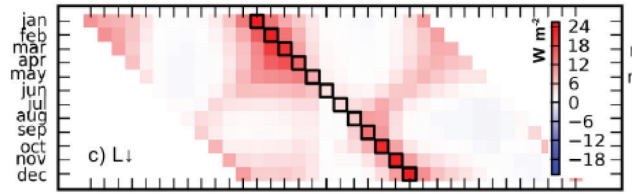

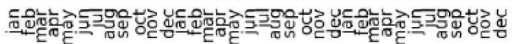

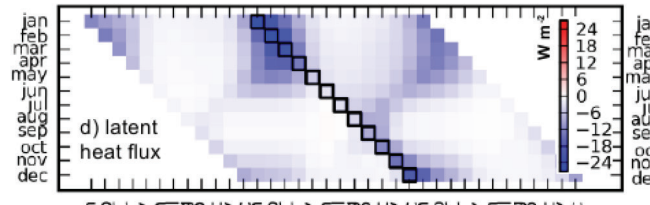

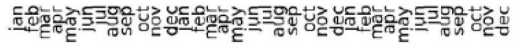

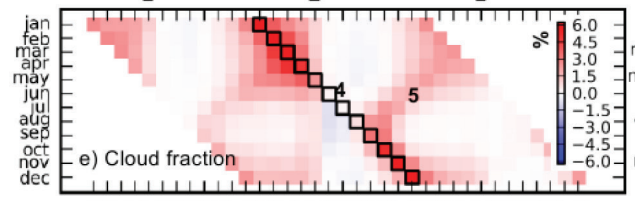

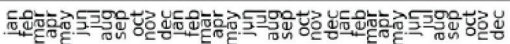

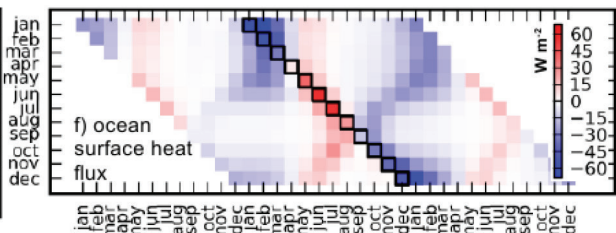

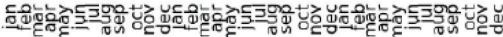

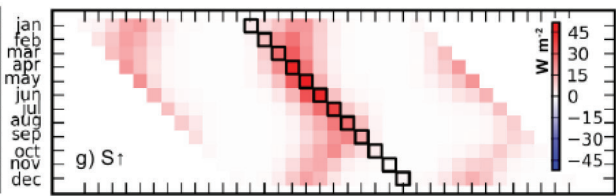

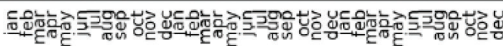

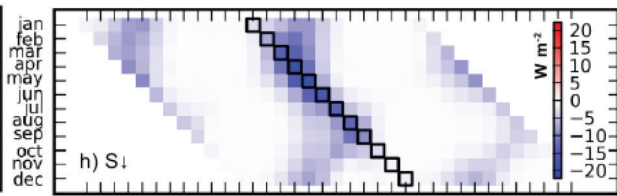

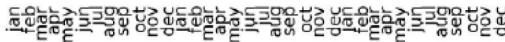

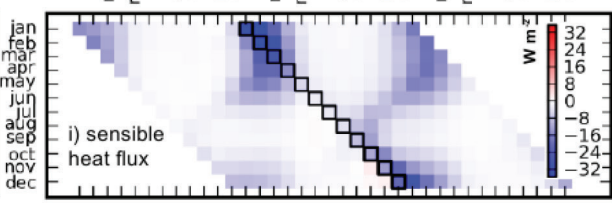

든.

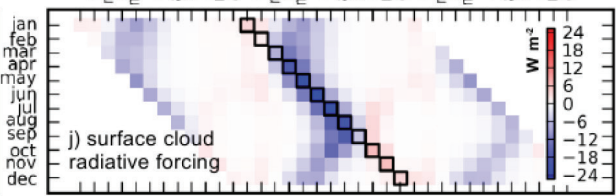

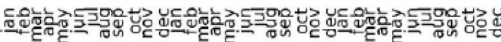

Figure 2.8: multi-model (a)-(d),(f)-(j) mean radiation and (e) cloud fraction anomalies at the location of negative sea ice anomalies and 12 months prior to and 12 months after their occurrence.

It is now also interesting to see how this delayed cloud response influences the seasonal sea ice albedo feedback, i.e. a cloud-ice feedback. Kay and Gettelman (2009) already concluded that cloud changes resulting from sea ice anomalies only play a minor role in regulating the sea ice albedo feedback in spring, but that it may contribute to a cloud-ice feedback during early fall. They couldn't quantify the magnitude, or sign, of this feedback. Our analysis does provide this opportunity. Figure 2.8e shows the anomaly in surface CRF, for negative sea ice anomalies. This is calculated by summing the longwave forcing ( $\left.\mathrm{LW}_{\text {CLOUD }}-\mathrm{LW}_{\text {CLEAR SKY }}\right)$ and the shortwave forcing ( $\mathrm{SW}_{\text {CLOUD }}-\mathrm{SW}_{\text {CLEAR SKY }}$ ), where LW and SW are the net longwave and net shortwave radiation at the surface. A positive CRF thus means more clouds warm the surface. During spring and summer, around lag zero, the CRF decreases by $\sim 25 \mathrm{~W} \mathrm{~m}^{-2}$. This is primarily related to the decrease in the multiple reflection component of $S \downarrow$, hence an indirect radiative effect. This is, as described above, caused by the decrease in surface albedo. The cloud response in fall, as a result of a SIA anomaly in spring, 
does result in a larger CRF of $\sim 6 \mathrm{~W} \mathrm{~m}^{-2}$. This increase in CRF is not due to a change in multiple-reflection, as it is also visible in the longwave cloud radiative forcing (not shown). If we compare this response to the original net radiation anomaly in spring $\left(\sim 25 \mathrm{Wm}^{-2}\right)$, i.e. the direct sea ice albedo effect, we find that the delayed response contributes about $20 \%$ to the seasonal sea ice albedo feedback. It must be noted here that this is only true if the sea ice anomaly indeed reemerges, as it does in about 25$50 \%$ of the times, depending on the month (see figure $2.2 \mathrm{a}$ ).

To understand why an increase in cloud fraction results in a positive CRF anomaly, we have calculated the multi-model mean surface CRF climatology (figure 2.9). From this figure we can deduce both a strong seasonal (i.e. solar zenith angle), and an albedo dependence. CRF is positive if the warming effect of enhanced $L \downarrow$ is larger than the cooling effect of less $S \downarrow$. During Arctic winter the enhanced $L \downarrow$ dominates because $S \downarrow$ is largely absent, hence clouds have a net warming effect. During Arctic summer $\mathrm{\downarrow} \downarrow$ becomes larger, hence the cooling effect of less $\mathrm{S} \downarrow$ also becomes larger. It depends on the surface albedo and the strength of $\mathrm{S} \downarrow$ (i.e. the net solar radiation) whether the cooling effect of less $S \downarrow$ becomes stronger than the warming effect of more $L \downarrow$. For the largest part of the year, the CRF is positive over the sea ice (indicated by the white line). Only during June and July there are regions on the Arctic sea ice with a negative CRF. Because there is no cloud response in spring, there is also no cloud-ice feedback in spring. When there is indeed a cloud response in late summer and autumn, the CRF has become positive due to the absence of solar radiation. The increase in clouds in autumn thus yields a more positive CRF. The response of clouds to the seasonal sea ice albedo effect is thus that it strengthens the feedback mechanism.

From figure 2.8 and 2.9 we can find two possible explanations for the positive correlation between $\mathrm{S} \downarrow$ and Arctic sea ice, found previously in figure $2.4 \mathrm{~b}$. The first is a positive CRF, where, as described above, an increase in $\mathrm{S} \downarrow$ is compensated by a stronger decrease in $L \downarrow$. The second explanation is the decrease of the multiple reflection component of $\mathrm{S} \downarrow$ due to an albedo decrease. Our analysis shows that, on average, the latter effect is stronger than the former. It should be noted however that $\mathrm{S} \downarrow$ can also be negatively correlated with sea ice variability. As indicated in figure 9, the CRF is not always positive, hence a $S \downarrow$ anomaly can also enhance sea ice retreat. This is clearly demonstrated by Kay et al. (2008) in the 2005 and 2007 sea ice melt seasons. 

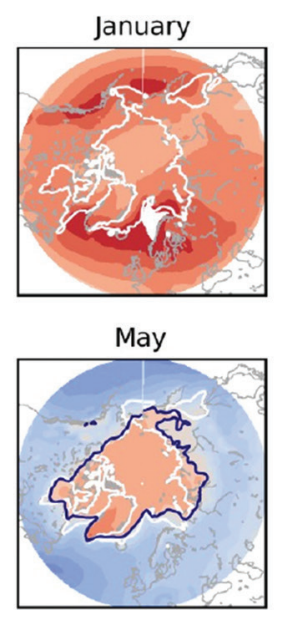

September

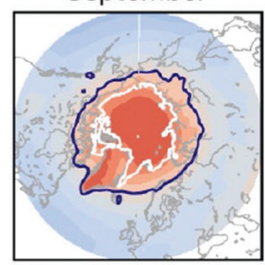

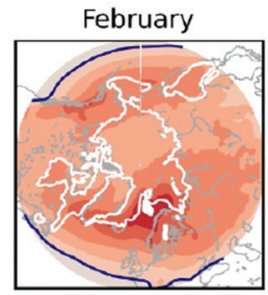

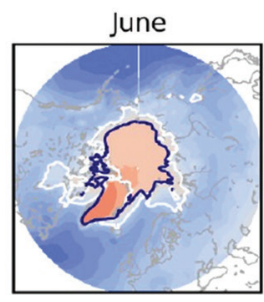

October

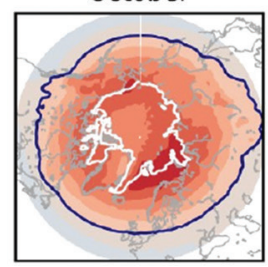

March

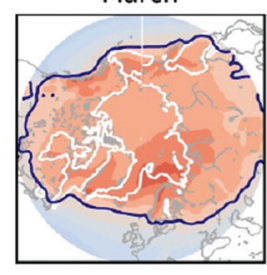

July

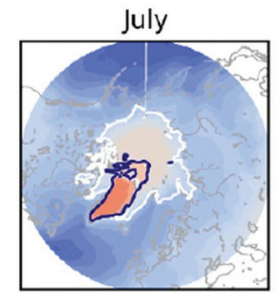

November

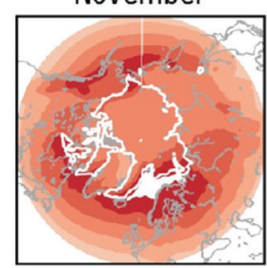

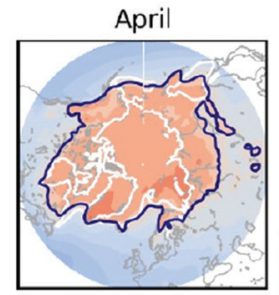

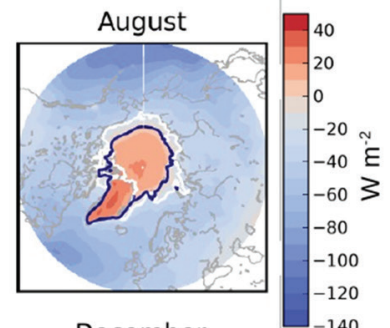

December

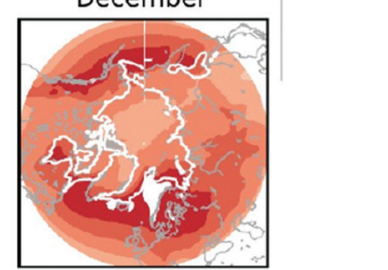

Figure 2.9: multi-model mean climatology of cloud radiative forcing. The white contour indicates the multi-model mean sea ice edge and the blue contour the $0 \mathrm{Wm}-2 \mathrm{CRF}$ isoline.

We have also performed the analysis presented in figure 2.8 and 2.9 with ERA-Interim and ORAS4. These results (not shown) also show the delayed cloud response of clouds on sea ice anomalies, and the decrease of $\mathrm{S} \downarrow$ because of a decrease of the multiple reflection component. The overall picture of CRF for the multi-model mean and ERA-Interim match reasonably well, although the amplitude of the seasonal cycle is smaller in ERA-Interim.

Recent work by Kapsch et al $(2013,2014)$ also investigated the role of spring atmospheric forcing on sea ice variability. They showed a clear connection between anomalies in spring $L \downarrow$ and $S \downarrow$, and September sea ice anomalies in a large part of the Arctic ocean. Our results (figure $2.8 \mathrm{~d}$ and $2.8 \mathrm{~h}$ ) also show a small $\mathrm{L} \downarrow$ anomaly in April and May (figure 2.8d) and a $\mathrm{S} \downarrow$ anomaly from May onwards. Our results therefore confirm their findings, but it must be noted that the signal is relatively small. 

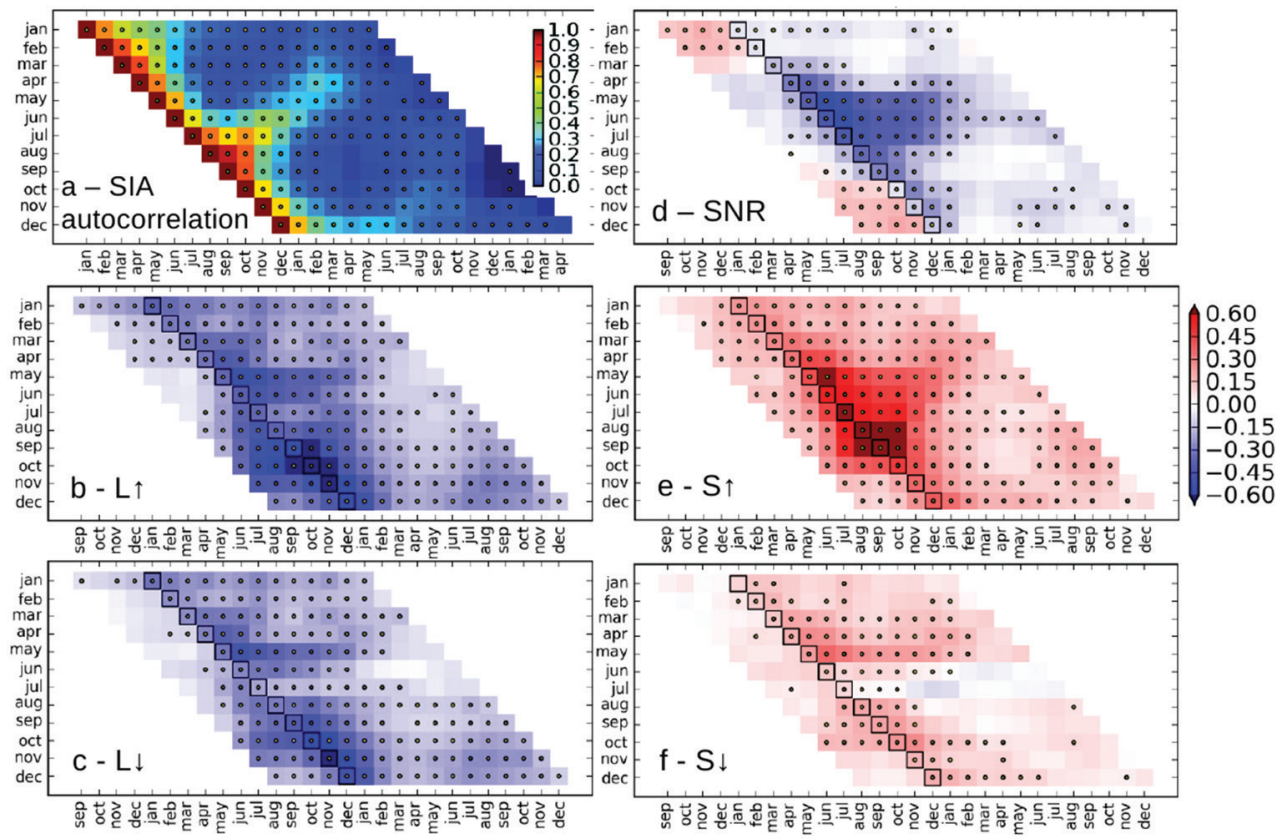

Figure 2.10: As in Figs. 2.2a, 2.3a, and 2.4, but now for RCP4.5 scenario, lagged correlation of (a) total sea ice area and cross correlation between (lagged) sea ice and (b) $L \uparrow,(c) L \downarrow$, (d) $S N R$, (e) $S \uparrow$, and (f) $S \downarrow$.

In this analysis we have used the pre-industrial (control) CMIP5 climate simulations. Because the simulations lack a long term trend, it allows us to focus on the role of natural variability in the Arctic sea ice. The question must be asked however, whether the findings presented above are also valid for the future climate. To test this we have performed part of the analysis presented above using the RCP45 scenario simulations (2005-2100). Figure 2.10 shows the lagged correlation of SIA, and the cross-correlation of SNR and the individual components of SNR with (lagged) sea ice, presented in the same manner as in figure 2.4. The RCP45 multi-model mean shows strong overall resemblance to the control multi-model mean. There are some slight differences in the specific values of the correlation, but the main patterns are very similar, indicating that the analysis presented above also seems valid for future sea ice regimes. This can be expected, as the physical mechanisms for the enhanced persistence and reemergence of anomalies, should still be working in a thinner, and smaller extent, sea ice regime. Andry et al (2016) even show that the sea ice albedo feedback will only strengthen when the amplitude of the seasonal cycle increases, as projected in future sea ice regimes. 


\subsection{Conclusions}

We performed an analysis on the natural variability of Arctic sea ice from an energy balance perspective. In this analysis we aimed to explain the physical mechanisms that provide predictability of Arctic sea ice on seasonal to yearly time-scales. For this we used a selection of state-of-the-art CMIP5 climate models. In the first part of the analysis we computed the lagged correlation of total Arctic sea ice and crosscorrelation between radiation components and (lagged) total arctic sea ice. In the second part we analysed the radiation anomalies on locations prior to and after sea ice anomalies. We compared our results with reanalysis data, namely ERA-Interim and ORAS4.

In the lagged correlation plots we found (1) typical decorrelation time-scales ranging from 2 to 5 months, (2) a reemergence of anomalies in autumn related to the seasonal sea ice albedo effect, (3) a winter to winter memory most likely related to ocean heat convergence anomalies (Bitz et al. 2005) and (4) a weak autumn to spring reemergence related to ocean thickness anomalies (BW11). These findings correspond to BW1 1 and DA14, which shows that these persistence and reemergence mechanisms are robust mechanisms in current climate models.

Net radiation, both at the surface and at the top of atmosphere, are negatively correlated with sea ice in summer, and weakly positively correlated in winter. The negative correlation in summer is mostly determined by upward shortwave radiation, which is directly related to the surface albedo. Hence, more radiation upward relates to more sea ice. The negative correlation during winter is mostly determined by upward longwave radiation, which acts to restore temperature anomalies to their equilibrium state. Hence, a positive sea ice anomaly is related to less upward longwave radiation which results in a positive correlation.

The individual radiation components also provide interesting insights. Spring upward shortwave radiation is a better predictor for September sea ice area than spring sea ice itself. This can be explained by the fact that a sea ice anomaly in spring only provides information in the region of the sea ice edge, whilst the sea ice edge in September is far more north. The upwelling solar radiation also provides information about the albedo where the sea ice edge will be in September. The albedo of sea ice slowly decreases in spring because of melting of snow and ice. A change in surface albedo in spring therefore provides information on the rate of melting at the region of the sea ice edge in September, as also suggested by Schröder et al. (2014) who show that spring meltpond fraction is a very good predictor for September sea ice. The downward shortwave component is, counter-intuitive, positively correlated with sea ice area. Hence, more radiation downward yields a positive sea ice area. This has previously been attributed to the generally positive cloud radiative forcing over the Arctic (Francis et al. 2005). Our analysis reveals however that this is primarily due to a decrease (increase) of multiple-reflection of shortwave radiation due a decreasing (increasing) surface albedo. Our results therefore suggest that under cloudy conditions, the direct effect of the sea ice albedo feedback, i.e. the enhanced absorbed solar radiation at the surface, is compensated up to $50 \%$ by reduced multiple-reflection of downwelling solar radiation. 
By analysing radiation anomalies at locations of sea ice anomalies, we found a delayed atmospheric response on spring sea ice anomalies. This delayed response is previously documented in an observational study by Kay and Gettelman (2009) over the 2006-2008 period. They related this lack of response in summer to a weaker ocean-atmosphere coupling due to a stronger atmospheric stability and weaker airsea temperature gradients. In early fall, the lower staticstability and stronger airsea temperature gradients result in stronger turbulent fluxes, which are further increased by the SST anomaly. The enhanced turbulent fluxes result in a higher cloud fraction, which in turn enhances downwelling longwave radiation and slows the icegrowth. Our analysis reveals that this mechanism is not only present in the 20062008 period, but that it is an integral part of the seasonal sea ice albedo feedback in the selected climate models and ERAInterim. Due to the delayed response the cloud radiative effect on the seasonal sea ice albedo effect results in a net warming.

\section{Acknowledgements}

We are grateful for useful advice and suggestions from Hylke de Vries, Richard Bintanja and Bert Holtslag. Furthermore, we thank three anonymous reviewers for their constructive comments which helped to improve the manuscript. This research is part of the Wageningen UR strategic R\&D programme 'TripleP@Sea'. We acknowledge the World Climate Research Programme's Working Group on Coupled Modelling, which is responsible for CMIP, and we thank the climate modeling groups (listed in Table 3.1) for producing and making available their model output. 



\section{Chapter 3}

Magnitude and pattern of Arctic warming governed by the seasonality of radiative forcing 


\begin{abstract}
Observed and projected climate warming is strongest in the Arctic regions, peaking in autumn/winter. Attempts to explain this feature have focused primarily on identifying the associated climate feedbacks, particularly the icealbedo and lapse-rate feedbacks. Here we use a state-of-theart global climate model in idealized seasonal forcing simulations to show that Arctic warming (especially in winter) and sea ice decline are particularly sensitive to radiative forcing in spring, during which the energy is effectively 'absorbed' by the ocean (through sea ice melt and ocean warming, amplified by the ice-albedo feedback) and consequently released to the lower atmosphere in autumn and winter, mainly along the sea ice periphery. In contrast, winter radiative forcing causes a more uniform response centered over the Arctic Ocean. This finding suggests that intermodel differences in simulated Arctic (winter) warming can to a considerable degree be attributed to model uncertainties in Arctic radiative fluxes, which peak in summer.
\end{abstract}




\subsection{Introduction}

The warming of the Arctic regions and the associated sea ice retreat are among the most prominent features of ongoing and projected climate change. A host of regional feedback mechanisms, mostly related to sea ice, contribute to Arctic warming being much stronger than the global response (e.g Lu and Cai, 2009; Pithan and Mauritsen, 2014; Winton 2006; Graversen and Wang, 2009; Bintanja and van der Linden, 2013; Hall, 2004; Bintanja et al., 2011 ; Held, 1979). Simulating Arctic warming using climate models (Hazeleger et al., 2010; Holland and Bitz, 2003) involves many uncertainties though, as indicated by the large intermodel differences. This may be attributed to uncertainties in the magnitude of climate feedbacks, to intermodel differences in the representation of important physics such as radiation (English et al., 2015), and to uncertainties in the radiative forcing. In any case, the interrelation between Arctic warming and sea ice decline clearly is a vital issue (Screen and Simmons, 2010), since this connection involves many of the relevant regional Arctic feedbacks as well as the shortwave and longwave radiation characteristics that govern the Arctic climate response.

Over the 21 st century, the CMIP5 RCP8.5 scenario (Collins et al., 2013) (see Methods) projects a model-mean annual mean Arctic warming of $8.5 \pm 4.1{ }^{\circ} \mathrm{C}$ (figure 3.1a) accompanied by a $49 \pm 18 \%$ retreat in sea ice cover, with summer sea ice having largely vanished in 2100 . Arctic warming exhibits a very pronounced seasonal cycle, however, with exceptionally strong warming in the winter months (up to $14.1 \pm 2.9$ ${ }^{\circ} \mathrm{C}$ in December) and only moderate warming during the summer season (figure $3.1 \mathrm{~b}$ ). Associated with this surface-based warming is a strong increase in precipitation (up to $60 \%$ ), which has been attributed mainly to reduced sea ice cover and the associated strong increase in evaporation from the open Arctic Ocean (Bintanja and Selten, 2014).
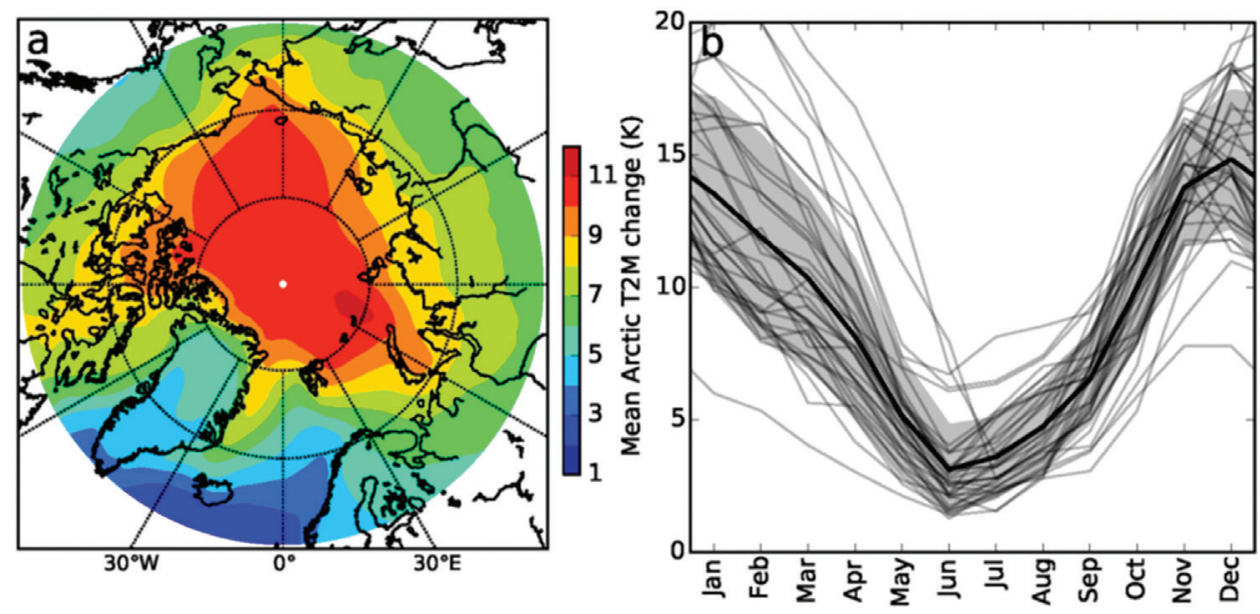

Figure 3.1: Projected 21 st century Arctic $\left(70^{\circ}-90^{\circ} \mathrm{N}\right)$ near-surface warming (T2m) using CMIP5 model ensemble. (a) Model-mean annual mean Arctic near-surface temperature change, (b) Annual cycle in Arctic near-surface warming, with the grey envelope representing the standard deviation of the intermodel mean. Dark-grey lines denote individual CMIP5 models. Results are for the strong (RCP8.5) forcing scenario trends in Arctic temperature are defined as the difference between the means over the periods 2091-2100 and 2006-2015 (37 models). 
The projected precipitation changes therefore also peak in winter, meaning that not only the magnitude but also the seasonal imprint of Arctic warming has important ramifications for various components of the Arctic (climate) system (ACIA, 2005). Evidently, the changing seasonal cycle in the Arctic climate will have profound effects on Arctic ecosystems, emerging economic activities (e.g. shipping, fishery, mining, tourism) and may even impact the climate in other parts of the world (Overland and Wang, 2010; Francis and Vavrus, 2012; Walsh, 2014), for instance through changes in sea level and global ocean currents (Bintanja and Selten, 2014; ACIA, 2005). It is therefore imperative to identify and quantify the climate mechanisms and feedbacks that cause the huge seasonal range in Arctic warming.

Until now, Arctic warming and its seasonal variation have been addressed primarily by studying various climate feedbacks (e.g. Pithan and Mauritsen, 2014; Bintanja et a., 2011; Walsh, 2014) related to, among others, surface albedo, atmospheric humidity and clouds, and poleward transport of dry static and latent heat. An important aspect of the seasonal response is the ice-albedo feedback, which operates mainly in the spring/summer seasons. However, this feedback contributes to winter warming 20 through interacting with storage (in summer) and release (in winter) of heat in the Arctic Ocean (Pithan and Mauritsen, 2014; Bintanja and van der Linden, 2013; Krikken and Hazeleger, 2015). Arctic winter warming is further amplified by feedbacks that operate in wintertime, such as the lapse-rate feedback (Bintanja et al., 2011 ). Another aspect that modulates the (seasonal) climate response in the Arctic is the direct radiative forcing by increasing concentrations of greenhouse gases, which does in fact exhibit a seasonal signature (Hansen et al., 1997).

\subsection{Results}

Here we use a state-of-the-art global climate model (EC-Earth, Hazeleger et al., 2010 , see Methods) in idealized climate ('ghost') forcing simulations to quantify the effect of seasonality in radiative forcing on the magnitude and pattern of seasonal Arctic warming. To infer the climate response throughout the year resulting from forcings in different seasons, an artificial longwave radiative forcing was applied to the surface for each season separately (see Methods). While the future climate response in near-surface temperature is maximum in winter (DJF, see figure $3.1 \mathrm{~b}$ ), the seasonal forcing simulations suggest that the forcing season causing the strongest annual temperature response is spring (table 3.1), and to a somewhat lesser degree summer. Interestingly, the spring and summer forcing combined contribute about $40 \%$ to the total wintertime temperature response. Even more surprising, summer forcing causes a much larger response in autumn and winter than in summer itself. In contrast, winter forcing is important for the wintertime response, but hardly for other seasons. The winter response is thus to a large degree governed by non-winter forcing, mainly through storage/release of ocean energy and associated feedbacks and possibly through changing atmospheric circulation. This clearly demonstrates that the near-surface Arctic temperature response to any climate forcing depends greatly on the season in which the forcing occurs, with the spring season being most effective. The only viable mechanism to invoke a surface air temperature response in 
seasons other than the forcing season relates to ocean storage and release of energy, which in turn is strongly modulated by sea ice (thickness) changes (Bintanja and van der Linden, 2013).

a) Near surface temperature $[K]$

\section{Response season}

\begin{tabular}{|l|r|r|r|r|r|}
\cline { 2 - 6 } \multicolumn{1}{c|}{} & \multicolumn{1}{c|}{ DJF } & \multicolumn{1}{c|}{ MAM } & \multicolumn{1}{c|}{ JJA } & \multicolumn{1}{c|}{ SON } & \multicolumn{1}{c|}{ ANN } \\
\hline DJF & $10.7 \pm 0.7$ & $3.2 \pm 0.5$ & $1.1 \pm 0.1$ & $6.1 \pm 0.6$ & $5.3 \pm 0.3$ \\
\hline MAM & $8.8 \pm 0.7$ & $9.1 \pm 0.3$ & $3.1 \pm 0.1$ & $10.3 \pm 0.4$ & $7.8 \pm 0.3$ \\
\hline JA & $7.3 \pm 0.6$ & $3.7 \pm 0.4$ & $2.9 \pm 0.1$ & $9.8 \pm 0.4$ & $5.9 \pm 0.2$ \\
\hline SON & $6.2 \pm 0.7$ & $3.1 \pm 0.5$ & $1.0 \pm 0.1$ & $9.0 \pm 0.5$ & $4.8 \pm 0.4$ \\
\hline
\end{tabular}

b) Sea ice area $\left[10^{6} \mathrm{~km}^{2}\right]$

\begin{tabular}{|c|c|c|c|c|c|}
\hline & DJF & MAM & JJA & SON & ANN \\
\hline DJF & $-2.6 \pm 0.2$ & $-2.0 \pm 0.2$ & $-3.7 \pm 0.3$ & $-4.3 \pm 0.3$ & $-3.1 \pm 0.2$ \\
\hline MAM & $-4.2 \pm 0.2$ & $-3.8 \pm 0.2$ & $-6.9 \pm 0.1$ & $-7.3 \pm 0.1$ & $-5.5 \pm 0.1$ \\
\hline JJA & $-3.2 \pm 0.1$ & $-2.0 \pm 0.1$ & $-5.2 \pm 0.1$ & $-6.9 \pm 0.1$ & $-4.3 \pm 0.1$ \\
\hline SON & $-2.9 \pm 0.2$ & $-1.8 \pm 0.2$ & $-3.0 \pm 0.3$ & $-4.9 \pm 0.4$ & $-3.2 \pm 0.3$ \\
\hline
\end{tabular}

c) Net downward total surface heat flux $\left[\mathrm{W} \mathrm{m}^{-2}\right]$

\begin{tabular}{|l|c|c|c|c|c|}
\cline { 2 - 6 } \multicolumn{1}{c|}{} & DJF & MAM & \multicolumn{1}{c|}{ JJA } & \multicolumn{1}{c|}{ SON } & \multicolumn{1}{c|}{ ANN } \\
\hline DJF & $-3.3 \pm 2.9$ & $-2.7 \pm 1.8$ & $16.2 \pm 1.5$ & $-16.9 \pm 1.7$ & $-1.6 \pm 0.9$ \\
\hline MAM & $-29.3 \pm 2.6$ & $25.1 \pm 1.5$ & $29.9 \pm 0.9$ & $-32.7 \pm 1.5$ & $-1.8 \pm 0.9$ \\
\hline JJA & $-22.5 \pm 2.4$ & $-1.1 \pm 1.5$ & $44.7 \pm 1.0$ & $-28.7 \pm 1.4$ & $-1.9 \pm 0.7$ \\
\hline SON & $-18.5 \pm 2.9$ & $-2.3 \pm 2.0$ & $14.1 \pm 1.9$ & $1.4 \pm 1.8$ & $-1.3 \pm 1.0$ \\
\hline
\end{tabular}

Table 3.1: Simulated seasonal and annual response resulting from a surface radiative forcing in various seasons (see Methods). Surface air temperature (in K, upper panel), Sea ice area (in $106 \mathrm{~km} 2$ , middle panel), Net downward total surface heat flux (in W $m-2$, bottom panel), which is the total of the net shortwave and longwave radiative fluxes and the sensible and latent heat fluxes. Note that the $30 \mathrm{~W} \mathrm{~m}-2$ additional downward forcing (see Methods) is included in the response value for the forcing season (as an example, the 44.7 W $m-2$ JJA response for JJA forcing includes the $30 \mathrm{~W} m-2$ forcing). ANN represents the annual mean response. The uncertainties represent the $95 \%$ confidence interval of the mean, where seasonal (annual) means are used to evaluate the seasonal (annual) response uncertainties. Colouring indicates the magnitude and sign of the responses.

The concurrent response in Arctic sea ice cover clearly peaks for spring and summer forcing (table 3.1). Spring forcing causes maximum sea ice decline in all other seasons, including the winter (even more than for winter forcing itself). This is due to the ice-albedo feedback amplifying the sea ice retreat over the summer months (Kapsch et al., 2013): the extra energy in spring thins the sea ice and/or creates melt ponds, lowering the surface albedo and allowing spring and summer insolation to more effectively warm the surface (figure 3.2a) and melt away sea ice (Perovich et al., 2007). Infact, reflected solar radiation in the Arctic peaks in spring, when both sea ice cover and insolation are relatively high, meaning that any change in spring sea ice has a profound effect on absorbed solar radiation. The ice-albedo feedback thus 
strongly amplifies the response only if the forcing occurs in the season in which the seasonal ice-albedo feedback is mainly active (spring/summer) and the additional energy is used to melt ice. This leads to enhanced absorption of shortwave radiation of the surface (figure 3.2a), increased sea surface temperatures, earlier onset of melt and an associated decline in sea ice cover. This amplified response for spring forcing is effectively carried over to subsequent seasons by storage of heat in the open Arctic Ocean, likely amplified by water vapour and cloud feedbacks (Kapsch et al., 2016), leading to delayed freeze-up and thinner sea ice. The autumn sea ice response is indeed most pronounced for spring radiative forcing, which corresponds very well with observations-based correlations between enhanced incoming longwave radiation in spring and reduced autumn sea ice extent (Kapsch et al., 2013).

Since sea ice effectively regulates the ocean-atmosphere energy exchange by acting as a lid, the total air-sea flux changes also exhibit a pronounced seasonal cycle (table 3.1 and figure 3.2b). In summer, nearly all additional longwave forcing is used to either melt sea ice or warm the upper Arctic ocean; this energy thus hardly contributes to warming of the lower atmosphere in this season, but it is instead stored and subsequently released in autumn/winter (figure 3.2b). A considerable part of the upward energy flux used to warm the lower atmosphere during autumn/winter originates from spring/summer forcing (table 3.1). In contrast, a large portion of the additional energy is immediately returned to warm the lower atmosphere (and is partly lost to space) in case of autumn and winter surface forcing. Additionally, the limited
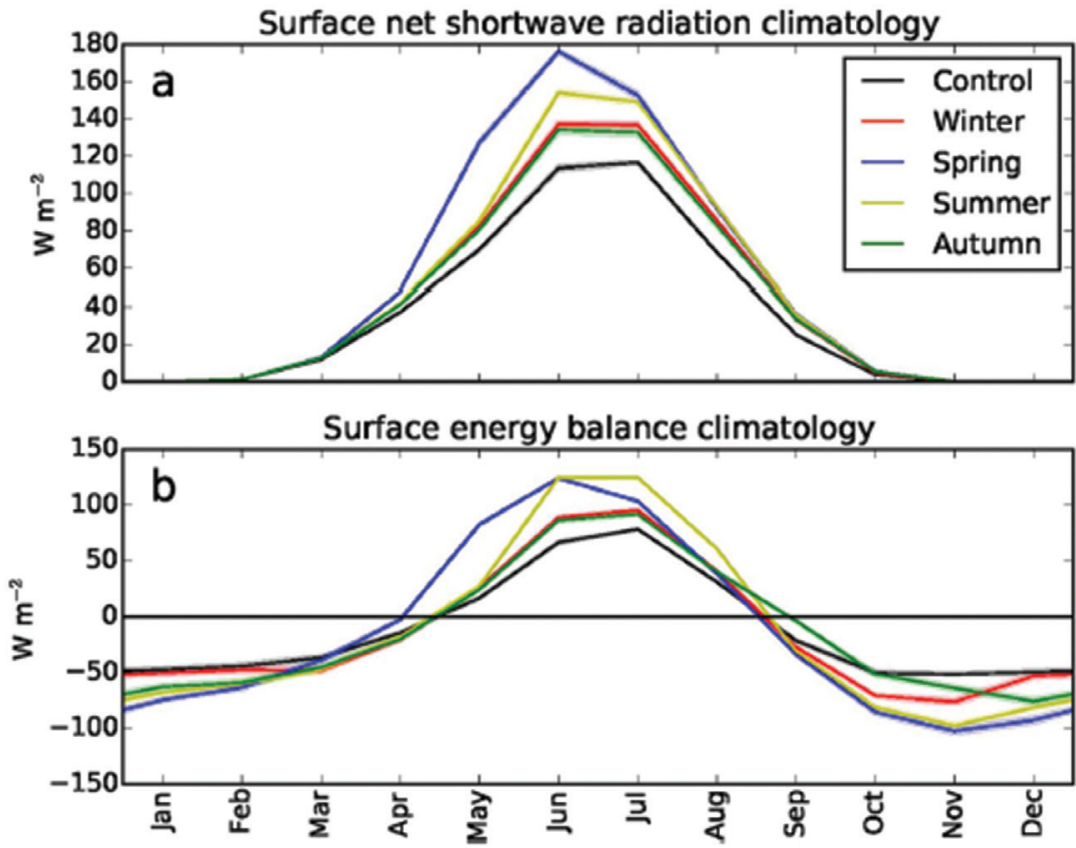

Figure 3.2: Simulated monthly Arctic mean surface energy budget components for each of the simulations (see Methods). (a) Net shortwave radiation, (b) Net surface flux (i.e. radiative fluxes plus turbulent fluxes). Downward fluxes are defined positive. The legend shows the forcing season. The uncertainty band represents the $95 \%$ confidence interval of the mean. 
impact of winter forcing on the response in other seasons can be attributed to the negative feedback between ice growth and ice thickness, meaning that ice thickness anomalies following a winter forcing will effectively decay in subsequent seasons. An extra downward forcing is thus most effective when the climatological net surface forcing is already downward (in late spring and summer, see figure $3.3 \mathrm{~b}$ ), so that the additional energy is predominantly used to warm the ocean and melt sea ice. In the winter months, the energy from the relatively mild and ice-depleted ocean surface is more easily radiated upward and thereby warms the overlying atmosphere (figure 3.2b). The stable stratification of the wintertime Arctic boundary layer reinforces warming of the near-surface atmosphere.

The seasonally varying response as shown in table 3.1 is purely the result of internal climate mechanisms since the magnitude of the applied radiative forcing was similar in all seasons. However, anthropogenic greenhouse forcing in the Arctic exhibits a pronounced seasonal cycle, peaking in late spring and summer (Hansen et al., 1997), which can be attributed mainly to the vertical distributions of temperature, water vapour and clouds, as well as to the temperature dependence of the emission/ absorption characteristics of greenhouse gases. Intrusions of relatively warm and humid air from lower latitudes also lead to positive anomalies in moisture content and cloud amount, which especially in spring cause a considerable longwave forcing at the surface that contributes to enhanced sea ice melt later in the year (Kapsch et al., 2013). Moreover, internal climate feedbacks, for instance those related to sea ice retreat and the associated enhanced surface evaporation and cloud formation, may lead to climate forcings that exhibit strong seasonal variations. In any case, the climate radiative forcing tends to peak in the seasons during which the Arctic system is most sensitive to additional forcing. With spring sensitivity being about $50 \%$ higher than in winter (table 3.1), the impact of enhanced spring/summer forcing on the annual temperature response reinforces the response from internal climate mechanisms alone, increasing the seasonality of the temperature response (maximum
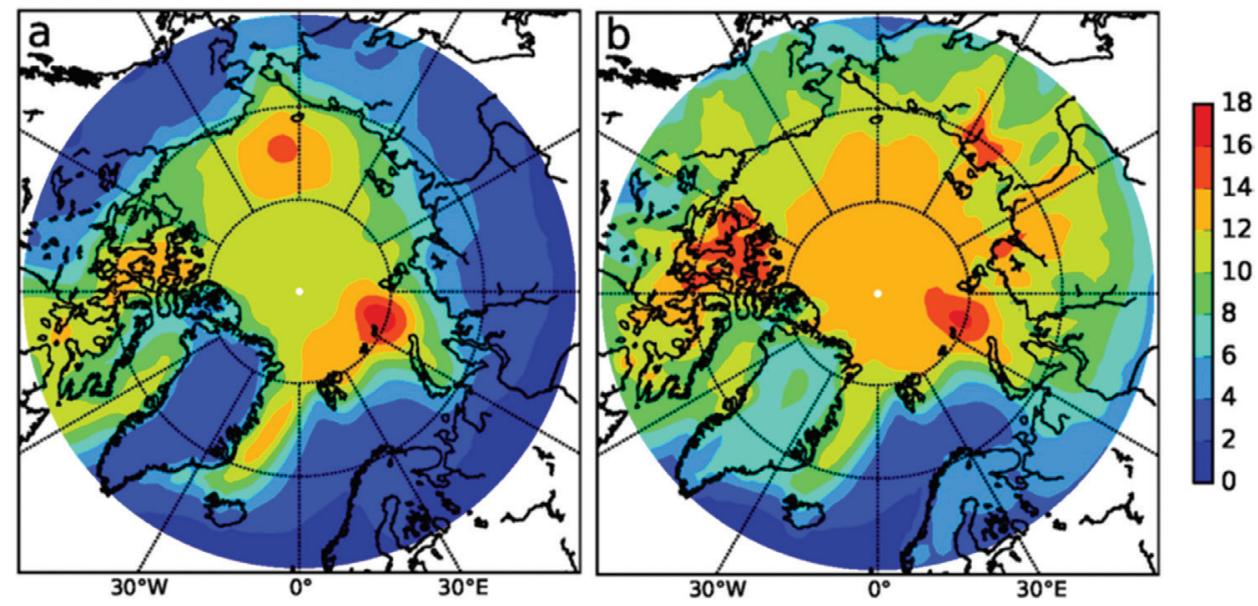

Figure 3.3: Simulated winter (DJF) temperature response as a function of seasonal radiative forcing (see Methods). (a) Response for spring (MAM) forcing, (b) Response for winter (DJF) forcing. 
in winter) as well as the magnitude of the annual response. The seasonality of Arctic surface radiative forcing thus exerts a comparatively strong impact on annual mean Arctic warming (compared to the hypothetical situation in which the forcing were seasonally invariant).

Over the Arctic Ocean, the 'transfer' of energy from one season to the other through storage and release of energy (Fig. 3.3b) is obviously most effective in the sea ice retreat regions, since these are the locations where a strong increase in upward energy flux can occur, heating the lower atmosphere in autumn/winter. Therefore, the effect of spring forcing on the surface temperature response in winter peaks in the sea ice retreat regions (the periphery of the Arctic region), especially in the Barents Sea (figure 3.3a). Remarkably, in these regions the winter temperature response due to spring forcing is even larger than that due to winter forcing itself. In contrast, winter forcing causes a somewhat more uniform response (figure 3.3b) centered over the Arctic. Being effectively decoupled from the Arctic Ocean by sea ice, the direct winter forcing is mainly used to warm the (low thermal inertia) stably stratified lower atmosphere. Also, winter forcing yields a much larger surface air temperature response over the subarctic continents compared to spring forcing. Spring/summer forcing evidently exhibits a different geographical imprint compared to winter forcing in terms of the wintertime temperature response (and thereby the annual response, since this is governed by winter warming). 


\subsection{Discussion}

Because Arctic radiative forcing peaks in spring/summer, it contributes strongly to Arctic winter and annual warming, especially in the peripheral sea ice regions where, according to our climate model simulations, spring forcing even dominates winter warming through seasonal storage and release of energy in the Arctic Ocean. To understand Arctic warming and its huge seasonal cycle, as well as related processes (such as sea ice decline and precipitation increases [Bintanja and Selten, 2014]) it is therefore imperative to study not only the governing feedbacks but also assess the impact of seasonally-varying radiative forcing. This also implies that an accurate representation of changes in the seasonality of radiative forcing (which are dominated by clouds [English et al., 2015], see Methods) is crucial to correctly project both the magnitude and the pattern of future Arctic warming. Uncertainties in Arctic radiative fluxes (which peak in summer [English et al., 2015]) mainly affect Arctic winter and annual warming (Holland et al., 2003), meaning that not only uncertain Arctic feedbacks but also the (spring and summer) radiative forcing contribute to the intermodel spread in Arctic climate change (Collins et al., 2013).

Current changes in the Arctic climate peak in Autumn (in particular November). With ongoing Arctic warming and further reductions in sea ice, the changes will probably become more winter centered, with peak warming shifting towards the winter (figure $3.1 \mathrm{~b}$ ), similar to the response simulated here (which represent an 'artificial' future warming relative to the present-day state).

Ongoing sea ice decline is expected to spark human activities in the Arctic (e.g., shipping, fishery, mining, tourism), which will lead to increased emissions of radiatively-active constituents (ACIA, 2005; Corbett et al., 2010), such as soot (Sand et al., 2013), especially in summer (also soot originating from summertime subArctic fires will enter the Arctic). By lowering the sea ice albedo, the additional soot may induce a net radiative surface forcing during summer. The seasonal timing of anthropogenic radiative forcing (in whatever form) is most powerful when it occurs in seasons when the surface is climatologically gaining energy (spring and summer), so future anthropogenic emissions peaking in summer may reinforce Arctic (winter) warming and sea ice retreat.

\subsection{Methods}

We used the global climate model EC-Earth V2.3 9 (one of the CMIP5 models) to assess the mechanisms relating seasonally-varying radiative forcing to Arctic warming and sea ice retreat. ECEarth V2.3 includes the following components: atmosphere, ECMWF's Integrated Forecast System (IFS cycle 31 r1), resolution T159L62, including HTESSEL as land surface module; ocean, NEMO V2, resolution 1 deg.; sea ice, LIM2, resolution $1 \mathrm{deg}$; all coupled through the OASIS3 coupler 9 . The performance of EC-Earth in terms of its simulation of the present-day climate is satisfactory, even though parts of the (sub) Arctic have too high winter temperatures, especially the continental regions of Siberia and Canada, while the central Arctic is somewhat too 
cold. We carried out 44-year simulations for perpetual year 2006 climate forcing (the model is in equilibrium for year 2006 radiative forcing), in which we added an artificial (or 'ghost') additional downward longwave radiative forcing of $30 \mathrm{~W} \mathrm{~m}^{-2}$ to the surface of the entire Arctic region north of $70{ }^{\circ} \mathrm{N}$ (we chose a relatively strong radiative forcing to obtain a climate response larger than the interannual variability yet small enough to avoid possible nonlinear effects becoming dominant; we additionally carried out simulations with smaller/larger forcing, and concluded that the first-order average Arctic response roughly linearly depends on the magnitude of the forcing); the forcing was applied in each season separately over the entire length of the simulation (hence each year). Thus, in total we performed 5 simulations: 4 simulations with additional forcing in winter (December-January-February, DJF), spring (March-April-May, MAM), summer (June-July-August, JJA) and autumn (SeptemberOctober-November, SON), respectively, and a control simulation without additional forcing. Note that the seasonal forcing of $30 \mathrm{~W} \mathrm{~m}^{-2}$ translates to an annual forcing of $7.5 \mathrm{~W} \mathrm{~m}^{-2}$, comparable to the RCP8.5 radiative forcing (but applied here only to the Arctic). The seasonal longwave forcing of $30 \mathrm{~W} \mathrm{~m}^{-2}$ corresponds to 15,10 , 13 and $17 \%$ of the modelled climatological (of the control run) downward longwave radiation in DJF, MAM, JJA and SON, respectively. The results in table 3.1 and figures 3.2 and 3.3 represent the differences between the additional forcing simulations and the control simulation over the final 30 years of the simulations (over which the residual trend is small). In this way the contributions of the feedbacks (for seasonally constant forcing) and of the (seasonally varying) radiative forcing on the seasonal climate response can effectively be separated. Obviously, the applied ghost forcing is a simplified representation of real radiative forcings, but previous studies (Hanset et al., 1997; Alexeev et al., 2005) have shown that this method nonetheless provides important insights into the primary response of the climate system. Note that the 30 year average climate state representing the year 2006 forcing (the control simulation) is used as a climatology to compare our sensitivity simulations to. A possible caveat in our simulations is the absence of a transition zone in which the $30 \mathrm{Wm}^{-2}$ forcing gradually reduces to zero, both spatial (at $70^{\circ} \mathrm{N}$ ) and temporal (at the beginning and ending of seasons), rather than instantaneous. Even though such a 'soft' transition (instead of the 'hard' one used here) probably affects the details of the response (e.g. atmospheric dynamics), it is unlikely to have a considerable effect on the overall (i.e. Arctic mean) temperature response. Hence, we do not expect the first-order results to be sensitive to minor changes at the edges. Our 'hard transition' forcing has the advantage that results are easy to interpret, moreover this simple forcing is also easy to apply (in other studies), and therefore facilitates intercomparison of results.

One of the most uncertain issues in terms of a longwave radiation response concerns the role of clouds. Among CMIP5 models, Arctic cloud cover varies significantly. Also, most CMIP5 models exhibit biases in especially Arctic cloud phase, with excessive cloud ice and insufficient cloud water content (English et al., 2011 ; Pithan et al., 2016). This leads to an overestimate of surface cooling in winter and spring, too strong surface inversions and biases in TOA radiative fluxes. EC-Earth V2.3 has a single prognostic variable for cloud condensate mass with a temperature-driven partitioning between cloud liquid and solid mass, and also generally underestimates cloud liquid mass in the Arctic. This deficiency may affect the climate response resulting from enhanced radiative forcing. 



\section{Chapter 4}

Uncertainty in Arctic climate projections linked to downwelling longwave radiation 


\begin{abstract}
The Arctic region has warmed rapidly over the last decades, and this warming is projected to continue. However, the uncertainty in these projections is very large, owing to considerable differences between climate models. A clear understanding of the sources behind this large uncertainty is currently lacking. Here we use state-of-the-art global climate models to show that springtime variability in downwelling longwave radiation (DLR) in the pre-industrial climate explains about two-thirds of the intermodel spread in projected Arctic warming under a high greenhouse gas emission scenario. This variability, which peaks on the land masses adjacent to the Arctic ocean, is related to the combined effects of the cloud radiative forcing and the albedo response to snowfall, which vary strongly among models in these regions. These processes govern interannual variability of DLR in the pre-industrial climate, but also largely modulate the climate response of DLR, sea ice cover and near-surface temperature. This finding elucidates the crucial interaction between clouds and surface radiation within the Arctic climate system. As such it provides important insights to reduce the uncertainty in future Arctic climate projections that are required to constrain regional mitigation and adaptation strategies to Arctic climate change.
\end{abstract}




\subsection{Introduction}

The rapidly evolving Arctic climate has become one of the most prominent features of climate change. Recently, Arctic sea ice has receded substantially, and this trend is projected to continue (Stroeve et al., 2012; Overland and Wang, 2013) and possibly accelerate. The rising Arctic temperature and associated sea ice retreat have extensive impacts, for instance on the unique Arctic ecosystem (Grebmeier et al., 2013; HoeghGuldberg and Bruno, 2010), on enhanced methane venting of the East Siberian Arctic Shelf (Shakhova et al., 2010) and possibly on mid-latitude weather patterns (Overland et al., 2015). On the other hand, economic activities in the Arctic may benefit from sea ice retreat, with the opening of the fabled northerly passages being the most prominent example (Rojas-Romagosa et al., 2015). Hence, from scientific, ecological and economic viewpoints there is a strong need for accurate projections of the Arctic climate response over the $21^{\text {st }}$ century. However, climate models in the Coupled Model Intercomparison Project phase 5 (CMIP5, Taylor et al., 2011) exhibit considerable intermodel differences in projected Arctic warming and sea ice decline. For instance, the projected first occurrence of an ice-free Arctic summer spans almost the entire $21^{\text {st }}$ century (Overland and Wang, 2013).

The intermodel spread in near-term climate trends in September Arctic sea ice is governed by the current sea ice state (Massonet et al., 2012), but on the longer-term the mean sea ice state is less relevant (Van der Linden et al., 2014) and regional climate feedbacks become more important Boé et al., 2010). The two climate feedbacks that largely govern Arctic warming, and thus the intermodel spread, are the lapse-rate feedback and the surface albedo feedback (Pithan and Mauritsen, 2014). It is, however, difficult to evaluate these climate feedbacks due to the relative short record of observations. An alternative way to assess intermodel differences is to identify governing physical processes and related climate feedbacks in the current climate and relate these to long-term climate projections in a suit of climate model simulations (e.g. CMIP5). An example of this approach concerns the link between seasonal and long-term changes in the albedo feedback strength over northern hemispheric land masses (Hall and Qu, 2006; Qu and Hall, 2014). The lapserate feedback is more difficult to evaluate, as it involves various atmospheric processes that affect the atmospheric lapse-rate differently (Pithan and Mauritsen, 2014). Most of these processes, however, impact downwelling longwave radiation (DLR), making this one of the most important variables in Arctic climate change.

DLR is an important driver of intermodel variability of Arctic sea ice (Kapsch et al., 2013) and Arctic climate change (Graversen and Burtu, 2016; Burt et al., 2015). Unfortunately, climate models have difficulty in adequately representing DLR climatology, which is therefore a source of large biases in current climate models (Pithan et al., 2013). These biases arise primarily from uncertainties in representing mixed-phase clouds and low-level stability (Pithan et al., 2017). Furthermore, the Arctic climate response is very sensitive to the seasonality of radiative forcing, in particular to radiative perturbations in spring (Bintanja and Krikken, 2016). Hence, the way models reproduce DLR seasonality, variability and trend are expected to have a large impact on their Arctic climate response. Arctic warming and DLR are 
intrinsically linked through the ice-insulation feedback (Burt et al., 2016). Increasing air temperature, water vapor and cloudiness all cause an increase in DLR, which leads to reduced sea ice and even higher temperatures, amplifying the original temperature increase. This positive feedback mechanism thus implies a strong link between projected increases in DLR, Arctic surface warming and sea ice retreat, rendering it difficult to infer a causal relation and to determine a specific variable or process as the main driver of the uncertainty in the projected DLR.

\subsection{Results}

Here we use 31 state-of-the-art CMIP5 climate models (Supplementary Table 4.1) in standardized $21^{\text {st }}$-century simulations (RCP8.5 emission scenario) and pre-industrial control simulations (piControl, 200 years per model) to infer the role of DLR in the models' control climate and variability, and in Arctic climate projections. Since we focus on the role of DLR, we first assess the relation between Arctic average $\left(>65^{\circ} \mathrm{N}\right)$ DLR in the control simulations and the projected increase DLR under RCP8.5 forcing. We find that the mean state of pre-industrial DLR has no predictive value for the DLR climate response (not shown), but that the pre-industrial interannual variability (standard deviation, std) of DLR has (Fig. 4.1). Specifically, May DLR std is a very good predictor for the annual climate response in DLR $(r=0.84)$, near surface temperature (TAS, $r=0.82$ ) and sea ice area (SIA, $r=0.77$ ), as it explains a considerable part of the intermodel spread.
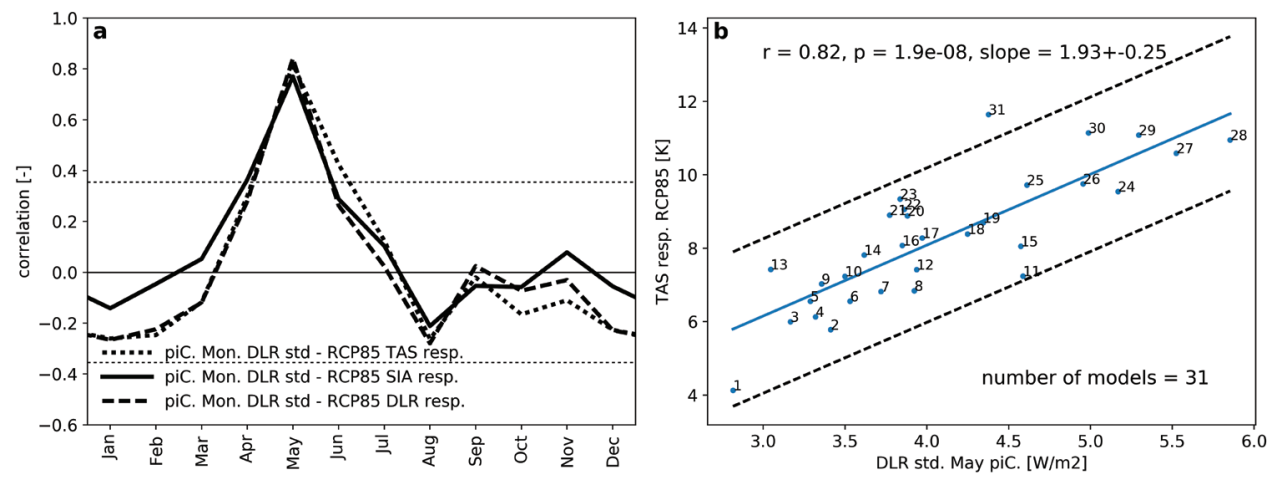

Figure 4.1: Intermodel correlation of Arctic average pre-industrial $\left(65^{\circ} \mathrm{N}-90^{\circ} \mathrm{N}\right) \mathrm{DLR}$ and RCP8.5 climate projections. (a) Intermodel correlation of monthly DLR standard deviation (piControl) with projected $D L R$, near surface temperature (TAS) and sea ice area (SIA) responses [annual average, 2090-2100 minus 2006-2016]. The dotted lines indicate the significance level for $p=0.05$. (b) Intermodel correlation of May DLR standard deviation and TAS response. The dotted lines indicate the $2 x$ standard deviation, while the numbers indicate individual models listed in Supplementary Table 4.1. 

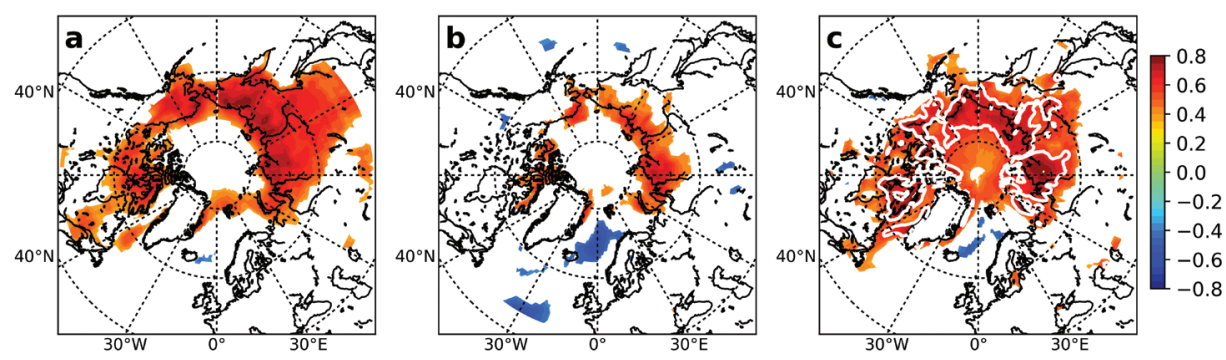

Figure 4.2: Intermodel correlation of pre-industrial climate variability and RCP8.5 Arctic warming projections. The predictand for $a, b$ and $c$ is Arctic warming [annual average, 2090-2100 minus 2006 $\left.2016,65^{\circ} \mathrm{N}-90^{\circ} \mathrm{N}\right]$ and as predictor pre-industrial gridpoint-wise (a) May DLR std., (b) correlation of May clear-sky and cloud-sky DLR and (c) correlation of May cloud-sky DLR and surface net radiation. Only significant values $(p<0.05)$ are plotted.

To infer why models with relatively large variability of May DLR in the pre-industrial climate exhibit a relatively strong Arctic climate response, we need to establish the source of the DLR variability in the various climate models. The main region where the intermodel relation between both is strong is, surprisingly, over the land masses surrounding the Arctic ocean (Fig. 4.2a). DLR can be decomposed in the clear-sky $\left(D_{C S}\right)$ and cloud-sky part $\left(D_{C L}\right)$, where the former is mainly governed by the lower atmospheric temperature and the latter by clouds. To further diagnose the source of $D L R$ variability we separately diagnose the variability of $D L R_{C S}$ and of $D L R_{C L}$, as well as their mutual correlation since the total variability of DLR can be damped or enhanced, depending on whether $D_{L S}$ and $D_{C S}$ covary. We find no significant correlation when we use the variability of either $D_{L R}$ or $D_{C L}$ as predictor for Arctic warming, but we do find significant correlation when we use their mutual correlation as predictor for Arctic warming (Fig. 4.2b). Note that the intermodel spread in correlation between $D_{L S}$ and $D L R_{C L}$ ranges from strongly negative to strongly positive over Siberia. This implies that the total variability of DLR depends mostly on whether anomalies in cloud cover covary with anomalies in lower atmospheric temperatures, and that this relation widely differs among the various climate models.

A possible explanation for the large intermodel spread is the effect of clouds on the surface net radiation (Q). Clouds can warm the surface through emitting longwave radiation (greenhouse effect), but can also cool the surface by reducing the amount of solar radiation that reaches the surface (shading effect) (Fig. 4.3a). The net effect of both mechanisms is the surface cloud radiative forcing (CRF), where positive values indicate that the greenhouse effect is stronger than the shading effect, resulting in a net increase of surface radiation and a warming at the surface. The sign and strength of the CRF impacts the correlation of $D L R_{C L}$ and $D L R_{C S}$ as follows: a positive anomaly of $D_{C L}$ (more clouds) results in an increase of $Q$ when the CRF is positive. This results in a higher surface temperature and thus in an increase of $D L R_{C S}$, which implies that $D_{L R}$ and $D L R_{C S}$ covary when the CRF is positive. The opposite holds for a negative CRF. However, though we find a significant correlation between the mean CRF and Arctic warming (Supplementary Fig. 4.1), it is still relatively weak $(\sim 0.5-0.6)$ and thus only partially explains the intermodel spread in the variability of DLR. Another important effect of clouds on $Q$ is not captured in the CRF. Snowfall 
variability, associated with cloud variability, will affect the surface albedo, thus altering reflected shortwave radiation (Fig. 4.3a). This effect can be elucidated by through the relation between $\mathrm{DLR}_{\mathrm{CL}}$ and $\mathrm{Q}$. The correlation between $\mathrm{DLR}_{\mathrm{CL}}$ and $\mathrm{Q}$ in the various climate models ranges from strongly negative (clouds cool) to strongly positive (clouds warm) over Siberia (not shown), and, more importantly, this relation is a good predictor for Arctic warming (Fig. 4.2c). This also explains why spring is so important (Fig. 4.1), as for these mechanisms to be active, snowfall has to be able to change the surface albedo and sufficient downwelling shortwave radiation is required, which typically happens in spring.

Note that the analysis is based on monthly averaged data, even though the proposed mechanism acts on much shorter time scales (days). Hence, we can identify the results of both mechanisms, but not the mechanisms themselves. As a result, we can find that more clouds can lead to less snowfall (secondary mechanisms) because the extra snowfall is melted due to a positive CRF or because the extra clouds mostly give rain.

Changes in clouds can thus increase or decrease Q, depending on the strength of the anomalies in CRF (primary effect) and in surface albedo response to snowfall (secondary effect). This leads to enhanced or decreased variability of DLR in the control climate, but, more importantly, to a strong link to the projected Arctic warming (Fig. 4.3b). If we combine both mechanisms as a predictor for Arctic warming, we find a correlation of 0.9 (Fig. 4.4), further reinforcing the significance of these mechanisms in the Arctic climate response.
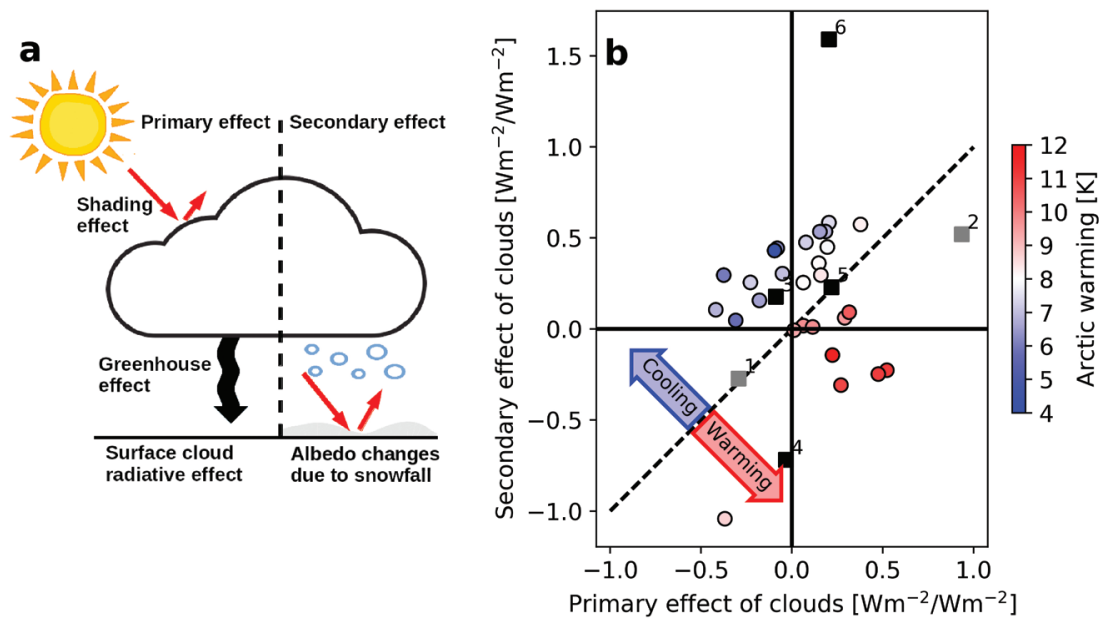

Figure 4.3: Overview of the primary and secondary effects of clouds. (a) A schematic of the cloud radiative forcing and the albedo response due to snowfall. (b) A process diagram with the primary and secondary effect of clouds measured trough respectively the regression coefficient of $D L R_{C L}$ and $C R F$ ( $x$-axis), and the regression coefficient of $D L R_{C L}$ and clear-sky upwelling solar radiation $\left(S_{C S} \uparrow\right)(y$-axis), based on May pre-industrial simulations at grid points where the correlation in Fig. $4.2 c$ is more than 0.5 . Positive values for the primary effect indicate the greenhouse effect is stronger than the shading effect of clouds thus more energy at the surface (warming). Positive values for the secondary effects indicate more $S_{C S}^{\uparrow}$ thus less energy at the surface (cooling). The colors of the dots indicate the annual average Arctic warming. The round markers indicate the CMIP5 climate models, the squares markers and associated numbers indicate reanalysis (black) or satellite (gray) derived products [listed in Supplementary Table 4.2]. 
Having established the mechanisms behind DLR variability in the pre-industrial climate, the next question is why models differ in their representation of these mechanisms, and why these mechanisms govern Arctic warming. The radiative effect of clouds over land is firmly linked to the surface albedo, which depends on the amount of snow cover, but also on the albedo of fully snowcovered land. The latter varies considerably among climate models (ranging from 0.3 to 0.8 ), owing mainly to differences in treatment of vegetation masking effects (Qu and Hall, 2007; 2014). A relatively large contrast in albedo between snow-covered and snow-free surfaces yields a stronger surface albedo feedback, because the net solar radiation increase will be larger if the albedo contrast is more pronounced. The surface albedo of snowcovered surfaces is therefore also a good predictor of Arctic warming (Hall and Qu, 2006; Qu and Hall, 2014. Note that both the albedo of the continents and sea ice surface are good predictors for Arctic warming (Supplementary Fig. 4.2). Indeed, the primary effect of clouds strongly relates to the average surface albedo $(r=0.79$, Supplementary Fig. 4.3). The cooling effect due to enhanced snowfall (secondary effect) is more difficult to physically relate to the model spread. Part of this effect relates to variability of surface albedo, as models that exhibit a positive relation between $D L R_{C L}$ and $S \downarrow_{C S}$ tend to be fully snowcovered in the regions where we find the highest correlation (Fig 4.2c). Hence, in those cases more snowfall will not lead to an increase in surface albedo compared to models with partial snow cover in the same region.

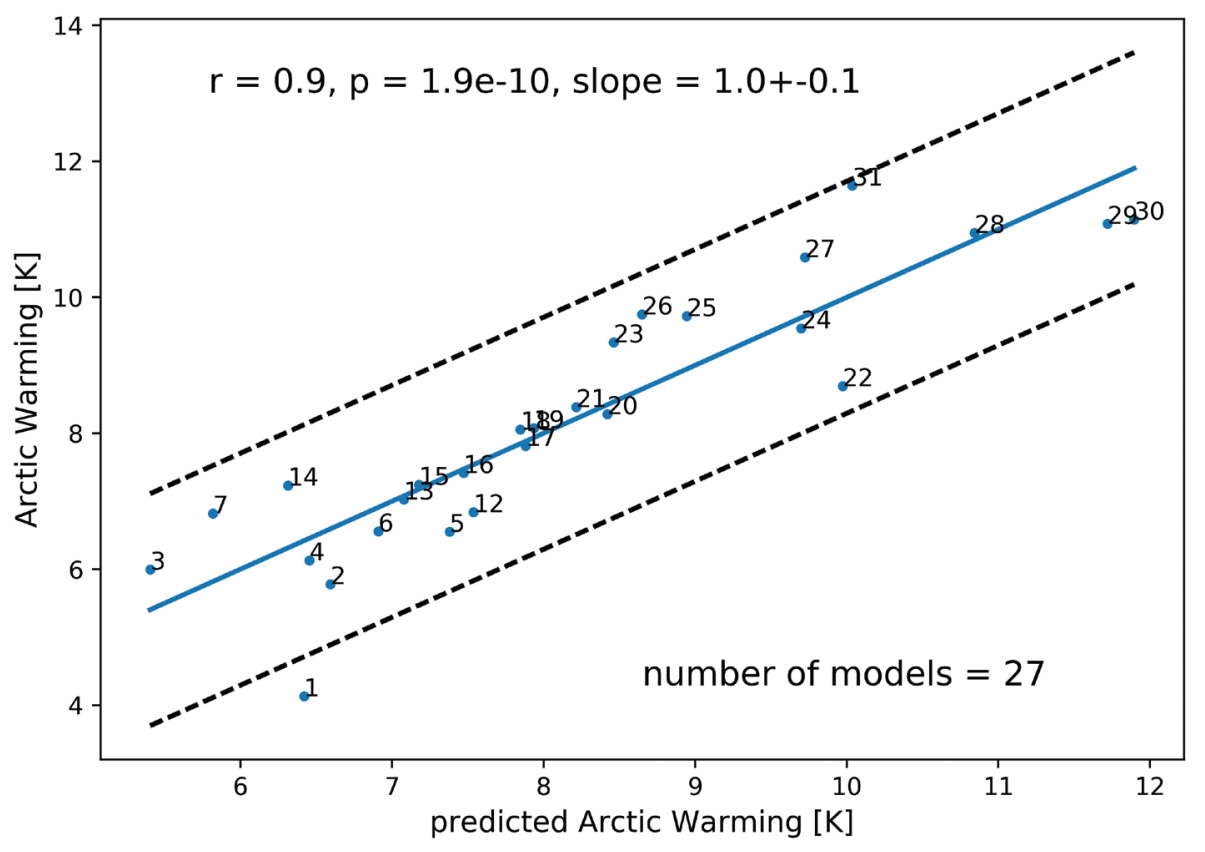

Figure 4.4: Arctic warming predicted by the primary and secondary effect of clouds. The predicted Arctic warming (AW) is based on multiple linear regression using the values of the primary (PE) and secondary effect (PE) of clouds from Fig. $4.3 \mathrm{~b}$ as predictors using the equation: $A W=\beta 0+\beta 1 \cdot P E+\beta 2 \cdot S E$. 
A correct representation of these mechanisms thus appears to be crucial for accurate projections of Arctic climate change. Hence, it is imperative to compare the climate models to relevant observations. For that reason we computed the strength of the primary and secondary effect of clouds in 4 reanalysis and 2 satellite derived products (Supplementary Table 4.2). Interestingly, the spread amongst the various reanalysis products with respect to the relevant processes is even larger than intermodel differences (Fig. 4.3b). This is partly explained by the relative short time period of the different reanalysis products, yielding large statistical uncertainties (Supplementary Table 4.2). However, it also reflects the inherent differences in cloud and surface parameterizations between the different products. Reanalsyis products are a mix of observations and model forecasts. In observation-sparse regions such as the Arctic the products are heavily influenced by the model forecast and thus its associated bias. This is especially true for variables such as surface radiative fluxes, which are not assimilated in the reanalysis and therefore heavily influenced by the cloud parameterizations (Lindsay et al., 2014). A comparison of the reanalysis and satellite products to local observations (Supplementary Table 4.3) reveals that it is difficult to point to a single products as being better. Hence, it is hard to draw firm conclusions as to what climate models, if any, best represent the relevant mechanisms.

The importance of cloud-surface interactions in the Arctic climate has long been recognized (e.g. Curry et al., 1993; Pithan et al., 2013; Kay et al., 2016). However, we find that the influence of clouds on surface radiation in current climate models is crucial because this explains to a considerable extent the large uncertainty in the Arctic climate response. This highlights the importance of more (and long-term) observational campaigns of clouds and radiation in the Arctic region. These will ultimately lead to more accurate climate projections that are crucial to implement mitigation and adaptation measures in the Arctic region.

\subsection{Methods}

For the multi-model analysis we use the CMIP5 dataset3. From this dataset we select the strong forcing scenario (RCP85) to study the Arctic climate response and the pre-industrial control runs (piControl) to study the control climate. Annual average climate responses are computed by subtracting the average of 2090-2100 from the average of 2006-2015. Note that taking 20 or 30 year averages from the beginning and end of the $21^{\text {st }}$ century hardly effect the results. piControl climatologies and climate variability are based on 200 years of monthly mean data per model. Arctic averages are computed using $65^{\circ} \mathrm{N}-90^{\circ} \mathrm{N}$, as this includes the Arctic ocean and relevant Arctic regions over land such as Siberia, Northern Canada and Alaska. All model output was regridded to a $1 \times 1$ grid for ease of comparison. The total sea ice area was computed on the original grid. The surface cloud radiative forcing is computed by summing longwave $\left(\mathrm{LW}-\mathrm{LW}_{\text {clear-sky }}\right)$ and shortwave radiative forcing $\left(\mathrm{SW}-\mathrm{SW}_{\text {clear-sky }}\right)$, where LW and SW are the net longwave and net shortwave radiation at the surface. 
For validation of the climate model results we study the same mechanisms in multiple satellite and reanalysis products. For the former we use the Surface Radiation Budget version 3 (SRB3.0, Cox et al., 2017) (1984-2007) and the NASA Clouds and the Earth's Radiant Energy System (CERES, Wielicki et al., 1998) (2000-2016). For the latter we use the Climate Forecast System Reanalysis (CSFR, Saha et al., 2010), ERA-Interim (ERA-I, Dee et al., 2011), the Japanese 55-year reanalysis (JRA-55, Kobayashi et al., 2015) and the Modern-Era Retrospective Analysis for Research and Application (MERRA2, Bosilovich et al., 2016) (Supplementary Table 4.2). All 6 products are regridded to the same $1 \times 1$ grid for ease of comparison, and are monthly averages. For a validation of the quality of the satellite and reanalysis products (Supplementary Table 3) we use monthly averaged surface radiative fluxes from four in-situ observations located around the Arctic ocean, provided by the CERES-Atmospheric Radiation Measurement Program (ARM) Validation Experiment (CAVE). Namely Barrow, Alaska (2000-2010); Ny-Alesund, Norway (2000-2015); Alert, Canada (2005-2015); Tiksi, Russia (20102015).

\section{Acknowledgements}

This research is part of the Wageningen UR strategic research and development program TripleP@Sea.WH was partly sponsored by the Blue-Action project (European Union's H2020 Research and Innovation programme grant nr. 727852). We acknowledge the World Climate Research Programme's Working Group on Coupled Modelling, which is responsible for CMIP, and we thank the climate modeling groups (listed in Supplementary Table 4.1) for producing and making available their model output. 


\subsection{Supplementary information}

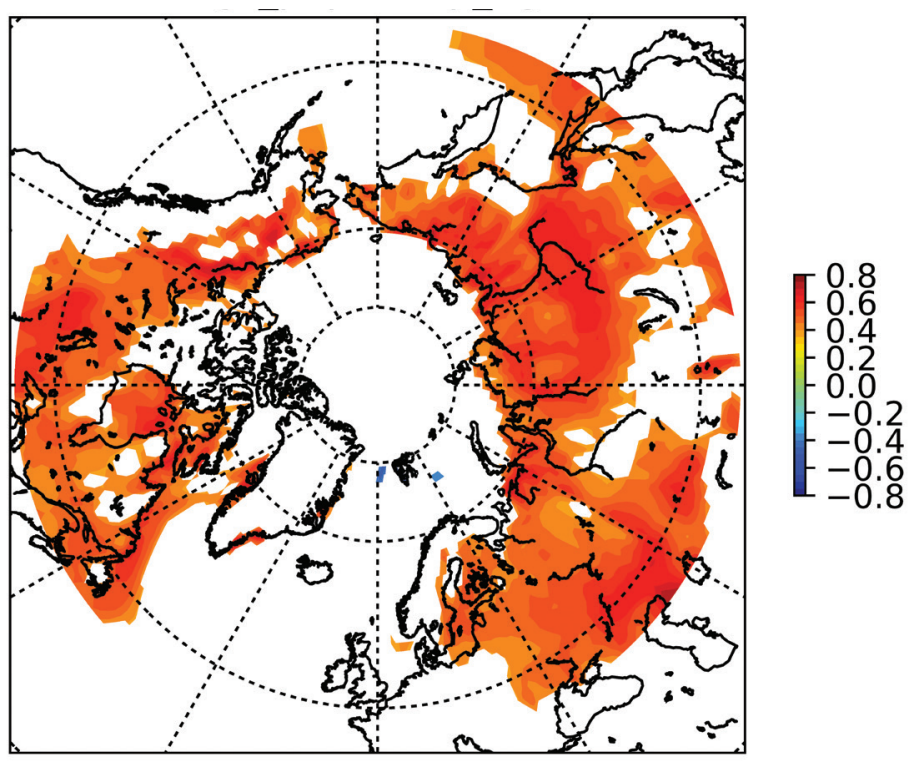

Supplementary Figure 4.1: Intermodel correlation of gridpoint-wise pre-industrial May average CRF and annual average Arctic warming [RCP85, 2090-2100 minus 2006-2016, $65^{\circ} \mathrm{N}-90^{\circ} \mathrm{N}$. Only significant values $(p<0.05)$ are plotted.

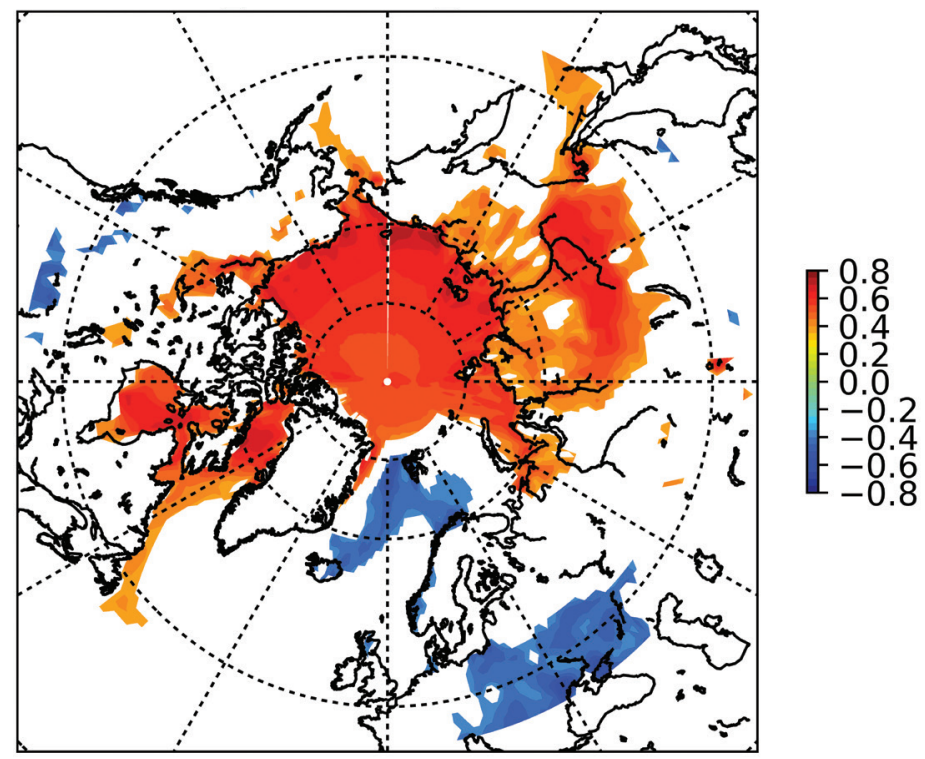

Supplementary Figure 4.2: Intermodel correlation of gridpoint-wise pre-industrial May average surface albedo and annual average Arctic warming [RCP8.5, 2090-2100 minus 2006-2016, 65' N-90'N]. Only significant values $(p<0.05)$ are plotted. 


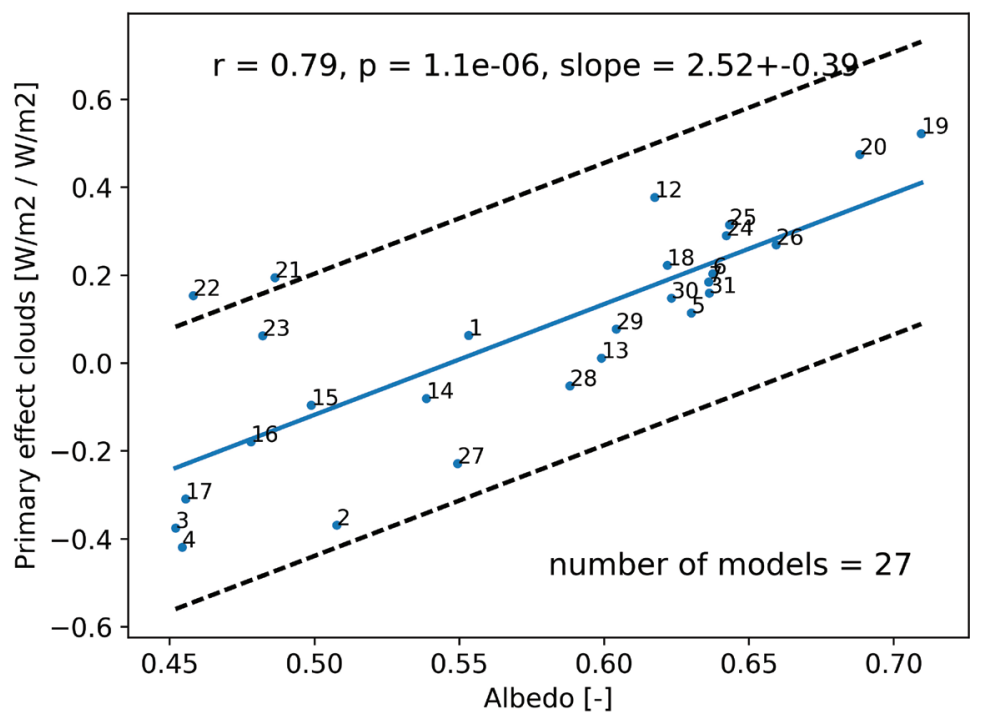

Supplementary Figure 4.3: Relation of the average surface albedo with the primary effect of clouds (regr. coef. DLR $R_{C L}$ with CRF). Both are averaged over the area where the correlation in Fig. $4.2 c$ is more than 0.5. 
Supplementary Table 4.1: List of the climate models used, their Arctic temperature response, DLR variability, primary effect (PE, regression coefficient DLRCL with CRF) and secondary effect (SE, regression coefficient DLRCL with $S{ }^{\top}$ ), based on 200 years of May pre-industrial simulations. The uncertainties represent the bootstrapped $(n=1 e 4)$ standard error for DLR and the standard error of the regression coefficient for PE and SE. The models are sorted by their Arctic temperature response under RCP8.5. The models indicated with $a$ * have no clear-sky radiation variables available.

\begin{tabular}{|c|c|c|c|c|c|}
\hline & Models & Arc. Warming [K] & DLR std. [W $\left.\mathrm{m}^{-2}\right]$ & $\mathrm{PE}\left[\mathrm{Wm}^{-2} / \mathrm{Wm}^{-2}\right]$ & $\mathrm{SE}\left[\mathrm{W} \mathrm{m}^{-2} / \mathrm{W} \mathrm{m}^{-2}\right]$ \\
\hline 1 & GISS-E2-R & 4.1 & $2.81 \pm 0.13$ & $0.43 \pm 0.24$ & $-0.1 \pm 0.06$ \\
\hline 2 & GFDL-ESM2M & 5.8 & $3.41 \pm 0.16$ & $0.05 \pm 0.16$ & $-0.31 \pm 0.08$ \\
\hline 3 & bcc-csm1-1-m & 6.0 & $3.17 \pm 0.15$ & $0.3 \pm 0.11$ & $-0.38 \pm 0.06$ \\
\hline 4 & GISS-E2-H & 6.1 & $3.32 \pm 0.16$ & $0.44 \pm 0.21$ & $-0.08 \pm 0.07$ \\
\hline 5 & IPSL-CM5A-MR & 6.6 & $3.29 \pm 0.15$ & $0.53 \pm 0.1$ & $0.15 \pm 0.06$ \\
\hline 6 & GFDL-ESM2G & 6.6 & $3.53 \pm 0.15$ & $0.16 \pm 0.16$ & $-0.18 \pm 0.08$ \\
\hline 7 & bcc-csm1-1 & 6.8 & $3.72 \pm 0.19$ & $0.11 \pm 0.11$ & $-0.42 \pm 0.07$ \\
\hline 8 & CESM1-BGC & 6.8 & $3.92 \pm 0.18$ & $0.54 \pm 0.16$ & $0.18 \pm 0.05$ \\
\hline 9 & MPI-ESM-LR & 7.0 & $3.36 \pm 0.18$ & $0.3 \pm 0.29$ & $-0.05 \pm 0.12$ \\
\hline 10 & MPI-ESM-MR & 7.2 & $3.5 \pm 0.19$ & $0.26 \pm 0.29$ & $-0.23 \pm 0.11$ \\
\hline 11 & MRI-CGCM3 & 7.2 & $4.59 \pm 0.22$ & $0.48 \pm 0.19$ & $0.08 \pm 0.05$ \\
\hline 12 & CCSM4 & 7.4 & $3.94 \pm 0.2$ & $0.58 \pm 0.16$ & $0.2 \pm 0.06$ \\
\hline 13 & CMCC-CESM* & 7.4 & $3.04 \pm 0.15$ & -- & -- \\
\hline 14 & IPSL-CM5A-LR & 7.8 & $3.62 \pm 0.18$ & $0.45 \pm 0.09$ & $0.19 \pm 0.05$ \\
\hline 15 & IPSL-CM5B-LR & 8.1 & $4.57 \pm 0.22$ & $0.25 \pm 0.1$ & $0.06 \pm 0.05$ \\
\hline 16 & NorESM1-M & 8.1 & $3.85 \pm 0.18$ & $0.36 \pm 0.13$ & $0.15 \pm 0.06$ \\
\hline 17 & CNRM-CM5 & 8.3 & $3.97 \pm 0.19$ & $0.57 \pm 0.17$ & $0.38 \pm 0.04$ \\
\hline 18 & NorESM1-ME & 8.4 & $4.25 \pm 0.21$ & $0.3 \pm 0.12$ & $0.16 \pm 0.05$ \\
\hline 19 & ACCESS1-3 & 8.7 & $4.34 \pm 0.24$ & $-1.04 \pm 0.21$ & $-0.37 \pm 0.08$ \\
\hline 20 & CESM1-CAM5* & 8.9 & $3.88 \pm 0.19$ & -- & -- \\
\hline 21 & CMCC-CM* & 8.9 & $3.77 \pm 0.19$ & -- & -- \\
\hline 22 & CMCC-CMS* & 9.1 & $3.86 \pm 0.18$ & -- & -- \\
\hline 23 & CanESM2 & 9.3 & $3.84 \pm 0.2$ & $-0.01 \pm 0.21$ & $0.01 \pm 0.07$ \\
\hline 24 & MIROC5 & 9.5 & $5.17 \pm 0.28$ & $0.06 \pm 0.16$ & $0.29 \pm 0.05$ \\
\hline 25 & BNU-ESM & 9.7 & $4.61 \pm 0.24$ & $0.01 \pm 0.15$ & $0.11 \pm 0.07$ \\
\hline 26 & ACCESS1-0 & 9.8 & $4.95 \pm 0.26$ & $0.02 \pm 0.21$ & $0.06 \pm 0.08$ \\
\hline 27 & MIROC-ESM & 10.6 & $5.52 \pm 0.29$ & $0.09 \pm 0.19$ & $0.31 \pm 0.06$ \\
\hline 28 & MIROC-ESM-CHEM & 10.9 & $5.85 \pm 0.28$ & $-0.31 \pm 0.16$ & $0.27 \pm 0.06$ \\
\hline 29 & HadGEM2-ES & 11.1 & $5.3 \pm 0.23$ & $-0.25 \pm 0.07$ & $0.47 \pm 0.02$ \\
\hline 30 & HadGEM2-CC & 11.1 & $4.99 \pm 0.31$ & $-0.23 \pm 0.06$ & $0.52 \pm 0.02$ \\
\hline 31 & GFDL-CM3 & 11.6 & $4.38 \pm 0.2$ & $-0.14 \pm 0.18$ & $0.22 \pm 0.07$ \\
\hline
\end{tabular}

Supplementary Table 4.2: Same as Supplementary Table 1, but for the satellite $(1,2)$ and reanalysis products $(3,4,5,6)$.

\begin{tabular}{|l|c|c|c|c|}
\cline { 2 - 5 } \multicolumn{1}{c|}{} & Products & DLR std. $\left[\mathrm{W} \mathrm{m}^{-2}\right]$ & $\mathrm{PE}\left[\mathrm{W} \mathrm{m}^{-2} / \mathrm{W} \mathrm{m}^{-2}\right]$ & $\mathrm{SE}\left[\mathrm{W} \mathrm{m}^{-2} / \mathrm{W} \mathrm{m}^{-2}\right]$ \\
\hline 1 & SRB3.0 & $3.45 \pm 0.46$ & $-0.25 \pm 0.42$ & $-0.22 \pm 0.97$ \\
\hline 2 & CERES & $2.84 \pm 0.42$ & $0.72 \pm 0.63$ & $0.18 \pm 0.86$ \\
\hline 3 & CSFR & $4.38 \pm 0.54$ & $0.24 \pm 0.21$ & $0.22 \pm 0.47$ \\
\hline 4 & ERA-Interim & $3.68 \pm 0.33$ & $-0.12 \pm 0.16$ & $0.11 \pm 0.52$ \\
\hline 5 & JRA-55 & $4.56 \pm 0.4$ & $-0.03 \pm 0.12$ & $-0.66 \pm 0.3$ \\
\hline 6 & MERRA2 & $2.34 \pm 0.29$ & $0.16 \pm 0.3$ & $1.53 \pm 0.57$ \\
\hline
\end{tabular}


Supplementary Table 4.3: The mean bias, root mean square error (RMSE) and correlation of the

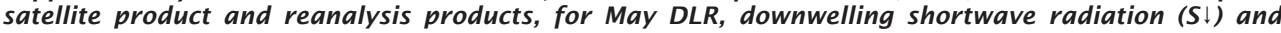
upwelling shortwave radiation (S $($ ) using 4 different observation stations surrounding the Arctic ocean of monthly mean data (see methods).

Mean bias [ $\mathrm{W} \mathrm{m}^{-2}$ ]

\begin{tabular}{|c|c|c|c|c|c|c|}
\hline & SRB & CERES & CSFR & ERA-I & JRA-55 & MERRA2 \\
\hline DLR & -2.0 & 0.3 & -6.4 & -3.9 & -14.1 & -10.5 \\
\hline$S \downarrow$ & -43.0 & 1.6 & 6.5 & -0.3 & 18.4 & -24.0 \\
\hline$S \uparrow$ & -86.5 & -37.2 & -65.1 & -24.9 & -47.9 & -66.9 \\
\hline
\end{tabular}

RMSE [W m-2]

\begin{tabular}{|c|c|c|c|c|c|c|}
\hline & SRB & CERES & CSFR & ERA-I & JRA-55 & MERRA2 \\
\hline DLR & 7.8 & 7.3 & 12.9 & 9.1 & 15.8 & 13.0 \\
\hline $\mathrm{S} \downarrow$ & 50.9 & 18.0 & 20.1 & 18.4 & 22.0 & 28.4 \\
\hline $\mathrm{S} \uparrow$ & 94.2 & 54.0 & 82.5 & 36.1 & 58.0 & 71.9 \\
\hline
\end{tabular}

Correlation [-]

\begin{tabular}{|c|c|c|c|c|c|c|}
\hline & SRB & CERES & CSFR & ERA-I & JRA-55 & MERRA2 \\
\hline DLR & 0.87 & 0.95 & 0.87 & 0.9 & 0.93 & 0.91 \\
\hline $\mathrm{S} \downarrow$ & 0.46 & 0.84 & 0.74 & 0.72 & 0.89 & 0.83 \\
\hline $\mathrm{S} \uparrow$ & 0.6 & 0.73 & 0.77 & 0.67 & 0.85 & 0.82 \\
\hline
\end{tabular}





\section{Chapter 5}

Skill improvement of dynamical seasonal Arctic sea ice forecasts 


\begin{abstract}
We explore the error and improve the skill of the outcome from dynamical seasonal Arctic sea ice reforecasts using different bias correction and ensemble calibration methods. These reforecasts consist of a five-member ensemble from 1979 to 2012 using the general circulation model EC-Earth. The raw model reforecasts show large biases in Arctic sea ice area, mainly due to a differently simulated seasonal cycle and long term trend compared to observations. This translates very quickly ( $1-3$ months) into large biases. We find that (heteroscedastic) extended logistic regressions are viable ensemble calibration methods, as the forecast skill is improved compared to standard bias correction methods. Analysis of regional skill of Arctic sea ice shows that the Northeast Passage and the Kara and Barents Sea are most predictable. These results show the importance of reducing model error and the potential for ensemble calibration in improving skill of seasonal forecasts of Arctic sea ice.
\end{abstract}




\subsection{Introduction}

Arctic sea ice has quickly retreated in recent decades, triggering both a large scientific and economic interest. Hence it is key to understand the processes at play and adequately predict the sea ice variability and long term trend. A promising method herein is the use of fully coupled general circulation models (GCMs) (Guemas et al., 2016), as the sea ice variability and trend are highly dependent on atmosphere (e.g. Kay et al., 2008; Graversen et al., 2010), ocean and sea ice processes (Shimada et al., 2006; Mahajan et al., 2011 ), and their interactions (Krikken and Hazeleger, 2015).

A prominent mechanism to provide seasonal predictability is persistence of sea ice area (SIA) anomalies up to 2-5 months, whereas thickness anomalies can persist for up to 12 months (Blanchard-Wrigglesworth et al., 2011). Other relevant mechanisms are winter-to-winter sea surface temperature (SST) memory at the sea ice edge (Bitz et al., 2005), summer-to-summer memory through persisting sea ice thickness anomalies and melt to freeze-up reemergence due to the icealbedo feedback and persistence of SST anomalies (Blanchard-Wrigglesworth et al., 2011; Krikken and Hazeleger, 2015), early season melt ponds (Schröder et al., 2014) and varying sea ice thickness distributions (Chevallier and Salas-Melia, 2012).

Model studies show high potential for skillful prediction of Arctic sea ice on seasonal time scales (Tietsche et al., 2014; Day et al., 2014). Turning the potential predictability into actual skillful predictions is, however, still challenging. GCMs have potential skill to predict sea ice cover 1-2 years ahead, but actual skill is only significant for 2-5 months (Guemas et al., 2016). This difference is caused by model and initialization errors. Biases in the models cause them to drift from the initialized state to the models' state that include systematic errors, resulting in large forecast errors and raising the need for bias correction (Meehl et al., 2013). These uncertainties and the chaotic nature of the atmospheric circulation (Serezze and Stroeve, 2015) imply that a probabilistic skill assessment of sea ice predictions could be considered.

An often-used bias correction method removes the mean bias of the forecast at each forecast time (Smith et al., 2007). However, the large negative trend in Arctic sea ice over the last decades, in combination with the underestimation of this trend in GCMs (Stroeve et al., 2012), introduces a time dependence of the model drift during the validation period (Oldenborgh et al., 2012; Meehl et al., 2013). Further complications arise from the fact that the model drift can be dependent on the varying initial state due to natural variability (e.g. Kharin et al., 2012; Fučkar et al., 2014), and on the initialization month (Day et al., 2014).

Here, we show how skill in Arctic sea ice predictions can be improved by taking into account some of the challenges described above. First, we analyze the forecast error of SIA in a set of retrospective initialized coupled model forecasts (Guemas et al., 2014). Second, we use ensemble calibration methods to improve the forecast skill and compare it to standard bias correction methods. Though often used in weather prediction (e.g. Roulston and Smith, 2003; Raftery et al., 2005; Schmeits and Kok, 2010), full ensemble calibration has so far not been applied to seasonal forecasts 
of Arctic sea ice. We use two recently developed methods, namely extended logistic regression (ELR) (Wilks, 2009) and heteroscedastic ELR (HELR) (Messner et al., 2014). Third, we apply these advanced methods to different regions in the Arctic to assess the regional differences in skill.

\subsection{Data and Methods}

\subsubsection{Datasets}

The retrospective initialized coupled model forecasts used in this study are described in detail by Guemas et al. (2014). They are performed with EC-Earth, v2.3 (Hazeleger et al., 2010, 2012). The sea ice component of the model is the Louvain-la-Neuve (LIM2) sea ice model (Fichefet and Maqueda, 1997; Goosse and Fichefet, 1999). We reforecast sea ice during the 1979-2012 period with start dates each year in May, August and November, 5 members for each start date and a simulation time of 12 months. The atmosphere initial state is obtained from ERA-Interim (Dee et al., 2011). The ocean initial states are obtained from the 5-member ORAS4 reanalysis (Balmaseda et al., 2013) and surface initial conditions from ERA-Interim. The sea ice initial conditions come from a sea ice reconstruction performed by forcing the ocean and sea ice components of EC-Earth v2.3 with ERA-Interim and nudging the ocean toward ORAS4. We use monthly averaged output for the analysis. Hereafter, this experiment will be referred to as EC-init, and May-init, Aug-init or Nov-init to further specify the initialization month. The ensemble of sea ice forecasts is generally underdispersive for all lead times (not shown).

We compare the re-forecasts to sea ice observations from NSIDC (Cavalieri et al., 1996). To illustrate EC-Earth's own climatology we use the ensemble mean of the historical (1979-2005) and RCP45 (2006-2013) simulations using the CMIP5 protocol, hereafter EC-free. The only difference between EC-init and EC-free is the initialization.

\subsubsection{Bias correction and ensemble calibration methods}

For the statistical post-processing of the sea ice forecasts we use multiple methods. The simple bias correction methods remove the (1) bias per lead time, (2) bias per lead time and the error in the long term linear trend, and (3) monthly linear trend of the bias, i.e. the trend for all Januaries, Februaries etc. The latter method is similar to the one used by Kharin et al. (2012). For the ensemble calibration we use ELR and HELR. ELR provides full continuous probability distribution forecasts, which is defined as,

$$
p\left(y<q_{j} \mid X\right)=\frac{\exp \left(\frac{q_{j}-\mu}{\sigma}\right)}{1+\exp \left(\frac{q_{j}-\mu}{\sigma}\right)}
$$


where $\mathrm{p}$ is the conditional probability that $\mathrm{y}$ (SIA) falls below a certain threshold $\mathrm{q}$, given a vector of predictor variables $(X)$. For the thresholds we use the quantiles qj $(0.1,0.2, \ldots, 0.9) . \mu$ and $\sigma$ are respectively the location and scale parameter of the logistic function. These are defined as $\mu=X^{\top} \gamma$ and $\sigma=1$, where $X$ is a vector of predictors and $\gamma$ a vector of coefficients that have to be estimated. Here we use the ensemble mean and ensemble standard deviation of SIA as predictors. Note that we only include the latter when it is a significant predictor.

The advantages of including the thresholds in the forecast equation are that the probabilities for different thresholds are mutually consistent, and that the set of regression coefficients only has to be calculated once, instead of per individual threshold. A disadvantage of ELR is that the scale parameter is constant. Hence the predictors only affect the location parameter (i.e. calibrated ensemble mean). As a result, using the ensemble spread as predictor has no effect on the scale parameter (i.e. calibrated ensemble spread) of the predictive distribution (Messner, 2014). HELR alleviates this problem by using the ensemble spread directly as a predictor for the dispersion of the predictive distribution through $\sigma=\exp \left(Z^{\top} \delta\right)$, where $Z^{\top}$ is an additional predictor (here ensemble standard deviation) and $\delta$ a coefficient that has to be estimated.

Because of the strong trend in Arctic sea ice, we linearly detrend the data before applying ELR and HELR. Furthermore, we perform the analysis per lead time, and use 'leave-one-out' crossvalidation to be able to assess the results of an independent dataset. For ELR and HELR, we use the 'crch' R package.

\subsubsection{Verification metrics}

To evaluate the sea ice forecasts and the impact of the different bias correction methods we use the root mean squared error (RMSE), as a measure for the error of the ensemble mean. To validate the ensemble forecasts we use the continuous ranked probability skill (score) (CRPS(S)). The CRPS is defined as,

$$
\text { CRPS }=\int_{-\infty}^{\infty}\left[F(y)-F_{0}(y)\right]^{2} d y \quad 5.2
$$

where $F(y)$ is the cumulative distribution function of an ensemble of forecasts, and $\mathrm{F}_{0}(\mathrm{y})$ a cumulative-probability step function that jumps from 0 to 1 where the forecast variable $y$ equals or is greater than the observation.

The CRPSS is defined as CRPSS $=1-\frac{C R P S_{\text {mod }}}{C R P S_{\text {ref }}}$ where CRPS $_{\text {ref }}$ is the CRPS of a reference

forecast. Here we use the climatological distribution of sea ice as a reference forecast, and corrected it for the long term trend so that it represents natural variability up to decadal time scales only. The CRPSS ranges from $-\infty$ to 1 , where values above (below) 0 indicate that the model (reference forecast) is better than the reference forecast (model). We use the bootstrapping resampling technique $(n=10000)$ to produce the 5-95\% confidence intervals (Wilks, 2011). 


\subsection{Results}

\subsubsection{Forecast bias}

As described in the introduction, GCMs such as EC-Earth drift towards their own climatology after initialization. Figure 5.1 a shows the long term trend of SIA for ECfree (gray) and NSIDC (black). Note that the only difference between EC-init and ECfree is the initialization. Generally, EC-free has a cold bias in the Arctic (Sterl et al., 2011 ) and therefore simulates too much sea ice. If we compare the trend of EC-free to the observed trend (NSIDC), we see that EC-free underestimates the decline in sea ice. This decline is strongest in the last 2 decades, which is not visible in the long term linear trend.

To illustrate model drift we show the error of Nov-init for each year (ensemble mean Novinit - NSDIC) relative to the linear trend of NSIDC (red, Fig. 5.1a). In this way, a perfect forecast would match the black line. On average (Fig. $5.1 \mathrm{~b}$ ), we find a positive drift, but it must be noted that drift depends strongly per month with a slightly negative bias in winter and spring months and a large positive bias in September. The drift also strongly varies from year to year. In the first decade there is no clear positive or negative drift, but in the last 2 decades the drift is generally positive, which brings EC-init closer to EC-free climatology. A possible explanation for the increase in positive drift is the increasing difference between NSIDC and EC-free sea ice area. From figure 5.1 we can clearly see that a drift correction needs to account for time dependency, both in lead time and analysis time.

To be able to better assess the bias of EC-init, we decompose the bias of EC-free relative to NSIDC into an average bias $\left(0.94 \cdot 106 \mathrm{~km}^{2}\right)$ and a bias in the seasonal cycle. This is illustrated in figure $5.1 \mathrm{c}$, which shows the average seasonal cycle of EC-free, and the average seasonal cycle of EC-free minus the average bias. A striking feature is that the SIA minimum of EC-free and EC-init is not in September, but in August. To better illustrate this, we show the bias of the seasonal cycle of EC-init and EC-free minus the average bias, relative to NSIDC (Fig. 5.1d). We find a strong resemblance between EC-init and EC-free minus the average bias. This indicates that the bias in the shape of the seasonal cycle in the free model to a large extent determines the model's bias for seasonal forecasts. The figure also shows that already within 2 months Aug-init shows a strong drift towards the seasonal cycle of EC-free. Also, May-init and Nov-init drift back towards the average seasonal cycle of EC-free albeit not as strong as Aug-init. Note that the individual linear trends seen in Fig. 5.1a are mostly positive because the largest model errors occur from August to October, which is at the end of the 1-year forecast for Nov-init resulting in a positive linear drift. For May-init and Auginit this is not the case. This results in a strong seasonality of the drift as shown in figure $5.1 \mathrm{~d}$.

A possible explanation for the large difference between EC-Earth and NSIDC could be a too early refreezing of open water in the central Arctic. The average seasonal cycle of sea ice extent (SIE) of EC-init has its minimum in September (not shown). This implies that around the edges, there is still mainly melting in August and September, 


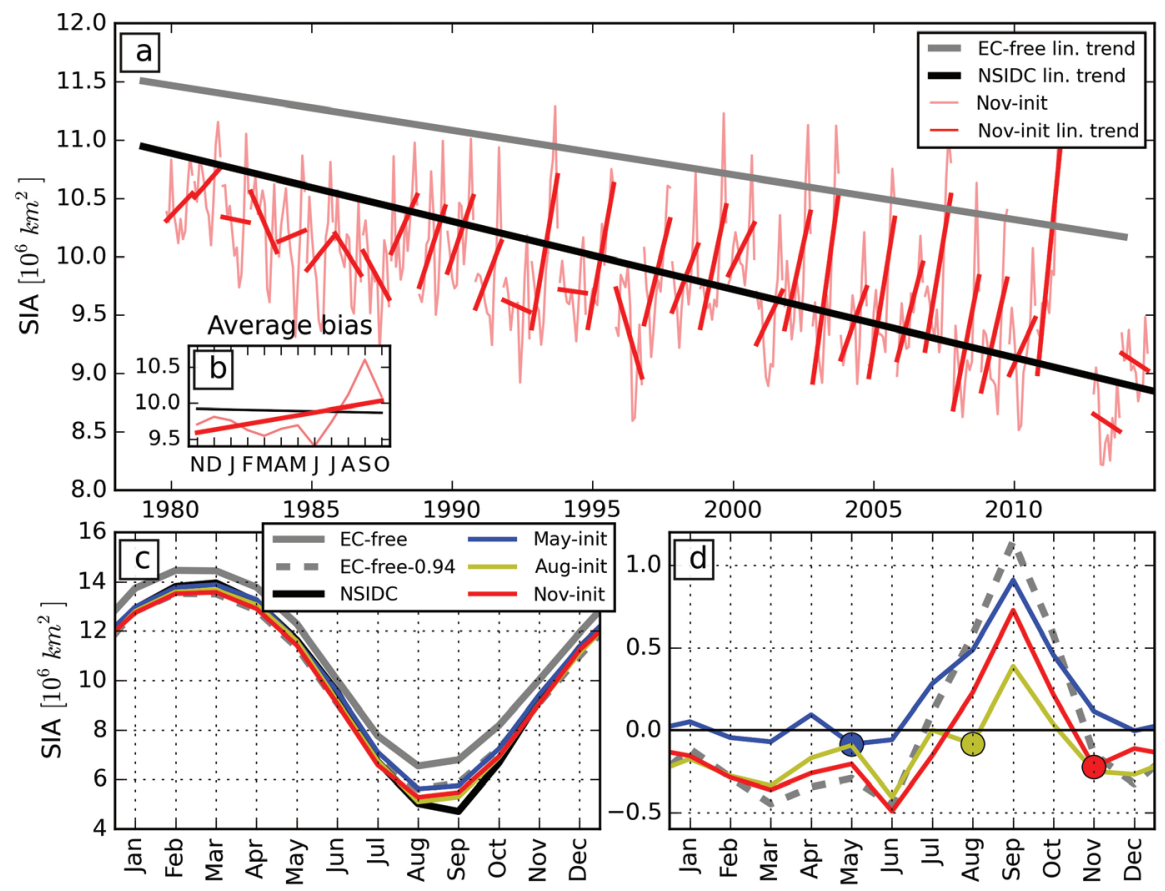

Figure 5.1. (a) Long term linear trend of SIA for EC-free (gray) and NSIDC (black) and the error of all individual Nov-init simulations (ensemble-mean) with the NSIDC long term linear trend added (Novinit-NSIDC + NSIDC lin .trend) (red, opaque) and the linear trends per forecast (red). (b) The average bias and its linear trend together with the average linear trend of NSIDC (black). (c) Average seasonal cycle of NSIDC, May-init, Aug-init, Nov-init, EC-free, and EC-free minus the avg. bias (0.94 . $106 \mathrm{km2})$, and $(d)$ the same as (c) but with NSIDC subtracted to get the seasonal anomalies relative to NSDIC.

but that the sea ice concentration already increases within the ice pack, leading to a higher total SIA. 


\subsubsection{Impact of bias correction on forecast error}

As demonstrated in the previous section, the raw forecasts of sea ice area contain large biases. We assess the impact of different bias correction methods on the error of the forecast ensemble mean, by calculating the RMSE for the different initialization months (May, August, November) as a function of lead time (figure 5.2). The raw model forecasts of May-init (Fig. 5.2a) show large RMSE, especially in September.
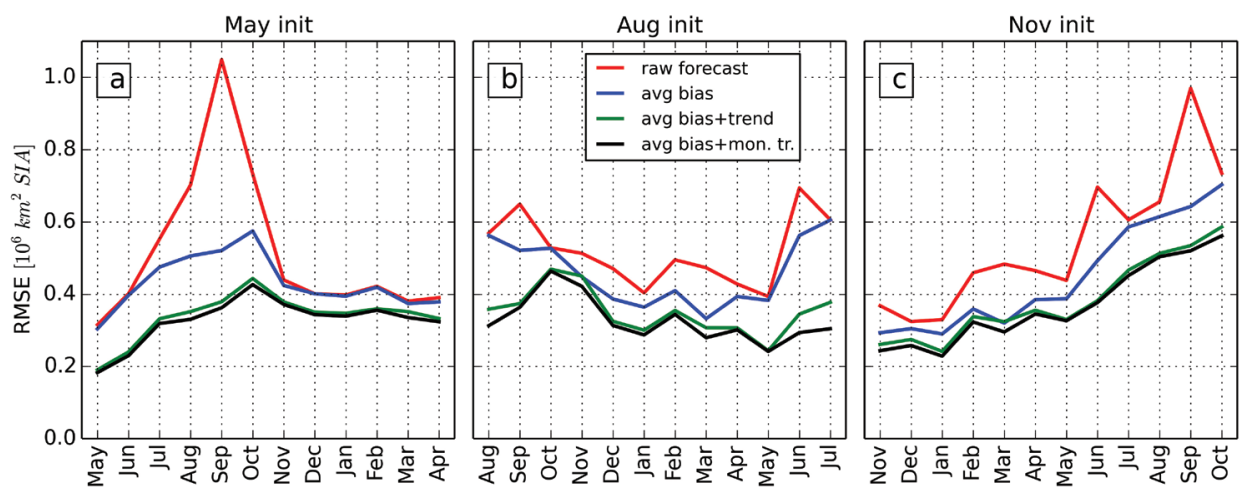

Figure 5.2: RMSE of SIA as a function of lead time for different bias correction methods for (a) May-init, (b) Aug-init, and (c) Nov-init.

In the following months the RMSE drops again to values comparable to those in the month of initialization. Note that a SIA error of $1.106 \mathrm{~km}^{2}$ represents roughly $20 \%$ of the total SIA in September. If we correct for the average bias per lead time (blue line) the RMSE in September is already halved. The raw forecasts of Aug-init and Nov-init also have large RMSE around September, but the effect of removing the average bias is smaller. This illustrates that especially around September there are large systematic errors in the model, which, as shown in the previous section, are related to the errors in the seasonal cycle of SIA in EC-free. If we also include a long-term trend correction on top of correcting the average bias per lead time (green line) the RMSE is reduced considerably, mainly in spring and summer. We can further improve the forecasts by applying a linear trend correction applied to each calendar month (black line) (Kharin et al., 2012), as the sea ice minimum (September) is known to have a larger negative trend than the sea ice maximum (March) (Stroeve et al., 2012). This method improves the forecasts further, mainly for Aug-init. It is striking that at short lead times the raw and bias corrected forecasts of Aug-init have a higher RMSE than at longer lead times (5-10 months). Apparently, the large bias in EC-free during the late summer and early autumn has a substantial impact on Aug-init yielding relatively large RMSE. The fact that we do not have a lower RMSE for the bias-corrected data shows that the strong bias of EC-free has a substantial impact on the prediction of anomalies. Also note that the bias-corrected error does not necessarily decrease for a specific target-month if the lead time decreases, as the RMSE of SIA in September and October is somewhat lower for May-init compared to Aug-init. 
We find that the RMSE is more dependent on the specific initialization month than on lead time. These results agree with findings from Wang et al. (2013). This indicates that errors in the mean state strongly affect prediction of anomalies respective to this mean state. Overall, SIA in some periods of the year is harder to predict than other months, with October showing the highest bias-corrected RMSE for all initialization.

\subsubsection{Forecast skill}

In this section, we aim to continue to reduce the error in the forecasts using ensemble postprocessing methods. Furthermore, we assess its skill, i.e. how good are the forecasts relative to reference forecasts.

Here we use a simple statistical reference forecast: damped persistence. This forecast starts from the observed anomaly, and then relaxes back to climatological values with a decreasing exponential function, where the relaxation time scale is given by the decorrelation time scale of SIA. Note that the climatological values include a monthly linear trend. Figure 5.3a-c show the RMSE of SIA forecasts based on damped persistence, and forecasts obtained from EC-init corrected with both ensemble calibration methods (ELR and HELR) and with the monthly linear trend removal (mon. tr.). All forecasts in figure 5.3 are verified using 'leave-one-out' cross-validation. Both ELR and HELR closely match mon.tr. at shorter lead times, but at longer lead times there is a substantial reduction of the RMSE for May-init and Nov-init. Thus, ELR and HELR also improve the ensemble mean of the forecasts. However, all forecasts have difficulty beating damped persistence, especially Aug-init. ELR and HELR for Mayinit outperform damped persistence for the months June to October, but for the other months and initializations ELR and HELR closely match damped persistence. It is clear, however, that calibration improves the forecasts relative to standard bias correction (mon.tr.). 


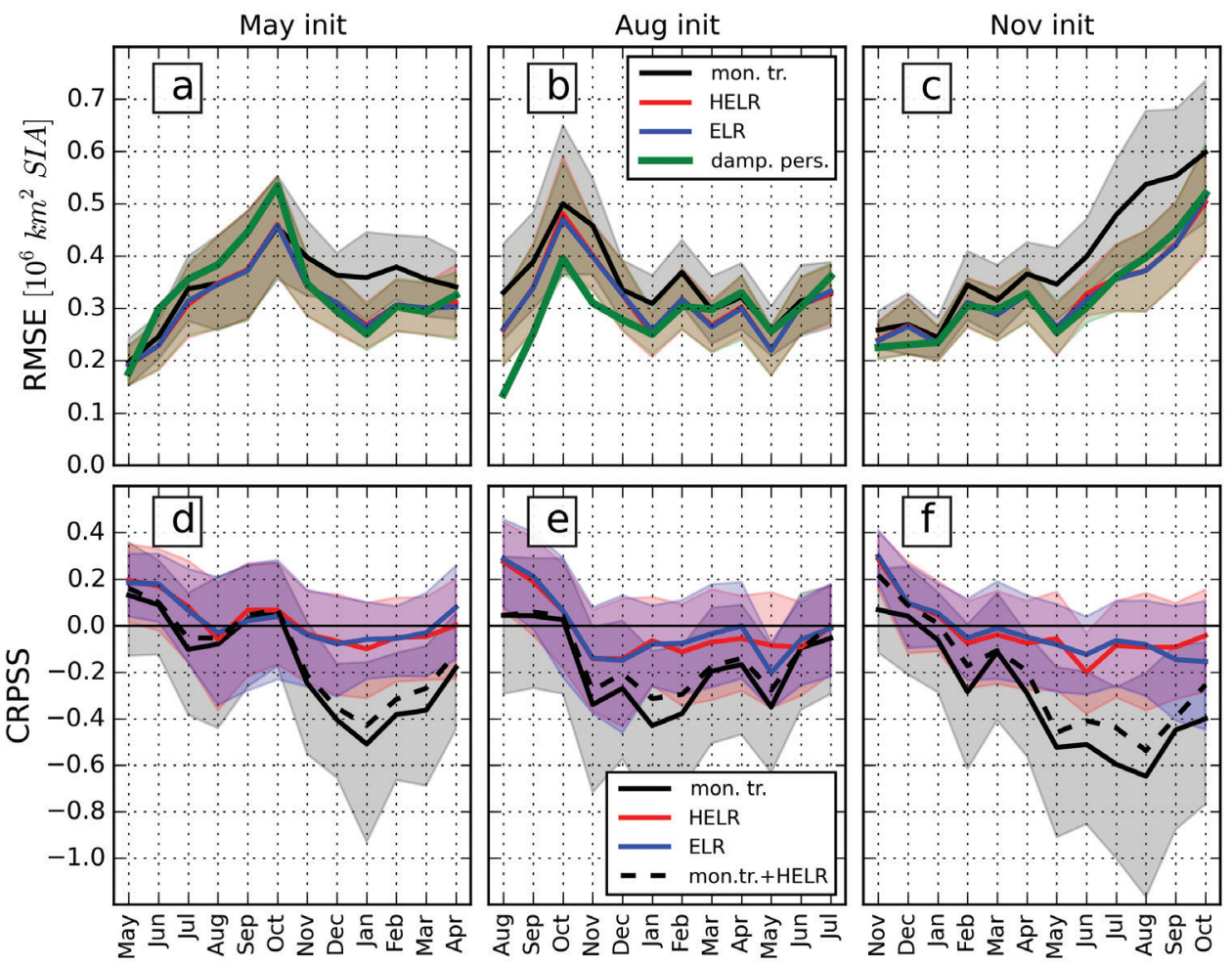

Figure 5.3: (a-c) The RMSE of SIA for the damped persistence forecasts, monthly trend corrected, and ELR and HELR initializations. (d-f) The CRPSS of monthly trend corrected and ELR and HELR initializations. The confidence interval is the 5-95\% confidence interval of the bootstrap distribution.

To assess the skill of the probabilistic forecast we use the CRPSS, which is well suited for verification of continuous probabilistic forecasts (e.g. Wilks, 2011). Here we use the climatological distribution as a reference forecast instead of damped persistence, as the latter is a deterministic forecast, hence not well suited as a reference for the CRPSS. For all initialization months (Fig. $5.3 \mathrm{df}$ ) we find some skill (CRPSS $>0$ ) up to 2 to 5 months. Again, it proves difficult to outperform a simple reference forecast. The higher CRPSS of $(H) E L R$ relative to mon.tr. is noteworthy, also at longer lead times, albeit with negative CRPSS. However, we do not find a distinction between ELR and HELR. The calibrated ensemble spread is more variable for HELR (not shown), as expected, but does not have a clear effect on the CRPSS. To illustrate the improved skill due to a better ensemble spread, we show the CRPSS of the ensemble mean of mon.tr. in combination with the ensemble spread of HELR (figure 5.3d-f, 'mon. tr.+HELR'). The forecast is slightly improved, relative to mon.tr., especially for Novinit. Overall, the effect of a corrected ensemble-mean is larger.

There is a large uncertainty in the skill as indicated by the spread determined through bootstrapping. We have used a small ensemble size and covered a relatively short forecast period (1979-2012) which makes it difficult to acquire statistically significant results. Hence, these results mainly show the potential of using these methods in seasonal forecasting of Arctic sea ice. 


\subsubsection{Regional forecast skill}

Next, we assess the skill of separately computed HELR-forecasts for the regional seas of the Arctic (figure 5.4, top right) and for the Northeast and Northwest passage. The CRPSS of the total SIA forecasts is shown in the lowest row. For May-init we find that most regional seas display higher skill in the first month than the total Arctic, except for the Greenland Sea and the Canadian Archipelago. The Kara and Barents Sea also show a higher skill at longer lead times than the total Arctic. Interestingly, the Northeast passage shows skillful forecasts up to 6 months, with a higher CRPSS than the total Arctic by approximately 0.1 to 0.2. Regional skill for Aug-init is also higher than the total Arctic for some seas (Laptev, East Siberian). Nov-init has overall higher skill than Aug-init, especially in the first months. For both passages we find significant skill in February, but it is not clear where this originates from as it cannot be seen in the regional seas individually. The difference in skill between the mon. tr., ELR and HELR is comparable to as found in Fig. 3d-f (not shown). We speculate that the higher skill scores at regional scales are due to different processes at play for each region defined here. The sea ice on the Atlantic side of the Arctic basin is influenced by modes of climate variability, e.g. those associated with the Atlantic ocean circulation (Mahajan et al., 2011.), which is predictable to some extent (Hazeleger et al., 2012) and can therefore be a source of skill, mostly in the winter months. Mechanisms that can offer skill during the summer months for the Laptev, East Siberian, Kara and Barents seas are early spring atmospheric moisture transport (Kapsch et al., 2013) and for a large part of the Arctic basin the melt pond fraction in May (Schröder et al., 2014). This might explain the higher skill found in the Kara and Barents seas and the Northeast passage, though a more detailed analysis is needed to provide definite answers which is outside of the scope of this study.

\subsection{Conclusions and discussion}

In this paper, we have analyzed a set of seasonal predictions of Arctic sea ice consisting of 5-member ensemble retrospective forecasts using the fully coupled EC-Earth general circulation model, initialized from estimates of observed data. The raw model forecasts contain large biases, especially during summer months. This is mainly caused by the large difference between the average simulated seasonal cycle in EC-Earth and the observed seasonal cycle. This translates directly into the errors in the forecasts, which drift back towards their own climatological seasonal cycle within months, especially in August. By correcting for the error in the average seasonal cycle, the errors in the forecast can already be reduced. Further errors are caused by a difference in long term trend between the observed sea ice, and the uninitialized EC-Earth simulation. Correcting for this difference in long term trend in the dynamical forecasts reduces the errors substantially, where correcting for the monthly linear trend reduces the root mean square error most. In addition, we investigated more advanced calibration methods. We found that logistic regression methods are viable ensemble calibration methods, and improve forecasts compared to standard bias correction methods. We found no clear distinction in skill between extended logistic regression and heteroscedastic logistic regression methods. The increase in skill 
arose mainly due to the correction of the ensemble-mean, and to a lesser extent due to correction of the ensemble spread.
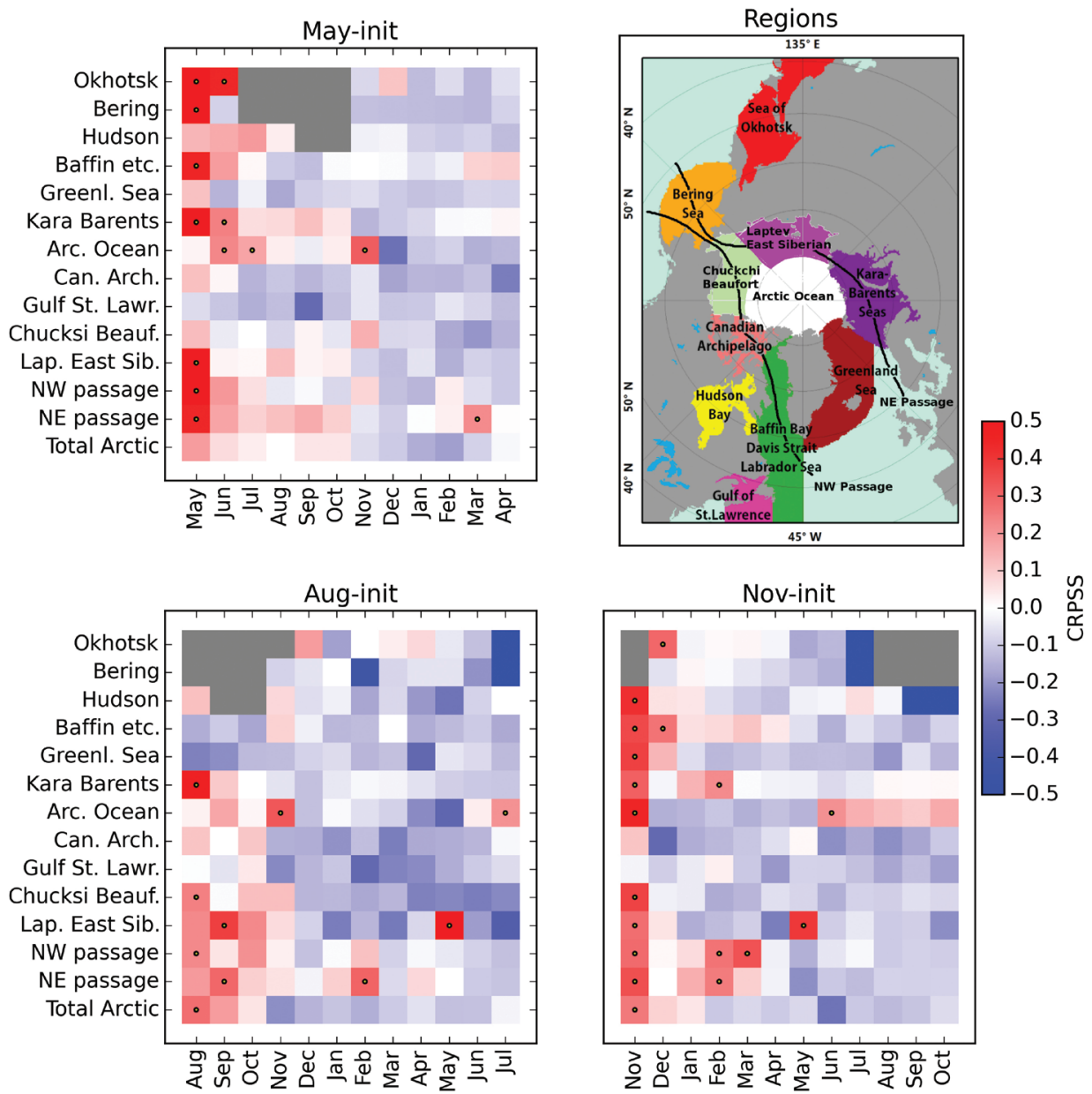

Figure 5.4: (top right) The regional seas of the Arctic, provided by NSIDC, used in the computation of the regional CRPSS. The Northwest and Northeast passages are constructed by only accounting for the different seas the routes pass through, indicated by the black lines. Further plots show the SIA CRPSS of HELR for May-init, Aug-init, and Nov-init for the different lead times. The dots indicate significant skill ( $5 \%$ bootstrapped confidence level > $)$ ), and gray pixels indicate months with no sea ice.

Concerning the different initialization months, we have found that forecasts starting in May have skill for longer lead times (CRPSS > 0 up to 5-6 months lead time) than forecasts starting in August (2-3 months) and November (2-3 months), with trendcorrected climatology as reference. This partly contrasts with results of Day et al. (2014), who showed that May forecasts lose skill faster than forecasts starting in January or July. Although we can only compare to forecasts initialized in August and November, it seems that dependence on initialization month of the forecasts skill strongly depends on the forecast system. The large model mean state errors during late summer could also explain the rapid increase in RMSE for Aug-init relative to Nov-init. 
We found distinct differences in skill of forecasts of sea ice area in different Arctic seas. Sea ice area in the Northeast passage and the Kara and Barents seas are more predictable compared to other regional seas, in particular for forecasts initialized in May and November. The non-linear characteristics of the system lead to additional errors that cannot be corrected through bias correction and ensemble calibration. Hence, to get skillful predictions of Arctic sea ice it is key to reduce model bias, both for seasonal forecasting and future climate projections. Our results indicate that the emphasis in model improvements should be on the seasonal cycle and long term trend. For future research a larger ensemble and more start dates are needed to reduce the sampling error and to better assess the sensitivity to initialization month.

Overall, we showed that ensemble calibration improves seasonal forecasts of Arctic sea ice. The gap between potential and real predictability is still large, but by reducing model biases and improved knowledge and initialization of the observed state of the Arctic there is a high potential to reduce this gap in the coming years.

\section{Acknowledgments and Data}

This research is part of, and funded by, the Wageningen UR strategic research and development program TripleP@Sea. For access to the data used in this study contact virginie.guemas@bsc.es. 



\section{Chapter 6}

General discussion and outlook 
Chapter 6 
The primary aim of this thesis is to assess the predictability of the Arctic climate, with an emphasis on its sea ice cover, on timescales ranging from monthly to centennial. This because of the large need for better predictions of monthly-to-annual Arctic sea ice cover due to the increase of economical activities in the region, and to increase the accuracy of climate projections of the Arctic climate in order to improve climate adaptation and mitigation strategies. In this synthesis we reflect upon the questions raised in the introduction and outline, the results from the previous chapters and put the results in a broader perspective.

\subsection{Understanding seasonal predictability of the Arctic climate}

Predictability on seasonal-to-annual time scales for any variable is only possible if it either has strong enough persistence, a strong enough trend or physical processes with seasonal time scales and longer that are resolved in the forecasting model. However, this potential can only be realized if the model can be initialized correctly. Here we will summarize and discuss the findings from chapter 2 and 5 , which aim at a better understanding of the processes that provide predictability for Arctic sea ice, and to assess if this potential can be translated to skillful predictions.

a. What are the physical mechanisms in current climate models that can provide predictability on seasonal to yearly time scales?

For Arctic sea ice, we find that persistence is the primary source of predictability on time scales of 2-5 months in a suit of CMIP5 climate models. There are several physical mechanisms that extend the predictably beyond persistence. Sea ice anomalies during the melting season correlate with anomalies during the refreeze season. In the case of less sea ice this can be explained through higher sea surface temperatures (SST's) due to more solar radiation, which persist up to the freezeup season, where the higher SST's prevent the sea ice from forming as quickly as normal. These results correspond to the results found by Blanchard-Wrigglesworth et al. (2010) and Day et al. (2014), who shows that these are robust mechanisms in current climate models.

We found a delayed atmospheric response on spring sea ice anomalies. This was previously documented in an observational study by Kay and Gettelman (2009) over the 2006-08 period. They related this lack of response in summer to a weaker ocean-atmosphere coupling due to a stronger atmospheric stability and weaker air-sea temperature gradients. In early fall, the lower static stability and stronger air-sea temperature gradients result in stronger turbulent fluxes, which are further increased by the SST anomaly. The enhanced turbulent fluxes result in a higher cloud fraction, which in turn enhances downwelling longwave radiation and slows the ice growth. Because of the delayed response, the cloud radiative effect on the seasonal sea ice-albedo effect results in a small net warming. 
More information on the future sea ice state can be found when looking at individual surface radiation components. Spring upward shortwave radiation is a better predictor for September sea ice area than spring sea ice itself, because of the information it contains on the surface albedo where the sea ice edge will be in September. Spring albedo of sea ice is generally a measure of the melt-pond fraction (Schroder et al., 2014), and henceforth the melting rate at the region of the September sea ice edge. Further, a decrease of spring downward shortwave radiation is found when there is less sea ice. This has previously been attributed to the generally positive cloud radiative forcing over the Arctic (Francis et al., 2005). Our analysis reveals, however, that for a negative sea ice anomaly this is primarily due to a decrease of multiple reflection of shortwave radiation resulting from a decreasing surface albedo. Our results therefore suggest that under cloudy conditions, the direct effect of the sea ice-albedo feedback (i.e., the enhanced absorbed solar radiation at the surface) is compensated up to $50 \%$ by reduced multiple reflection of downwelling solar radiation.

Note that all the results are the average over 15 different climate models, in order to yield robust results. However, as shown in chapter 5 , models may strongly differ in certain aspects such as the cloud radiative forcing or the strength of the multiple reflection component. Though not part of this analysis, it is very likely that individual model results can strongly differ from the modelmean, which makes the potential for seasonal forecast skill also highly model dependent. Further, the focus of our study was on predictability of short-term natural variability. This was done by removing the 11 -year running mean from the model data. The longer term natural variability greatly varies among climate models (Day et al., 2014). Models with more long-term variability will have increased persistence and possibly skillful forecast for up to multiple years, depending on the predictability of the long-term natural variability and whether they correctly simulate the long-term variability.

\section{b. How well can a climate model re-forecast the Arctic sea ice on seasonal to yearly time-scales?}

In chapter 5 we have analyzed a set of seasonal predictions of Arctic sea ice consisting of fivemember ensemble retrospective forecasts using the fully coupled EC-Earth general circulation model, initialized from estimates of observed data.

The raw model forecasts contain large biases, especially during summer months. This is mainly caused by the large difference between the average simulated seasonal cycle in EC-Earth and the observed seasonal cycle. This translates directly into the errors in the forecasts, which drift back toward their own climatological seasonal cycle within months, especially in August. By correcting for the error in the average seasonal cycle, the errors in the forecast can already be reduced substantially. Further errors lie in the correct representation in the long term trend in the dynamical forecasts, which also differ for the individual months.

In addition, we investigated more advanced calibration methods. We found that logistic regression methods are viable ensemble calibration methods and improve forecasts compared to standard bias correction methods. We found no clear distinction in 
skill between extended logistic regression and heteroscedastic logistic regression methods. The increase in skill arose mainly due to the correction of the ensemblemean and to a lesser extent due to correction of the ensemble spread.

Concerning the different initialization months, we have found that forecasts starting in May have skill for longer lead times than forecasts starting in August and November. This partly contrasts with results of Day et al. (2014), who showed that May forecasts lose skill faster than forecasts starting in January or July. Although we can only compare to forecasts initialized in August and November, it seems that dependence on initialization month of the forecasts skill strongly depends on the forecast system. The large model mean state errors during late summer could also explain the rapid increase in RMSE for initializations in August relative to November. We found distinct differences in skill of forecasts of sea ice area in different Arctic seas. Sea ice area in the Northeast Passage and the Kara and Barents seas is more predictable compared to other regional seas, in particular for forecasts initialized in May and November. The nonlinear characteristics of the system lead to additional errors that cannot be corrected through bias correction and ensemble calibration. Hence, to get skillful predictions of Arctic sea ice it is key to reduce model bias, both for seasonal forecasting and future climate projections. Our results indicate that the emphasis in model improvements should be on the seasonal cycle and long term trend. For future research a larger ensemble and more start dates are needed to reduce the sampling error and to better assess the sensitivity to initialization month.

Overall, we have shown that ensemble calibration improves seasonal forecasts of Arctic sea ice. The gap between potential and real predictability is still large, but by reducing model biases and improved knowledge and initialization of the observed state of the Arctic there is a high potential to reduce this gap in the coming years. Note however, that especially at shorter time scales, it is still difficult to outperform a relative simple statistical model.

An important aspect is missing in this analysis, namely the quality of the initialisation. Because the data was provided as monthly means, it was impossible to determine whether the error in the first month was due to initialisation error or due to model drift. Moreover, sea ice thickness information was not incorporated in the initialisation, whilst the thickness anomalies are important predictors for the sea ice pack later in the season (Chevallier and Salas-Melia, 2012). First results in using sea ice thickness information in initialisation of Arctic sea ice forecasting are promising (Collow et al., 2015; Dirkson et al., 2017) and can thus be used to further bridge the gap between potential and real predictability.

Initialized climate models simulations can contain a lot information on the sources of the model bias. However, the bias developed so quickly that with only monthly data it was impossible to separate cause and effect in the responses of multiple variables. Hence, for future research it would be very interesting to perform a similar analysis on daily data in order to better understand the formation of the model bias. 


\subsection{Understanding long-term predictability of the Arctic climate}

The Arctic climate is a complex dynamical system, with feedback mechanisms active over different parts of the year. Climate models struggle to capture the complex radiative and cloud microphysical processes that are key in adequately simulating the Arctic climate (e.g. Pithan et al., 2016), resulting in large uncertainties in Arctic climate projections (IPCC). Here we will summarize and discuss the findings of chapter 3 and 4, which aim at a better understanding of key physical mechanisms that drive Arctic climate change on longer term (i.e. beyond annual time scale)

\section{a. How sensitive is the Arctic climate to the seasonality of a radiative forcing?}

As shown in chapter 2, the Arctic responds differently to radiative forcings over different parts of the year, caused by the strong seasonality of solar radiation and energy storage and release in the multiple components of the Arctic climate. This raises the question how sensitive the Arctic is to the seasonality of a radiative forcing.

Hence, in chapter 3 we tested the sensitivity of the Arctic climate to the seasonality of a radiative forcing. For this we used the global climate model EC-Earth in idealized climate forcing simulations to quantify the effect of seasonality in radiative forcing on the magnitude and pattern of seasonal Arctic warming. To infer the climate response throughout the year resulting from forcings in different seasons, an artificial downwelling longwave radiative (DLR) forcing of $30 \mathrm{Wm}^{-2}$ was applied to the surface north of $70^{\circ} \mathrm{N}$ for each season separately.

While the future climate response in near-surface temperature is maximum in winter, the seasonal forcing simulations suggest that the forcing season causing the strongest annual temperature response is spring, and to a somewhat lesser degree summer. Also, summer forcing causes a much larger response in autumn and winter than in summer itself, whilst winter forcing is mostly important for the wintertime response. This demonstrates that the near-surface Arctic temperature response to any climate forcing depends greatly on the season in which the forcing occurs, with the spring season being most effective. Similar results are found for the Arctic sea ice cover response. The explanation for the strong response caused by spring forcing is the following: the extra energy in spring thins the sea ice and/or creates melt ponds, lowering the surface albedo and allowing spring and summer insolation to more effectively warm the surface and melt away sea ice. The ice-albedo feedback thus strongly amplifies the response only if the forcing occurs in the season in which the seasonal ice-albedo feedback is mainly active (spring/summer) and the additional energy is used to melt ice. This leads to enhanced absorption of shortwave radiation of the surface, increased sea surface temperatures, earlier onset of melt and an associated decline in sea ice cover. This amplified response for spring forcing is effectively carried over to subsequent seasons by storage of heat in the open Arctic Ocean, likely amplified by water vapor and cloud feedbacks (Chapter 2), leading to delayed freeze-up and thinner sea ice. 
The mechanism to invoke a surface air temperature response in seasons other than the forcing season relates to ocean storage and release of energy, which is the same mechanism that causes the reemergence of sea ice anomalies during the melt-up season as shown in chapter 2 . These results imply that whilst the Arctic warming is mostly confined to the winter months, the causes of this warming could be related to processes during spring and summer months. Ongoing sea ice decline is expected to spark human activities in the Arctic especially in the summer months (e.g., shipping, fishery, mining, tourism), which will lead to increased emissions of radiativelyactive constituents such as soot. By lowering the sea ice albedo, the additional soot may induce a net radiative surface forcing during summer. This finding suggests that the large intermodel differences in simulated Arctic (winter) warming can to a considerable degree be attributed to model uncertainties in Arctic radiative fluxes, which peak in summer.

b. What is the role of downwelling longwave radiation in the intermodel spread in future climate projections of Arctic climate change?

Though the results from chapter 3 highlight the sensitivity of the Arctic climate to spring forcing, it is difficult to quantify the importance of this mechanism in real climate projections from our sensitivity analysis. Hence, in chapter 4 we use 31 CMIP5 climate models in a high greenhouse gas emission scenario and pre-industrial control simulations to infer the role of DLR in the models' control climate and variability, and in Arctic climate projections.

We found that springtime variability in DLR in the pre-industrial climate explains about two-thirds of the intermodel spread in projected Arctic warming under a high greenhouse gas emission scenario. This variability, which peaks on the land masses adjacent to the Arctic ocean, is related to the combined effects of the cloud radiative forcing and the albedo response to snowfall, which vary strongly among models in these regions. These processes govern interannual variability of DLR in the pre-industrial climate, but also largely modulate the climate response of DLR, sea ice cover and near-surface temperature. When both processes are combined as a predictor for Arctic warming, we can explain up to $~ 80 \%$ of the intermodel spread in projected Arctic warming.

The cloud radiative forcing is strongly related to the snow covered surface albedo. Intermodel spread herein has previously been attributed to different treatment of vegetation masking effects (Hall and Qu, 2006; Qu and Hall, 2014). They found that a higher the snow-covered albedo yields a stronger surface albedo feedback, hence a stronger climate response. Hence, this can explain why the cloud radiative forcing explains part of the uncertainty in Arctic climate projections. The cooling effect due to enhanced snowfall is more difficult to physically relate to the model spread. Hence, it is still unclear why this process appears to be an important predictor for the models' Arctic climate response.

When comparing the strength of the relevant processes in various reanalysis and satellite derived products, we found that the spread herein was even larger than found 
in the climate models. It is therefore currently not yet possible to get an observational estimate of the strength of the relevant processes. This highlights the importance of more (and long-term) observational campaigns of clouds in order to improve cloudradiative and microphysics parameterizations in climate models.

This finding elucidates a crucial interaction between clouds and surface radiation within the Arctic climate system. As such it provides important insights to reduce the uncertainty in future Arctic climate projections that are required to constrain regional mitigation and adaptation strategies to Arctic climate change.

A caveat in this analysis is that the proposed mechanisms act on time-scales of hours or days, whilst the strength of the mechanisms is computed from monthly mean data. Hence, we cannot identify the mechanism itself, but rather the combined effect of both mechanisms. This implies an inherent uncertainty of our findings. Further research should therefore focus on daily model data rather than monthly mean data, which are currently not available in the CMIP5 dataset.

It must be noted that other research also points to an important role of ocean dynamics in explaining the uncertainty in Arctic climate projections, more specifically the northward Atlantic ocean heat transport (Hodson et al., 2013; Mahlstein and Knutti, 2011).

\subsection{Outlook}

Whilst the Arctic sea ice is rapidly retreating, the research on the Arctic climate is rapidly growing. This thesis builds on, and contributes to, a vast body of research on the Arctic climate. In this outlook we focus on possibilities to expand this body of research further, partly based on the research presented in this thesis.

The work in chapter 5, but also many other studies on seasonal predictability of Artic sea ice (e.g. Bushik et al., 2017; Dirkson et al., 2016), have shown that the skill of Arctic sea ice predictions is improving and that there is still lots of room to improve the forecasts. However, especially at longer lead times, the uncertainties of the forecasts will remain large. Hence, for stakeholders in the Arctic region it is difficult to assess how useful these forecasts are for their operations. The needs for specific stakeholders will vary considerably because of e.g. different planning horizons, areas of interest and sensitivity to wrong forecasts as for some stakeholders wrong forecasts could have catastrophic consequences. Hence, future research should focus on analysing the potential economic value of Arctic sea ice forecasts for the specific stakeholders in the region. This can be done in the same manner as done for economic value of weather forecasts, namely through cost / loss analysis for the specific stakeholders, and combine this with the probabilistic forecasts to compute the potential economic value (Richardson, 2000; Palmer et al., 2006). This approach can provide tailored information about the value of Arctic sea ice forecasts for stakeholders. 
The limited observations in the Arctic region, both spatially as temporally, is an important obstacle for almost any research on the Arctic climate. The Arctic is a region home to substantial (multi-)decadal variability (e.g. Boer and Lambert, 2008; van der Linden et al., 2017). The relative short observational satellite record makes it difficult to isolate natural variability from externally forced climate change. This renders e.g. assessing the bias in the long term trend of Arctic sea ice in EC-Earth, as done in chapter 5 , very difficult. Also, there remain large observational uncertainties of the ice pack because of difficulties in e.g. separating melt ponds from open water (e.g. Notz et al., 2013). Only in recent times can sea ice thickness be measured trough satellite remote sensing techniques (Laxon et al., 2013). However, these also contain large uncertainties due to difficulties in correctly measuring the sea ice freeboard because of the influence of snow thickness variations (e.g. Alexandrov et al., 2010). Because ensemble forecasts of Arctic sea ice sample the observational uncertainty, this automatically translates into larger uncertainties, thus lower skill, in seasonal forecasts (Bunzel et al., 2016). Hence, one of the most important aspects for the future of Arct climate change research is the continuation of satellite observations in the Arctic region, and to expand on measurement campaigns for detailed measurements of the Arctic climate.

With the Year of Polar Predictability (YOPP) there is already currently a period of intensive observing, modeling, prediction and verification which will hopefully increase our knowledge on the complex Arctic climate. It will also provide possibilities for more use of high-resolution models such as large eddy simulation (LES) and Direct Numerical Simulations (DNS), because the observations can be used to to set up multiple case studies. LES and DNS can aid in further understanding the complex processes, such as Arctic clouds (Pithan and Mauritsen, 2014), and use it to improve parameterizations of the large scale climate models (e.g. Ovchinnikov et al., 2014). This can lead to a better understanding of the mechanisms described in chapter 5 that, to a large extent, control Arctic climate model projections.

An important assumption in statistical calculations is that the sample on which a calculation is performed is taken from, in our case, independent climate models. We make this assumption in chapter 2 by taking the ensemble mean with equal weights to all models, and in chapter 4 by treating all models equal. However, the multi-model ensemble in both chapter 2 and 4 contain e.g. different versions of the same model, multiple models that use the either the same ocean model and or the same atmospheric model, or even both (Knutti et al., 2013). Hence, the models in a multimodel ensemble are not independent from each other. The actual degrees of freedom, i.e. sample size, is thus smaller than the number of models used. This implies that the actual sampling of the uncertainty of future climate projection due to model error is relatively small. Furthermore, the ensemble of models is constructed by modeling groups that all try to construct the best model possible, and not in an organized setting in order to get the best possible sampling of model errors. This most likely leads to an underestimation of the real climate uncertainty due to model error (Carslaw et al., 2018). Hence, as also advocated by Carslaw et al. (2018), climate model development should not only focus on creating the best model possible, but also on creating an ensemble of model versions that best sample the model error. 
Just as in weather forecasting in which a significant part of the model development is devoted to the ensemble generation. This would provide a much improved estimate of the uncertainty in climate projections, and a wealth of information on model sensitivities to perturbation in model parameters.

This research has aided in a better understanding of processes that provide predictability on seasonal to centennial time scales. This will ultimately lead to better navigability of the treacherous Arctic ocean and adjacent seas, and better constraints of climate model projections of the Arctic climate which can be used by policy makers to make improved mitigation and adaptation strategies. 


\section{Bibliography}

Abbe, C., 1901. The physical basis of long-range weather forecasts. Mon. Weather Rev. 29, 551-561. https://doi.org/10.1175/1520-0493(1901)29[551c:TPBOLW] 2.0.CO;2

Alexandrov, V., Sandven, S., Wahlin, J., Johannessen, O.M., 2010. The relation between sea ice thickness and freeboard in the Arctic. The Cryosphere 4, 373380. https://doi.org/10.5194/tc-4-373-2010

Alexeev, V.A., Langen, P.L., Bates, J.R., 2005. Polar amplification of surface warming on an aquaplanet in "ghost forcing" experiments without sea ice feedbacks. Clim. Dyn. 24, 655-666. https://doi.org/10.1007/s00382-005-0018-3

Andry, O., Bintanja, R., Hazeleger, W., 2016. Time-Dependent Variations in the Arctic's Surface Albedo Feedback and the Link to Seasonality in Sea Ice. J. Clim. 30, 393-410. https://doi.org/10.1175/JCLI-D-15-0849.1

Balmaseda, M.A., Mogensen, K., Weaver, A.T., 2013. Evaluation of the ECMWF ocean reanalysis system ORAS4. Q. J. R. Meteorol. Soc. 139, 1132-1161. https:// doi.org/10.1002/qj.2063

- Barnes Elizabeth A., 2013. Revisiting the evidence linking Arctic amplification to extreme weather in midlatitudes. Geophys. Res. Lett. 40, 4734-4739. https:// doi.org/10.1002/grl.50880

Bauer, P., Thorpe, A., Brunet, G. (2015) The quiet revolution of numerical weather prediction. Nature, 525, 47-55

Bintanja, R., Graversen, R.G., Hazeleger, W., 2011. Arctic winter warming amplified by the thermal inversion and consequent low infrared cooling to space. Nat. Geosci. 4, 758-761. https://doi.org/10.1038/ngeo1285

Bintanja, R., Krikken, F., 2016. Magnitude and pattern of Arctic warming governed by the seasonality of radiative forcing. Sci. Rep. 6, 38287. https://doi. org/10.1038/srep38287

Bintanja, R., Linden, E.C. van der, 2013. The changing seasonal climate in the Arctic. Sci. Rep. 3, 1556. https://doi.org/10.1038/srep01556

Bintanja, R., Selten, F.M., 2014. Future increases in Arctic precipitation linked to local evaporation and sea ice retreat. Nature 509, 479-482. https://doi. org/10.1038/nature13259

Bitz, C.M., Holland, M.M., Hunke, E.C., Moritz, R.E., 2005a. Maintenance of the sea ice Edge. J. Clim. 18, 2903-2921. https://doi.org/10.1175/JCLI3428.1

Bitz, C.M., Holland, M.M., Hunke, E.C., Moritz, R.E., 2005b. Maintenance of the sea ice Edge. J. Clim. 18, 2903-2921. https://doi.org/10.1175/JCLI3428.1

Bjerknes, V., 2009. The problem of weather prediction, considered from the viewpoints of mechanics and physics. Meteorol. Z. 663-667. https://doi. org/10.1127/0941-2948/2009/416

Blanchard-Wrigglesworth, E., Armour, K.C., Bitz, C.M., DeWeaver, E., 2010. Persistence and Inherent Predictability of Arctic Sea Ice in a GCM Ensemble and Observations. J. Clim. 24, 231-250. https://doi.org/10.1175/2010JCLI3775.1

Blanchard-Wrigglesworth, E., Cullather, R.I., Wang, W., Zhang, J., Bitz, C.M., 2015. Model forecast skill and sensitivity to initial conditions in the seasonal Sea Ice Outlook. Geophys. Res. Lett. 42, 2015GL065860. https://doi. 
org/10.1002/2015GL065860

Bodman Roger W., Rayner Peter J., Jones Roger N., 2016. How do carbon cycle uncertainties affect IPCC temperature projections? Atmospheric Sci. Lett. 17, 236-242. https://doi.org/10.1002/asl.648

- Boé, J., Hall, A., Qu, X., 2010. Sources of spread in simulations of Arctic sea ice loss over the twenty-first century. Clim. Change 99, 637-645. https://doi. org/10.1007/s10584-010-9809-6

Boer, G.J., Lambert, S.J., 2008. Multi-model decadal potential predictability of precipitation and temperature. Geophys. Res. Lett. 35, L05706. https://doi. org/10.1029/2008GL033234

- Bunzel Felix, Notz Dirk, Baehr Johanna, Müller Wolfgang A., Fröhlich Kristina, 2016. Seasonal climate forecasts significantly affected by observational uncertainty of Arctic sea ice concentration. Geophys. Res. Lett. 43, 852-859. https://doi.org/10.1002/2015GL066928

Burt, M.A., Randall, D.A., Branson, M.D., 2015. Dark Warming. J. Clim. 29, 705719. https://doi.org/10.1175/JCLI-D-15-0147.1

Bushuk Mitchell, Msadek Rym, Winton Michael, Vecchi Gabriel A., Gudgel Rich, Rosati Anthony, Yang Xiaosong, 2017. Skillful regional prediction of Arctic sea ice on seasonal timescales. Geophys. Res. Lett. 44, 4953-4964. https://doi.org/10.1002/2017GL073155

- Chevallier, M., Salas y Mélia, D., Voldoire, A., Déqué, M., Garric, G., 2013. Seasonal Forecasts of the Pan-Arctic Sea Ice Extent Using a GCM-Based Seasonal Prediction System. J. Clim. 26, 6092-6104. https://doi.org/10.1175/JCLID-12-00612.1

- Chevallier, M., Salas-Mélia, D., 2011. The Role of Sea Ice Thickness Distribution in the Arctic Sea Ice Potential Predictability: A Diagnostic Approach with a Coupled GCM. J. Clim. 25, 3025-3038. https://doi.org/10.1175/JCLID-11-00209.1

Climate Models Are Uncertain, but We Can Do Something About It [WWW Document], n.d. URL https://eos.org/opinions/climate-models-are-uncertainbut-we-can-do-something-about-it (accessed 5.3.18).

Cohen, J., Screen, J.A., Furtado, J.C., Barlow, M., Whittleston, D., Coumou, D., Francis, J., Dethloff, K., Entekhabi, D., Overland, J., Jones, J., 2014. Recent Arctic amplification and extreme mid-latitude weather. Nat. Geosci. 7, 627-637. https://doi.org/10.1038/ngeo2234

- Collins, M. et al. in Climate Change 2013: The Physical Science Basis. Contribution of Working Group I to the Fifth Assessment Report of the Intergovernmental Panel on Climate Change (eds Stocker, T. F. et al.) 1029-1136 (Cambridge Univ. Press, 2013)

Collow, T.W., Wang, W., Kumar, A., Zhang, J., 2015. Improving Arctic Sea Ice Prediction Using PIOMAS Initial Sea Ice Thickness in a Coupled Ocean-Atmosphere Model. Mon. Weather Rev. 143, 4618-4630. https://doi.org/10.1175/ MWR-D-15-0097.1

- Comiso, J.C., Hall, D.K., 2014. Climate trends in the Arctic as observed from space. Wiley Interdiscip. Rev. Clim. Change 5, 389-409. https://doi.org/10.1002/ wcc. 277

Corbett, J.J., Lack, D.A., Winebrake, J.J., Harder, S., Silberman, J.A., Gold, M., 2010. Arctic shipping emissions inventories and future scenarios. Atmos Chem Phys 10, 9689-9704. https://doi.org/10.5194/acp-10-9689-2010 
Cosimo, J.C., 2000. Bootstrap sea ice Concentrations from Nimbus-7 SMMR and DMSP SSM/I-SSMIS. Version 2. January 1978 to December 2013. Boulder, Colorado USA: NASA DAAC at the National Snow and Ice Data Center.

Cox, S.J., Stackhouse, P.W., Gupta, S.K., Mikovitz, J.C., Zhang, T., Davies, R., Egli, L., Schmutz, W., 2017. NASA/GEWEX shortwave surface radiation budget: Integrated data product with reprocessed radiance, cloud, and meteorology inputs, and new surface albedo treatment. AIP Conf. Proc. 1810, 090001. https:// doi.org/10.1063/1.4975541

Curry, J.A., Schramm, J.L., Ebert, E.E., 1993. Impact of clouds on the surface radiation balance of the Arctic Ocean. Meteorol. Atmospheric Phys. 51, 197-217. https://doi.org/10.1007/BF01030494

Day, J.J., Tietsche, S., Hawkins, E., 2014. Pan-Arctic and Regional Sea Ice Predictability: Initialization Month Dependence. J. Clim. 27, 4371-4390. https:// doi.org/10.1175/JCLI-D-13-00614.1

Dee, D.P., Uppala, S.M., Simmons, A.J., Berrisford, P., Poli, P., Kobayashi, S., Andrae, U., Balmaseda, M.A., Balsamo, G., Bauer, P., Bechtold, P., Beljaars, A.C.M., van de Berg, L., Bidlot, J., Bormann, N., Delsol, C., Dragani, R., Fuentes, M., Geer, A.J., Haimberger, L., Healy, S.B., Hersbach, H., Hólm, E.V., Isaksen, L., Kållberg, P., Köhler, M., Matricardi, M., McNally, A.P., Monge-Sanz, B.M., Morcrette, J.-J., Park, B.-K., Peubey, C., de Rosnay, P., Tavolato, C., Thépaut, J.-N., Vitart, F., 2011. The ERA-Interim reanalysis: configuration and performance of the data assimilation system. Q. J. R. Meteorol. Soc. 137, 553-597. https://doi.org/10.1002/qj.828

DeWeaver, E.T., Hunke, E.C., Holland, M.M., 2008. Comment on "On the reliability of simulated Arctic sea ice in global climate models" by I. Eisenman, N. Untersteiner, and J. S. Wettlaufer. Geophys. Res. Lett. 35, L04501. https://doi. org/10.1029/2007GL031325

Ding, Q., Schweiger, A., L'Heureux, M., Battisti, D.S., Po-Chedley, S., Johnson, N.C., Blanchard-Wrigglesworth, E., Harnos, K., Zhang, Q., Eastman, R., Steig, E.J., 2017. Influence of high-latitude atmospheric circulation changes on summertime Arctic sea ice. Nat. Clim. Change 7, 289-295. https://doi.org/10.1038/nclimate3241

Dirkson, A., Merryfield, W.J., Monahan, A., 2016. Impacts of Sea Ice Thickness Initialization on Seasonal Arctic Sea Ice Predictions. J. Clim. 30, 1001-1017. https://doi.org/10.1175/JCLI-D-16-0437.1

Eguíluz, V.M., Fernández-Gracia, J., Irigoien, X., Duarte, C.M., 2016. A quantitative assessment of Arctic shipping in 2010-2014. Sci. Rep. 6, 30682. https://doi. org/10.1038/srep30682

English, J.M., Gettelman, A., Henderson, G.R., 2015. Arctic Radiative Fluxes: Present-day biases and future projections in CMIP5 models. J. Clim. https://doi. org/10.1175/JCLI-D-14-00801.1

Fichefet, T., Maqueda, M.A.M., 1997. Sensitivity of a global sea ice model to the treatment of ice thermodynamics and dynamics. J. Geophys. Res. Oceans 102 , 12609-12646. https://doi.org/10.1029/97JC00480

Fischbach, A.S., Monson, D.H., Jay, C.V., n.d. Enumeration of Pacific Walrus Carcasses on Beaches of the Chukchi Sea in Alaska Following a Mortality Event, September 200918.

Fontela, M., García-Ibáñez, M.I., Hansell, D.A., Mercier, H., Pérez, F.F., 2016. Dissolved Organic Carbon in the North Atlantic Meridional Overturning 
Circulation. Sci. Rep. 6, srep26931. https://doi.org/10.1038/srep26931

Fossheim, M., Primicerio, R., Johannesen, E., Ingvaldsen, R.B., Aschan, M.M., Dolgov, A.V., 2015. Recent warming leads to a rapid borealization of fish communities in the Arctic. Nat. Clim. Change 5, 673-677. https://doi. org/10.1038/nclimate2647

Francis, J.A., Hunter, E., Key, J.R., Wang, X., 2005. Clues to variability in Arctic minimum sea ice extent. Geophys. Res. Lett. 32, L21501. https://doi. org/10.1029/2005GL024376

Francis Jennifer A., Vavrus Stephen J., 2012. Evidence linking Arctic amplification to extreme weather in mid-latitudes. Geophys. Res. Lett. 39. https://doi. org/10.1029/2012GL051000

Friedlingstein, P., Cox, P., Betts, R., Bopp, L., von Bloh, W., Brovkin, V., Cadule, P., Doney, S., Eby, M., Fung, I., Bala, G., John, J., Jones, C., Joos, F., Kato, T., Kawamiya, M., Knorr, W., Lindsay, K., Matthews, H.D., Raddatz, T., Rayner, P., Reick, C., Roeckner, E., Schnitzler, K.-G., Schnur, R., Strassmann, K., Weaver, A.J., Yoshikawa, C., Zeng, N., 2006. Climate-Carbon Cycle Feedback Analysis: Results from the C4MIP Model Intercomparison. J. Clim. 19, 3337-3353. https://doi. org/10.1175/JCLI3800.1

Fučkar, N.S., Volpi, D., Guemas, V., Doblas-Reyes, F.J., 2014. A posteriori adjustment of near-term climate predictions: Accounting for the drift dependence on the initial conditions. Geophys. Res. Lett. 41, 5200-5207. https://doi. org/10.1002/2014GL060815

Gautier, D.L., Bird, K.J., Charpentier, R.R., Grantz, A., Houseknecht, D.W., Klett, T.R., Moore, T.E., Pitman, J.K., Schenk, C.J., Schuenemeyer, J.H., Sørensen, K., Tennyson, M.E., Valin, Z.C., Wandrey, C.J., 2009. Assessment of Undiscovered Oil and Gas in the Arctic. Science 324, 1175-1179. https://doi.org/10.1126/ science. 1169467

Gilg Olivier, Kovacs Kit M., Aars Jon, Fort Jérôme, Gauthier Gilles, Grémillet David, Ims Rolf A., Meltofte Hans, Moreau Jérôme, Post Eric, Schmidt Niels Martin, Yannic Glenn, Bollache Loïc, 2012. Climate change and the ecology and evolution of Arctic vertebrates. Ann. N. Y. Acad. Sci. 1249, 166-190. https://doi. org/10.1111/j.1749-6632.2011.06412.x

Gorodetskaya, I.V., Tremblay, L.-B., 2008. Arctic Cloud Properties and Radiative Forcing from Observations and their Role in Sea Ice Decline Predicted by the NCAR CCSM3 Model During the 21 st Century, in: DeWeaver, E.T., Bitz, C.M., Tremblay, L.-B. (Eds.), Arctic Sea Ice Decline: Observations, Projections, Mechanisms, and Implications. American Geophysical Union, pp. 47-62.

Gosselin, M., Levasseur, M., Wheeler, P.A., Horner, R.A., Booth, B.C., 1997. New measurements of phytoplankton and ice algal production in the Arctic Ocean. Deep Sea Res. Part II Top. Stud. Oceanogr. 44, 1623-1644. https://doi. org/10.1016/S0967-0645(97)00054-4

- Graham, R.M., Cohen, L., Petty, A.A., Boisvert, L.N., Rinke, A., Hudson, S.R., Nicolaus, M., Granskog, M.A., 2017. Increasing frequency and duration of Arctic winter warming events. Geophys. Res. Lett. 44, 2017 GL073395. https://doi.org/10.1002/2017GL073395

Graversen, R.G., Burtu, M., 2016. Arctic amplification enhanced by latent energy transport of atmospheric planetary waves. Q. J. R. Meteorol. Soc. 142, 20462054. https://doi.org/10.1002/qj.2802 
Graversen, R.G., Mauritsen, T., Drijfhout, S., Tjernström, M., Mårtensson, S., 2010. Warm winds from the Pacific caused extensive Arctic sea ice melt in summer 2007. Clim. Dyn. 36, 2103-2112. https://doi.org/10.1007/s00382-010-0809-z Graversen, R.G., Wang, M., 2009. Polar amplification in a coupled climate model with locked albedo. Clim. Dyn. 33, 629-643. https://doi.org/10.1007/s00382009-0535-6

Grebmeier, J.M., Overland, J.E., Moore, S.E., Farley, E.V., Carmack, E.C., Cooper, L.W., Frey, K.E., Helle, J.H., McLaughlin, F.A., McNutt, S.L., 2006. A major ecosystem shift in the northern Bering Sea. Science 311, 1461-1464. https:// doi.org/10.1126/science.1121365

Guemas, V., Blanchard-Wrigglesworth, E., Chevallier, M., Day, J.J., Déqué, M., Doblas-Reyes, F.J., Fučkar, N.S., Germe, A., Hawkins, E., Keeley, S., Koenigk, T., Salas y Mélia, D., Tietsche, S., 2014a. A review on Arctic sea ice predictability and prediction on seasonal to decadal time-scales. Q. J. R. Meteorol. Soc. n/a-n/a. https://doi.org/10.1002/qj.2401

Guemas, V., Doblas-Reyes, F.J., Mogensen, K., Keeley, S., Tang, Y., 2014b. Ensemble of sea ice initial conditions for interannual climate predictions. Clim. Dyn. 43, 2813-2829. https://doi.org/10.1007/s00382-014-2095-7

Hall,A., 2004. The Role ofSurfaceAlbedoFeedbackinClimate.J.Clim. 17, 1550-1568. https://doi.org/10.1175/1520-0442(2004)017<1550:TROSAF> 2.0.CO;2

Hall, A., Qu, X., 2006. Using the current seasonal cycle to constrain snow albedo feedback in future climate change. Geophys. Res. Lett. 33, L03502. https://doi. org/10.1029/2005GL025127

Hazeleger, W., Severijns, C., Semmler, T., Ştefănescu, S., Yang, S., Wang, X., Wyser, K., Dutra, E., Baldasano, J.M., Bintanja, R., Bougeault, P., Caballero, R., Ekman, A.M.L., Christensen, J.H., van den Hurk, B., Jimenez, P., Jones, C., Kållberg, P., Koenigk, T., McGrath, R., Miranda, P., Van Noije, T., Palmer, T., Parodi, J.A., Schmith, T., Selten, F., Storelvmo, T., Sterl, A., Tapamo, H., Vancoppenolle, M., Viterbo, P., Willén, U., 2010. EC-Earth: A Seamless Earth-System Prediction Approach in Action. Bull. Am. Meteorol. Soc. 91, 1357-1363. https://doi. org/10.1175/2010BAMS2877.1

Hazeleger, W., Wang, X., Severijns, C., Ştefănescu, S., Bintanja, R., Sterl, A., Wyser, K., Semmler, T., Yang, S., Hurk, B. van den, Noije, T. van, Linden, E. van der, Wiel, K. van der, 2011. EC-Earth V2.2: description and validation of a new seamless earth system prediction model. Clim. Dyn. 39, 2611-2629. https://doi. org/10.1007/s00382-011-1228-5

Held, I.M., 1978. The Tropospheric Lapse Rate and Climatic Sensitivity: Experiments with a Two-Level Atmospheric Model. J. Atmospheric Sci. 35, $2083-$ 2098. https://doi.org/10.1 175/1520-0469(1978)035<2083:TTLRAC>2.0.CO;2

Hezel, P.J., Zhang, X., Bitz, C.M., Kelly, B.P., Massonnet, F., 2012. Projected decline in spring snow depth on Arctic sea ice caused by progressively later autumn open ocean freeze-up this century. Geophys. Res. Lett. 39, L17505. https://doi.org/10.1029/2012GL052794

Hodson, D.L.R., Keeley, S.P.E., West, A., Ridley, J., Hawkins, E., Hewitt, H.T., 2013. Identifying uncertainties in Arctic climate change projections. Clim. Dyn. 40, 2849-2865. https://doi.org/10.1007/s00382-012-1512-z

Hoegh-Guldberg, O., Bruno, J.F., 2010. The Impact of Climate Change on the 
World's Marine Ecosystems. Science 328, 1523-1528. https://doi.org/10.1126/ science. 1189930

Holland, M.M., Bailey, D.A., Vavrus, S., 2011 . Inherent sea ice pre

Holtslag, A. a. M., Svensson, G., Baas, P., Basu, S., Beare, B., Beljaars, A.C.M., Bosveld, F.C., Cuxart, J., Lindvall, J., Steeneveld, G.J., Tjernström, M., Van De Wiel, B.J.H., 2013. Stable Atmospheric Boundary Layers and Diurnal Cycles: Challenges for Weather and Climate Models. Bull. Am. Meteorol. Soc. 94, 1691-1706. https://doi.org/10.1175/BAMS-D-11-00187.1

Hopsch, S., Cohen, J., Dethloff, K., 2012. Analysis of a link between fall Arctic sea ice concentration and atmospheric patterns in the following winter. Tellus Dyn. Meteorol. Oceanogr. 64, 18624. https://doi.org/10.3402/tellusa.v64i0.18624 IPCC climate models do not capture Arctic sea ice drift acceleration: Consequences in terms of projected sea ice thinning and decline - Rampal - 2011 - Journal of Geophysical Research: Oceans - Wiley Online Library [WWW Document], n.d. URL http://onlinelibrary.wiley.com/doi/10.1029/2011JC007110/abstract (accessed 2.1.18).

Jackson, L., A. Wood, R., 2017. Timescales of AMOC decline in response to fresh water forcing. Clim. Dyn. https://doi.org/10.1007/s00382-017-3957-6

Ji, R., Jin, M., Varpe, Ø., 2013. Sea ice phenology and timing of primary production pulses in the Arctic Ocean. Glob. Change Biol. 19, 734-741. https:// doi.org/10.1111/gcb.12074

Kapsch, M.-L., Graversen, R.G., Economou, T., Tjernström, M., 2014. The importance of spring atmospheric conditions for predictions of the Arctic summer sea ice extent. Geophys. Res. Lett. 41, 5288-5296. https://doi. org/10.1002/2014GL060826

Kapsch, M.-L., Graversen, R.G., Tjernström, M., 2013. Springtime atmospheric energy transport and the control of Arctic summer sea ice extent. Nat. Clim. Change 3, 744-748. https://doi.org/10.1038/nclimate1884

Kapsch, M.-L., Graversen, R.G., Tjernström, M., Bintanja, R., 2015. The Effect of Downwelling Longwave and Shortwave Radiation on Arctic Summer Sea Ice. J. Clim. 29, 1143-1159. https://doi.org/10.1175/JCLI-D-15-0238.1

Kay, J.E., Gettelman, A., 2009. Cloud influence on and response to seasonal Arctic sea ice loss. J. Geophys. Res. Atmospheres 114, D18204. https://doi. org/10.1029/2009JD011773

Kay, J.E., L’Ecuyer, T., Chepfer, H., Loeb, N., Morrison, A., Cesana, G., 2016. Recent Advances in Arctic Cloud and Climate Research. Curr. Clim. Change Rep. 2, 159-169. https://doi.org/10.1007/s40641-016-0051-9

Kay, J.E., L'Ecuyer, T., Gettelman, A., Stephens, G., O'Dell, C., 2008. The contribution of cloud and radiation anomalies to the 2007 Arctic sea ice extent minimum. Geophys. Res. Lett. 35, L08503. https://doi.org/10.1029/2008GL033451

- Kelly, B.P., Whiteley, A., Tallmon, D., 2010. The Arctic melting pot. Nature 468, 891-891. https://doi.org/10.1038/468891a

Kerby, J.T. and E. Post. 2013. Advancing plant phenology and reduced herbivore production in a terrestrial system associated with sea ice decline. Nature Communications doi: 10.1038/ncomms3514.

Khan, S.A., Kjær, K.H., Bevis, M., Bamber, J.L., Wahr, J., Kjeldsen, K.K., Bjørk, A.A., Korsgaard, N.J., Stearns, L.A., Broeke, M.R. van den, Liu, L., Larsen, N.K., 
Muresan, I.S., 2014. Sustained mass loss of the northeast Greenland ice sheet triggered by regional warming. Nat. Clim. Change 4, 292-299. https://doi. org/10.1038/nclimate2 161

Kharin, V.V., Boer, G.J., Merryfield, W.J., Scinocca, J.F., Lee, W.-S., 2012. Statistical adjustment of decadal predictions in a changing climate. Geophys. Res. Lett. 39, L1 9705. https://doi.org/10.1029/2012GL052647

Knutti Reto, Masson David, Gettelman Andrew, 2013. Climate model genealogy: Generation CMIP5 and how we got there. Geophys. Res. Lett. 40, 1194-1199. https://doi.org/10.1002/grl.50256

Kobayashi, S., Ota, Y., Harada, Y., Ebita, A., Moriya, M., Onoda, H., Onogi, K., Kamahori, H., Kobayashi, C., Endo, H., Miyaoka, K., Takahashi, K., 2015. The JRA55 Reanalysis: General Specifications and Basic Characteristics. J. Meteorol. Soc. Jpn. Ser II 93, 5-48. https://doi.org/10.2151/jmsj.2015-001

Krikken, F., Hazeleger, W., 2015. Arctic Energy Budget in Relation to Sea Ice Variability on Monthly-to-Annual Time Scales. J. Clim. 28, 6335-6350. https:// doi.org/10.1175/JCLI-D-15-0002.1

Kwok, R., Spreen, G., Pang, S., 2013. Arctic sea ice circulation and drift speed: Decadal trends and ocean currents. J. Geophys. Res. Oceans 118, 2408-2425. https://doi.org/10.1002/jgrc.20191

Lameris, T.K., Scholten, I., Bauer, S., Cobben, M.M.P., Ens, B.J., Nolet, B.A., n.d. Potential for an Arctic-breeding migratory bird to adjust spring migration phenology to Arctic amplification. Glob. Change Biol. n/a-n/a. https://doi.org/10.1111/gcb.13684

Laxon, S.W., Giles, K.A., Ridout, A.L., Wingham, D.J., Willatt, R., Cullen, R., Kwok, R., Schweiger, A., Zhang, J., Haas, C., Hendricks, S., Krishfield, R., Kurtz, N., Farrell, S., Davidson, M., 2013 . CryoSat-2 estimates of Arctic sea ice thickness and volume. Geophys. Res. Lett. 40, 732-737. https://doi.org/10.1002/grl.50193

Linden Eveline C., Bintanja Richard, Hazeleger Wilco, 2017. Arctic decadal variability in a warming world. J. Geophys. Res. Atmospheres 122, 5677-5696. https://doi.org/10.1002/2016JD026058

Lindsay, R., Wensnahan, M., Schweiger, A., Zhang, J., 2014. Evaluation of Seven Different Atmospheric Reanalysis Products in the Arctic*. J. Clim. 27, 2588-2606. https://doi.org/10.1175/JCLI-D-13-00014.1

Lindsay, R.W., Zhang, J., Schweiger, A.J., Steele, M.A., 2008. Seasonal predictions of ice extent in the Arctic Ocean. J. Geophys. Res. Oceans 113, C02023. https:// doi.org/10.1029/2007JC004259

Liu, M., Kronbak, J., 2010. The potential economic viability of using the Northern Sea Route (NSR) as an alternative route between Asia and Europe. J. Transp. Geogr., Tourism and climate change 18, 434-444. https://doi.org/10.1016/j.jtrangeo.2009.08.004

Lorenz, E.N., 1963. Deterministic Nonperiodic Flow. J. Atmospheric Sci. 20, $130-$ 141. https://doi.org/10.1175/1520-0469(1963)020<0130:DNF>2.0.CO;2

Lu, J., Cai, M., 2010. Quantifying contributions to polar warming amplification in an idealized coupled general circulation model. Clim. Dyn. 34, 669-687. https:// doi.org/10.1007/s00382-009-0673-x

Lynch, P., 2008. The origins of computer weather prediction and climate modeling. J. Comput. Phys., Predicting weather, climate and extreme events 227, 
3431-3444. https://doi.org/10.1016/j.jcp.2007.02.034

Mahajan, S., Zhang, R., Delworth, T.L., 2011 . Impact of the Atlantic Meridional Overturning Circulation (AMOC) on Arctic Surface Air Temperature and Sea Ice Variability. J. Clim. 24, 6573-6581. https://doi.org/10.1175/2011JCLI4002.1

Mahlstein, I., Knutti, R., 2011. Ocean Heat Transport as a Cause for Model Uncertainty in Projected Arctic Warming. J. Clim. - J Clim. 24, 1451-1460. https:// doi.org/10.1175/2010JCLI3713.1

Manabe, S., Stouffer, R.J., 1980. Sensitivity of a global climate model to an increase of $\mathrm{CO} 2$ concentration in the atmosphere. J. Geophys. Res. Oceans 85 , 5529-5554. https://doi.org/10.1029/JC085iC10p05529

Massonnet, F., Fichefet, T., Goosse, H., Bitz, C.M., Philippon-Berthier, G., Holland, M.M., Barriat, P.-Y., 2012. Constraining projections of summer Arctic sea ice. The Cryosphere 6, 1383-1394. https://doi.org/10.5194/tc-6-1383-2012

Meehl, G.A., Goddard, L., Boer, G., Burgman, R., Branstator, G., Cassou, C., Corti, S., Danabasoglu, G., Doblas-Reyes, F., Hawkins, E., Karspeck, A., Kimoto, M., Kumar, A., Matei, D., Mignot, J., Msadek, R., Navarra, A., Pohlmann, H., Rienecker, M., Rosati, T., Schneider, E., Smith, D., Sutton, R., Teng, H., van Oldenborgh, G.J., Vecchi, G., Yeager, S., 2013. Decadal Climate Prediction: An Update from the Trenches. Bull. Am. Meteorol. Soc. 95, 243-267. https://doi.org/10.1175/ BAMS-D-12-00241.1

Meehl, G.A., Goddard, L., Murphy, J., Stouffer, R.J., Boer, G., Danabasoglu, G., Dixon, K., Giorgetta, M.A., Greene, A.M., Hawkins, E., Hegerl, G., Karoly, D., Keenlyside, N., Kimoto, M., Kirtman, B., Navarra, A., Pulwarty, R., Smith, D., Stammer, D., Stockdale, T., 2009. Decadal Prediction. Bull. Am. Meteorol. Soc. 90, 1467-1485. https://doi.org/10.1175/2009BAMS2778.1

Melia, N., Haines, K., Hawkins, E., 2016. Sea ice decline and 21 st century transArctic shipping routes. Geophys. Res. Lett. 43, 2016GL069315. https://doi. org/10.1002/2016GL069315

Messner, J.W., Mayr, G.J., Zeileis, A., Wilks, D.S., 2014. Heteroscedastic Extended Logistic Regression for Postprocessing of Ensemble Guidance. Mon. Weather Rev. 142, 448-456. https://doi.org/10.1175/MWR-D-13-00271.1

Moody, A.T., Hobson, K.A., Gaston, A.J., 2012. High-arctic seabird trophic variation revealed through long-term isotopic monitoring. J. Ornithol. 153, 10671078. https://doi.org/10.1007/s10336-012-0836-0

Moss, R.H., Edmonds, J.A., Hibbard, K.A., Manning, M.R., Rose, S.K., Vuuren, D.P. van, Carter, T.R., Emori, S., Kainuma, M., Kram, T., Meehl, G.A., Mitchell, J.F.B., Nakicenovic, N., Riahi, K., Smith, S.J., Stouffer, R.J., Thomson, A.M., Weyant, J.P., Wilbanks, T.J., 2010. The next generation of scenarios for climate change research and assessment. Nature 463, 747-756. https://doi.org/10.1038/nature08823

Notz, D., Haumann, A., Haak, H., H. Jungclaus, J., Marotzke, J., 2013. Arctic sea ice evolution as modeled by Max Planck Institute for Meteorology's Earth system model. J. Adv. Model. Earth Syst. 5. https://doi.org/10.1002/jame.20016

Oldenborgh, G.J., Doblas-Reyes, F.J., Wouters, B., Hazeleger, W., 2012. Decadal prediction skill in a multi-model ensemble. Clim. Dyn. 38, 1263-1280. https:// doi.org/10.1007/s00382-012-1313-4

On the structure and evolution of ENSO related climate variability in the tropical Pacific: - Lessons from TOGA - Wallace - 1998 - Journal of Geophysical Research: 
Oceans - Wiley Online Library [WWW Document], n.d. URL https://agupubs. onlinelibrary.wiley.com/doi/abs/10.1029/97JC02905 (accessed 5.6.18).

Ovchinnikov Mikhail, Ackerman Andrew S., Avramov Alexander, Cheng Anning, Fan Jiwen, Fridlind Ann M., Ghan Steven, Harrington Jerry, Hoose Corinna, Korolev Alexei, McFarquhar Greg M., Morrison Hugh, Paukert Marco, Savre Julien, Shipway Ben J., Shupe Matthew D., Solomon Amy, Sulia Kara, 2014. Intercomparison of large-eddy simulations of Arctic mixed-phase clouds: Importance of ice size distribution assumptions. J. Adv. Model. Earth Syst. 6, 223-248. https://doi. org/10.1002/2013MS000282

Overland, J., Francis, J.A., Hall, R., Hanna, E., Kim, S.-J., Vihma, T., 2015. The Melting Arctic and Midlatitude Weather Patterns: Are They Connected? J. Clim. 28, 7917-7932. https://doi.org/10.1175/JCLI-D-14-00822.1

Overland, J.E., Wang, M., 2013. When will the summer Arctic be nearly sea ice free? Geophys. Res. Lett. 40, 2097-2101. https://doi.org/10.1002/grl.50316

Overland, J.E., Wang, M., 2010. Large-scale atmospheric circulation changes are associated with the recent loss of Arctic sea ice. Tellus A 62, 1-9. https://doi. org/10.1111/j.1600-0870.2009.00421.x

Palmer T. N., 2006. The economic value of ensemble forecasts as a tool for risk assessment: From days to decades. Q. J. R. Meteorol. Soc. 128, 747-774. https:// doi.org/10.1256/0035900021643593

Perovich Donald K., Light Bonnie, Eicken Hajo, Jones Kathleen F., Runciman Kay, Nghiem Son V., 2007. Increasing solar heating of the Arctic Ocean and adjacent seas, 1979-2005: Attribution and role in the ice-albedo feedback. Geophys. Res. Lett. 34. https://doi.org/10.1029/2007GL031480

Pithan, F., Ackerman, A., Angevine, W.M., Hartung, K., Ickes, L., Kelley, M., Medeiros, B., Sandu, I., Steeneveld, G.-J., Sterk, H. a. M., Svensson, G., Vaillancourt, P.A., Zadra, A., 2016. Select strengths and biases of models in representing the Arctic winter boundary layer over sea ice: the Larcform 1 single column model intercomparison. J. Adv. Model. Earth Syst. 8, 1345-1357. https://doi. org/10.1002/2016MS000630

Pithan, F., Mauritsen, T., 2014. Arctic amplification dominated by temperature feedbacks in contemporary climate models. Nat. Geosci. 7, 181-184. https://doi. org/10.1038/ngeo2071

Pithan, F., Medeiros, B., Mauritsen, T., 2013. Mixed-phase clouds cause climate model biases in Arctic wintertime temperature inversions. Clim. Dyn. 43, 289303. https://doi.org/10.1007/s00382-013-1964-9 Post, E., Bhatt, U.S., Bitz, C.M., Brodie, J.F., Fulton, T.L., Hebblewhite, M., Kerby, J., Kutz, S.J., Stirling, I., Walker, D.A., 2013. Ecological Consequences of sea ice Decline. Science 341, 519-524. https://doi.org/10.1126/science.1235225

Qu, X., Hall, A., 2014. On the persistent spread in snow-albedo feedback. Clim. Dyn. 42, 69-81. https://doi.org/10.1007/s00382-013-1774-0

Qu, X., Hall, A., 2007. What Controls the Strength of Snow-Albedo Feedback? J. Clim. 20, 3971-3981. https://doi.org/10.1175/JCLI4186.1

- Radiative forcing and climate response, 1997. . J. Geophys. Res. Atmospheres 102, 6831-6864. https://doi.org/10.1029/96JD03436

Raftery, A.E., Gneiting, T., Balabdaoui, F., Polakowski, M., 2005. Using Bayesian model averaging to calibrate forecast ensembles. 
Rojas-Romagosa, H., Bekkers, E., Francois, J.F., 2015. Melting Ice Caps and the Economic Impact of Opening the Northern Sea Route (CPB Discussion Paper No. 307). CPB Netherlands Bureau for Economic Policy Analysis.

Roulston, M.S., Smith, L.A., 2003. Combining dynamical and statistical ensembles. Tellus Dyn. Meteorol. Oceanogr. 55, 16-30. https://doi.org/10.3402/tellusa. v55i1.12082

Saha, S., Moorthi, S., Pan, H.-L., Wu, X., Wang, Jiande, Nadiga, S., Tripp, P., Kistler, R., Woollen, J., Behringer, D., Liu, H., Stokes, D., Grumbine, R., Gayno, G., Wang, Jun, Hou, Y.-T., Chuang, H.-Y., Juang, H.-M.H., Sela, J., Iredell, M., Treadon, R., Kleist, D., Van Delst, P., Keyser, D., Derber, J., Ek, M., Meng, J., Wei, H., Yang, R., Lord, S., Van Den Dool, H., Kumar, A., Wang, W., Long, C., Chelliah, M., Xue, Y., Huang, B., Schemm, J.-K., Ebisuzaki, W., Lin, R., Xie, P., Chen, M., Zhou, S., Higgins, W., Zou, C.-Z., Liu, Q., Chen, Y., Han, Y., Cucurull, L., Reynolds, R.W., Rutledge, G., Goldberg, M., 2010. The NCEP Climate Forecast System Reanalysis. Bull. Am. Meteorol. Soc. 91, 1015-1057. https://doi.org/10.1175/2010BAMS3001.1

Sand, M., Berntsen, T.K., Kay, J.E., Lamarque, J.F., Seland, Ø., Kirkevåg, A., 2013. The Arctic response to remote and local forcing of black carbon. Atmos Chem Phys 13, 211-224. https://doi.org/10.5194/acp-13-211-2013

Schmeits, M.J., Kok, K.J., 2010. A Comparison between Raw Ensemble Output, (Modified) Bayesian Model Averaging, and Extended Logistic Regression Using ECMWF Ensemble Precipitation Reforecasts. Mon. Weather Rev. 138, 4199-4211. https://doi.org/10.1175/2010MWR3285.1

Schröder, D., Feltham, D.L., Flocco, D., Tsamados, M., 2014. September Arctic sea ice minimum predicted by spring melt-pond fraction. Nat. Clim. Change 4, 353-357. https://doi.org/10.1038/nclimate2203

Screen, J.A., Francis, J.A., 2016. Contribution of sea ice loss to Arctic amplification is regulated by Pacific Ocean decadal variability. Nat. Clim. Change 6, 856-860. https://doi.org/10.1038/nclimate3011

Screen, J.A., Simmonds, I., 2010. The central role of diminishing sea ice in recent Arctic temperature amplification. Nature 464, 1334-1337. https://doi. org/10.1038/nature09051

Screen James A., Simmonds Ian, 2013. Exploring links between Arctic amplification and mid-latitude weather. Geophys. Res. Lett. 40, 959-964. https:// doi.org/10.1002/grl.50174

Seitola, T., Järvinen, H., 2014. Decadal climate variability and potential predictability in the Nordic region.

Sejas, S.A., Cai, M., Hu, A., Meehl, G.A., Washington, W., Taylor, P.C., 2014. Individual Feedback Contributions to the Seasonality of Surface Warming. J. Clim. 27, 5653-5669. https://doi.org/10.1175/JCLI-D-13-00658.1

Serreze, M.C., Barry, R.G., 2014. The Arctic Climate System, 2 edition. ed. Cambridge University Press, New York, NY, USA.

Serreze, M.C., Holland, M.M., Stroeve, J., 2007. Perspectives on the Arctic's Shrinking sea ice Cover. Science 315, 1533-1536. https://doi.org/10.1126/ science. 1139426

Serreze, M.C., Stroeve, J., 2015. Arctic sea ice trends, variability and implications for seasonal ice forecasting. Philos. Trans. R. Soc. Lond. Ser. A 373, 20140159 20140159. https://doi.org/10.1098/rsta.2014.0159 
Shakhova, N., Semiletov, I., Salyuk, A., Yusupov, V., Kosmach, D., Gustafsson, Ö., 2010. Extensive Methane Venting to the Atmosphere from Sediments of the East Siberian Arctic Shelf. Science 327, 1246-1250. https://doi.org/10.1126/ science. 1182221

Shimada, K., Kamoshida, T., Itoh, M., Nishino, S., Carmack, E., McLaughlin, F., Zimmermann, S., Proshutinsky, A., 2006. Pacific Ocean inflow: Influence on catastrophic reduction of sea ice cover in the Arctic Ocean. Geophys. Res. Lett. 33, L08605. https://doi.org/10.1029/2005GL025624

Shine, K.P., 1984. Parametrization of the shortwave flux over high albedo surfaces as a function of cloud thickness and surface albedo. Q. J. R. Meteorol. Soc. 110 , 747-764. https://doi.org/10.1002/qj.49711046511

Sigmond, M., Fyfe, J.C., Flato, G.M., Kharin, V.V., Merryfield, W.J., 2013. Seasonal forecast skill of Arctic sea ice area in a dynamical forecast system. Geophys. Res. Lett. 40, 529-534. https://doi.org/10.1002/grl.50129

Skill and relative economic value of the ECMWF ensemble prediction system Richardson - 2000 - Quarterly Journal of the Royal Meteorological Society - Wiley Online Library [WWW Document], n.d. URL https://rmets.onlinelibrary.wiley.com/ doi/full/10.1002/qj.49712656313 (accessed 5.6.18).

Smith, D.M., Cusack, S., Colman, A.W., Folland, C.K., Harris, G.R., Murphy, J.M., 2007. Improved surface temperature prediction for the coming decade from a global climate model. Science 317, 796-799. https://doi.org/10.1126/ science. 1139540

Statistical Methods in the Atmospheric Sciences, 3rd Edition | Daniel Wilks | ISBN 9780123850225 [WWW Document], n.d. URL http://store.elsevier.com/StatisticalMethods-in-the-Atmospheric-Sciences/Daniel-Wilks/isbn-9780123850225/ (accessed 2.18.16).

Stephenson, S.R., Smith, L.C., Brigham, L.W., Agnew, J.A., 2013. Projected 21 stcentury changes to Arctic marine access. Clim. Change 118, 885-899. https:// doi.org/10.1007/s10584-012-0685-0

Sterl, A., Bintanja, R., Brodeau, L., Gleeson, E., Koenigk, T., Schmith, T., Semmler, T., Severijns, C., Wyser, K., Yang, S., 2011. A look at the ocean in the EC-Earth climate model. Clim. Dyn. 39, 2631-2657. https://doi.org/10.1007/s00382$011-1239-2$

Stirling, I., Derocher, A.E., 2012. Effects of climate warming on polar bears: a review of the evidence. Glob. Change Biol. 18, 2694-2706. https://doi. org/10.1111/j.1365-2486.2012.02753.x

Stockdale, T.N., Molteni, F., Ferranti, L., 2015. Atmospheric initial conditions and the predictability of the Arctic Oscillation. Geophys. Res. Lett. 42, 2014 GL062681. https://doi.org/10.1002/2014GL062681

Stroeve, J.C., Kattsov, V., Barrett, A., Serreze, M., Pavlova, T., Holland, M., Meier, W.N., 2012. Trends in Arctic sea ice extent from CMIP5, CMIP3 and observations. Geophys. Res. Lett. 39, L16502. https://doi.org/10.1029/2012GL052676

Stroeve Julienne C., Maslanik James, Serreze Mark C., Rigor Ignatius, Meier Walter, Fowler Charles, 2011. Sea ice response to an extreme negative phase of the Arctic Oscillation during winter 2009/2010. Geophys. Res. Lett. 38. https://doi.org/10.1029/2010GL045662

Stroeve Julienne, Holland Marika M., Meier Walt, Scambos Ted, Serreze Mark, 
2007. Arctic sea ice decline: Faster than forecast. Geophys. Res. Lett. 34. https:// doi.org/10.1029/2007GL029703

Taylor, K.E., Stouffer, R.J., Meehl, G.A., 2011. An Overview of CMIP5 and the Experiment Design. Bull. Am. Meteorol. Soc. 93, 485-498. https://doi. org/10.1175/BAMS-D-11-00094.1

· $\quad$ Tietsche, S., Day, J.J., Guemas, V., Hurlin, W.J., Keeley, S.P.E., Matei, D., Msadek, R., Collins, M., Hawkins, E., 2014. Seasonal to interannual Arctic sea ice predictability in current global climate models. Geophys. Res. Lett. 41, 1035-1043. https:// doi.org/10.1002/2013GL058755

- Tschudi, M.A., Stroeve, J.C., Stewart, J.S., 2016. Relating the Age of Arctic Sea Ice to its Thickness, as Measured during NASA's ICESat and IceBridge Campaigns. Remote Sens. 8, 457. https://doi.org/10.3390/rs8060457

van der Linden, E.C., Bintanja, R., Hazeleger, W., Katsman, C.A., 2014. The Role of the Mean State of Arctic Sea Ice on Near-Surface Temperature Trends. J. Clim. 27, 2819-2841. https://doi.org/10.1175/JCLI-D-12-00617.1

Walsh, J.E., 2014. Intensified warming of the Arctic: Causes and impacts on middle latitudes. Glob. Planet. Change 117, 52-63. https://doi.org/10.1016/j. gloplacha.2014.03.003

Walsh, J.E., Fetterer, F., Scott Stewart, J., Chapman, W.L., n.d. A database for depicting Arctic sea ice variations back to 1850. Geogr. Rev. n/a-n/a. https://doi. org/10.1111/j.1931-0846.2016.12195.x

Wang, W., Chen, M., Kumar, A., 2012. Seasonal Prediction of Arctic Sea Ice Extent from a Coupled Dynamical Forecast System. Mon. Weather Rev. 141, 1375-1394. https://doi.org/10.1175/MWR-D-12-00057.1

Whiteman, G., Hope, C., Wadhams, P., 2013. Climate science: Vast costs of Arctic change. Nature 499, 401-403. https://doi.org/10.1038/499401a

Wielicki, B.A., Barkstrom, B.R., Baum, B.A., Charlock, T.P., Green, R.N., Kratz, D.P., Lee, R.B., Minnis, P., Smith, G.L., Wong, T., Young, D.F., Cess, R.D., Coakley, J.A., Crommelynck, D.A.H., Donner, L., Kandel, R., King, M.D., Miller, A.J., Ramanathan, V., Randall, D.A., Stowe, L.L., Welch, R.M., 1998. Clouds and the Earth's Radiant Energy System (CERES): algorithm overview. IEEE Trans. Geosci. Remote Sens. 36, 1127-1141. https://doi.org/10.1109/36.701020

Wilks, D.S., 2009. Extending logistic regression to provide full-probabilitydistribution MOS forecasts. Meteorol. Appl. 16, 361-368. https://doi. org/10.1002/met.134

- Winton, M., 2006. Amplified Arctic climate change: What does surface albedo feedback have to do with it? Geophys. Res. Lett. 33. https://doi. org/10.1029/2005GL025244

Woods, C., Caballero, R., 2016. The Role of Moist Intrusions in Winter Arctic Warming and Sea Ice Decline. J. Clim. 29, 4473-4485. https://doi.org/10.1175/ JCLI-D-15-0773.1

- Yan, Q., Wang, H., Johannessen, O.M., Zhang, Z., 2014. Greenland ice sheet contribution to future global sea level rise based on CMIP5 models. Adv. Atmospheric Sci. 31, 8-16. https://doi.org/10.1007/s00376-013-3002-6

- Yeager, S.G., Karspeck, A.R., Danabasoglu, G., 2015. Predicted slowdown in the rate of Atlantic sea ice loss. Geophys. Res. Lett. 2015GL065364. https://doi. org/10.1002/2015GL065364 
- Zygmuntowska, M., Mauritsen, T., Quaas, J., Kaleschke, L., 2012. Arctic Clouds and Surface Radiation - a critical comparison of satellite retrievals and the ERA-Interim reanalysis. Atmos Chem Phys 12, 6667-6677. https://doi.org/10.5194/acp-12-6667-2012 


\section{Dankwoord}

In mijn dankwoord wil ik graag iedereen bedanken die heeft bijgedragen bij de totstandkoming van deze thesis.

In eerste instantie is dat mijn promotor, Wilco. Door middel van je inhoudelijke kennis en ervaring heb je zowel de inhoud als het traject van mijn promotie heel goed begeleid. Door een goeie combinatie van geduld, ongeduld en inlevingsvermogen heb ik jouw begeleiding als erg fijn ervaren. Ik heb dan ook erg veel van je geleerd over de afgelopen jaren en ben daar erg dankbaar voor.

In tweede instantie is dat mijn co-promotor, Richard. Vanuit de vraag of ik zin had om misschien samen met jou naar een leuk gevoeligheidsonderzoekje met EC-Earth te kijken zijn twee leuke en goeie hoofdstukken gekomen, die mijn oorspronkelijke planning compleet overhoop gooiden. Ik heb veel geleerd van je schrijfkunsten, maar vooral hoe je op een relaxte en luchtige manier heel productief en efficient kan zijn. Voor al deze dingen, waaronder het omgooien van mijn oorspronkelijke planning, ben ik je erg dankbaar.

Verder wil ik graag alle oud-collega's van MAQ bedanken voor de gezellige en leerzame tijd op de vakgroep. Bert Holtslag, bedankt voor je hulp tijdens het solliciatietraject en tijdens mijn thesis. Gert-Jan, bedankt voor je hulp bij mijn eerste publicatie en daarbij mijn eerste echte contact met wetenschappelijk onderzoek. Ook wil ik mijn huidige collega's op het KNMI bedanken, waar het nog steeds erg gezellig is en ik ook nog veel leer. Geert Jan, bedankt voor je begrip dat er af en toe ook nog wat tijd werd gestoken in het afronden van mijn proefschrift.

En natuurlijk mijn familie en vrienden, waar ik juist even lekker uit het phd-leven kon stappen en we het over hele andere dingen konden hebben.

Verder wil ik graag mijn 'Lieve Linde' bedankten voor al haar steun tijdens de afgelopen jaren. Er is het nodige veranderd in ons leven de afgelopen jaren wat vooral erg leuk was, maar niet altijd makkelijk te combineren met een phd-student tijdens de laatste fase van zijn promotie. Maar met jouw hulp en geduld hebben we het toch maar mooi gedaan!

\section{About the author}

Folmer Krikken was born on the $1^{\text {st }}$ of January 1985 in Nyland, the Netherlands. He attended the secondary school at the RSG Magister Alvinus in Sneek, and obtained a vwo diploma in 2005. In 2007 he started the bachelor study Soil, Water and Atmosphere on Wageningen University, and graduated in 2012 on the master 'Meteorology and Air quality'. After the graduation Folmer started his PhD, also at Wageningen University, on seasonal to decadal predictions of Arctic sea ice, which resulted in this thesis. From 2017 onwards, Folmer is working as a postdoc at KNMI on seasonal predictions and climate change of forest fire risks. 


\section{List of journal publications}

- Bintanja, R., Krikken, F., 2016. Magnitude and pattern of Arctic warming governed by the seasonality of radiative forcing. Sci. Rep. 6, 38287. https://doi.org/10.1038/srep38287

- Krikken, F., Hazeleger, W., 2015. Arctic Energy Budget in Relation to Sea Ice Variability on Monthly-to-Annual Time Scales. J. Clim. 28, 6335-6350. https://doi.org/10.1175/JCLI-D-15-0002.1

- Krikken, F., Schmeits, M., Vlot, W., Guemas, V., Hazeleger, W., 2016. Skill improvement of dynamical seasonal Arctic sea ice forecasts. Geophys. Res. Lett. 43, 2016GL068462. https://doi.org/10.1002/2016GL068462

- Krikken, F., Steeneveld, G.-J., 2012. Modelling the re-intensification of tropical storm Erin (2007) over Oklahoma: understanding the key role of downdraft formulation. Tellus Dyn. Meteorol. Oceanogr. 64, 17417. https://doi.org/10.3402/tellusa.v64i0.17417

- Krikken, F., Bintanja, R., Van Heerwaarden, C., Hazeleger, W., In review. Uncertainty in Arctic climate projections linked to downwelling longwave radiation. Nat. Comm.

- Theeuwes, N.E., Steeneveld, G.J., Krikken, F., Holtslag, A.A.M., 2010. Mesoscale modeling of lake effect snow over Lake Erie - sensitivity to convection, microphysics and the water temperature. Adv Sci Res 4, 15-22. https://doi.org/10.5194/asr-4-15-2010 


\section{Graduate school certificate}

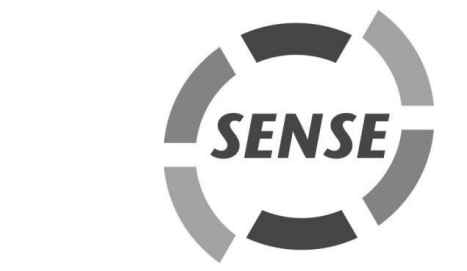

Netherlands Research School for the

Socio-Economic and Natural Sciences of the Environment

\section{I P L O M A}

For specialised PhD training

The Netherlands Research School for the

Socio-Economic and Natural Sciences of the Environment

(SENSE) declares that

\section{Folmer Krikken}

born on 01 January 1985 in Wymbritseradiel, The Netherlands

has successfully fulfilled all requirements of the

Educational Programme of SENSE.

Wageningen, 05 September 2018

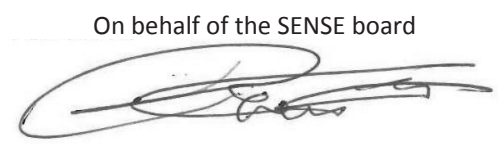

Prof. dr. Huub Rijnaarts

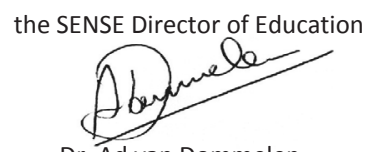

Dr. Ad van Dommelen

The SENSE Research School has been accredited by the Royal Netherlands Academy of Arts and Sciences (KNAW)

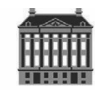

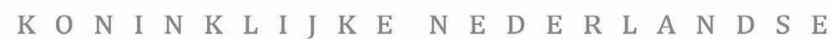
$\begin{array}{lllllllllllllllllllllllll}\text { A } & \text { K } & \text { A } & \text { D } & \text { E } & \text { M } & \text { I } & \text { E } & \text { V } & \text { A } & N & \text { W } & \text { E } & \text { T } & \text { E } & N & \text { S } & \text { C } & \text { H } & \text { A } & \text { P } & \text { P } & \text { E } & \text { N }\end{array}$ 


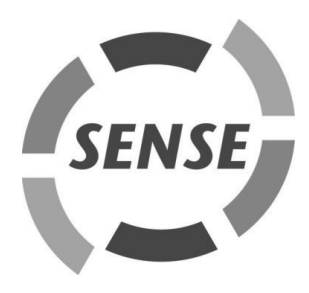

The SENSE Research School declares that Folmer Krikken has successfully fulfilled all requirements of the Educational PhD Programme of SENSE with a work load of $37.9 \mathrm{EC}$, including the following activities:

\section{SENSE PhD Courses}

- Environmental research in context (2013)

- Research in context activity: 'Writing an article for the Dutch professional journal Meteorologica: "De vroegere, huidige en toekomstige staat van het Arctische zee-ijs"' (2016)

\section{Other PhD and Advanced MSc Courses}

- Environmental Economics for Environmental Sciences, Wageningen University (2014)

- Efficient writing strategies, Wageningen University (2016)

\section{Management and Didactic Skills Training}

o Teaching in the BSc course 'Meteorology and Climate' (2013 -2014)

- Supervising MSc student with thesis entitled 'Assessing model bias and drift for EC Earth seasonal to interannual Arctic sea ice predictions' (2015)

\section{Workshop}

- Workshop Seasonal forecasting and downscaling. Organised by the Seasonal to decadal climate prediction for the improvement of European climate services project, 8-12 September 2014, Santander, Spain

\section{Oral Presentations}

- Arctic energy budget in relation to sea ice variability on monthly-to-annual time scale. European Geophysical Union (EGU), 12-17 April 2015, Vienna, Austria

- Skill improvement of dynamical seasonal Arctic sea Ice forecasts. European Geophysical Union (EGU), 25-28 April 2016, Vienna, Austria

SENSE Coordinator PhD Education

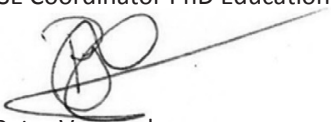


Cover photo: www.wallpaper.enam.site

Cover design: ProefschriftMaken.nl

Printing: ProefschriftMaken.nl

This research is part of the Wageningen UR strategic research and development program TripleP@Sea,which is financially supported by the Netherlands Organisation for Scientific Research (NWO).

Financial support from Wageningen University for printing this thesis is gratefully acknowledged. 


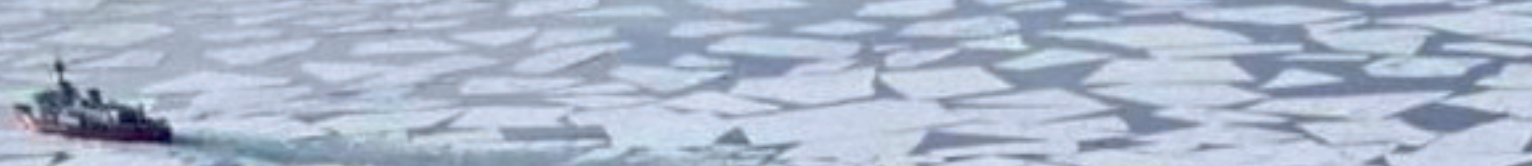

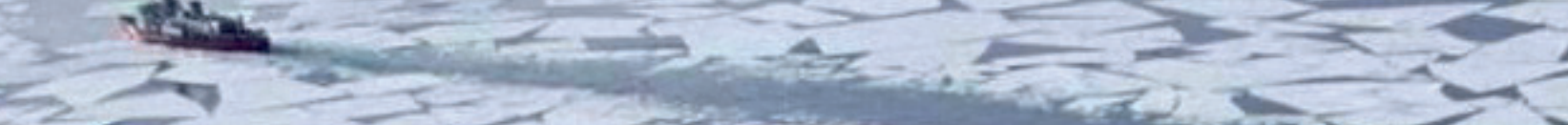

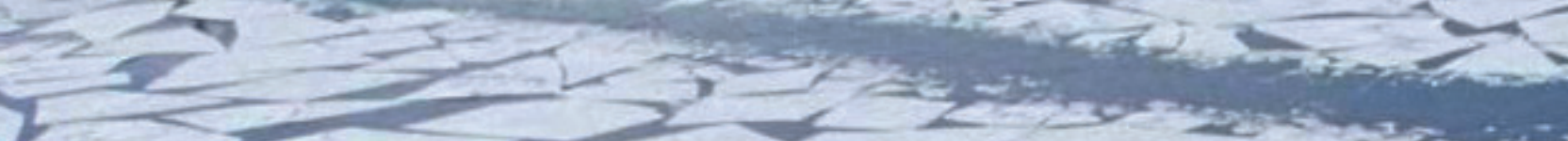
$121 \leq 12$

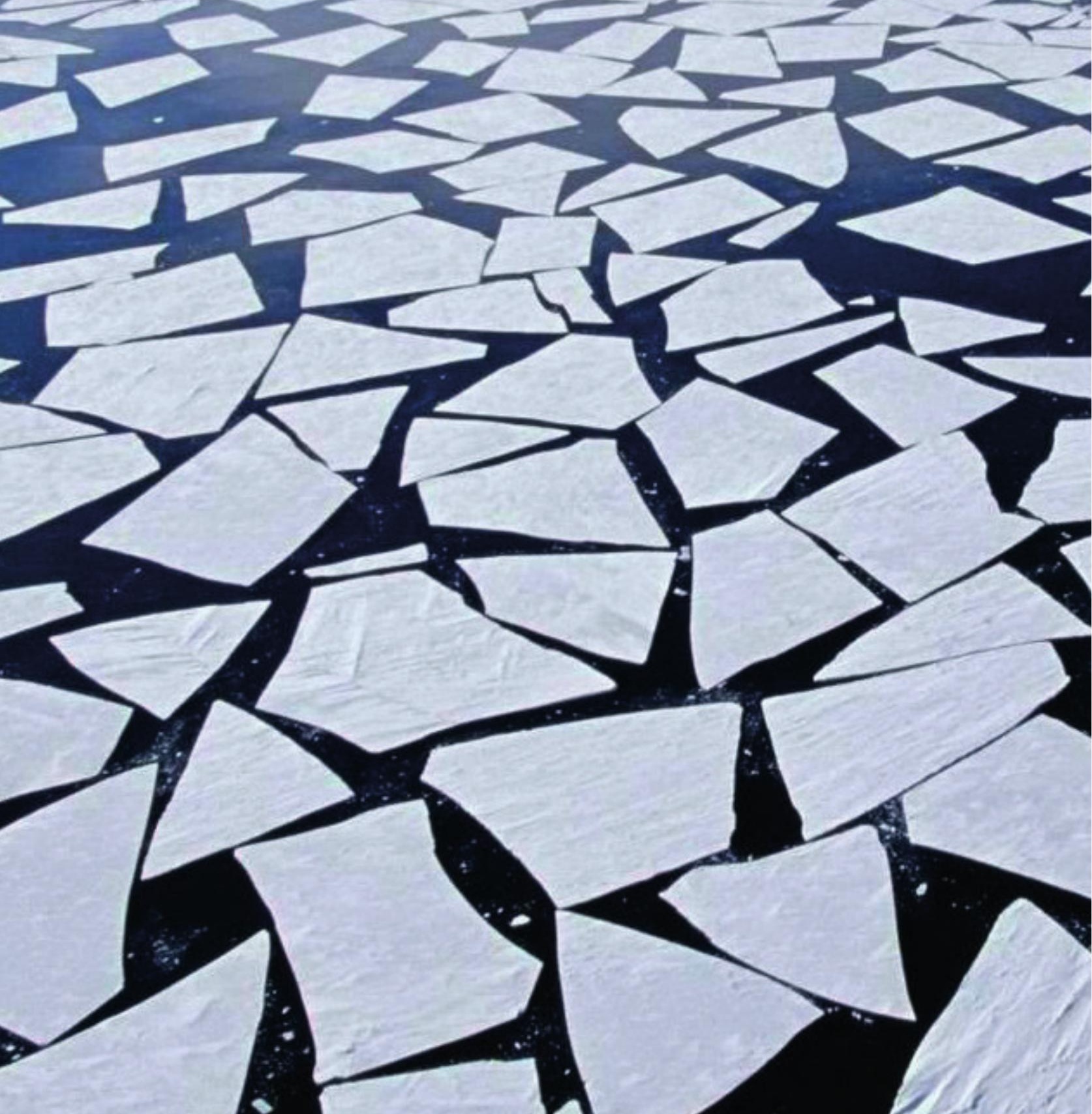

